Florida International University FIU Digital Commons

\title{
Sustainable Public Pension System for Florida Local Governments: Financial Solvency, Paradigm Switch, and Interperiod Equity
}

Yongqing Cong

Florida International University, ycong001@fiu.edu

DOI: $10.25148 /$ etd.FI14071127

Follow this and additional works at: https://digitalcommons.fiu.edu/etd

\section{Recommended Citation}

Cong, Yongqing, "Sustainable Public Pension System for Florida Local Governments: Financial Solvency, Paradigm Switch, and Interperiod Equity" (2014). FIU Electronic Theses and Dissertations. 1455.

https://digitalcommons.fiu.edu/etd/1455 


\section{FLORIDA INTERNATIONAL UNIVERSITY}

Miami, Florida

\section{SUSTAINABLE PUBLIC PENSION SYSTEM FOR FLORIDA LOCAL GOVERNMENTS: FINANCIAL SOLVENCY, PARADIGM SWITCH, AND INTERPERIOD EQUITY}

A dissertation submitted in partial fulfillment of the requirements for the degree of DOCTOR OF PHILOSOPHY in PUBLIC AFFAIRS

by

Yongqing Cong 
To: Interim Dean Michael R. Heithaus

College of Arts and Sciences

This dissertation, written by Yongqing Cong, and entitled Sustainable Public Pension System for Florida Local Governments: Financial Solvency, Paradigm Switch, and Interperiod Equity, having been approved in respect to style and intellectual content, is referred to you for judgment.

We have read this dissertation and recommend that it be approved.

Hai Guo

Shaoming Cheng

John S. Zdanowicz

Howard A. Frank, Major Professor

Date of Defense: May 12, 2014

The dissertation of Yongqing Cong is approved.

Interim Dean Michael R. Heithaus

College of Arts and Sciences

Dean Lakshmi N. Reddi

University Graduate School

Florida International University, 2014 
C Copyright 2014 by Yongqing Cong

All rights reserved. 


\section{DEDICATION}

I dedicate this dissertation to my husband, $\mathrm{Yu} \mathrm{Du}$, who gave me infinite love, support, and courage during this challenging process. To my parents, who always had faith in me and impelled me to accomplish the critical milestone in my life. To my parents-in-law, who brought me a perfect husband and a happy family, allowing me to fully concentrate on my research. And to all my friends in Miami, who never let me feel lonely. Many thanks. 


\section{ACKNOWLEDGMENTS}

I want to express my sincere gratitude to my major professor and academic father, Dr. Howard A. Frank, for your continuous support and patience. From the very beginning, you had confidence in my research abilities and guided me in determination of dissertation topic. As my advisor, your professional involvement contributed a lot to the conception of this research. Your academic advice and spiritual support encouraged me to accomplish this strenuous task.

I also appreciate the long-term support from Dr. Hai Guo. Thank you for your guidance to the composition of the dissertation and for facilitating my professional development. Furthermore, I convey my gratitude to committee members Dr. Shaoming Cheng and Dr. John S. Zdanowicz for your valuable input to my dissertation.

Finally, I am thankful to the efforts of the University of Graduate School at Florida International University for providing financial support and a great research environment. Special acknowledgment also goes to Dr. Meredith A. Newman for approval of survey funding. 


\begin{abstract}
OF THE DISSERTATION
SUSTAINABLE PUBLIC PENSION SYSTEM FOR FLORIDA LOCAL GOVERNMENTS: FINANCIAL SOLVENCY, PARADIGM SWITCH, AND

INTERPERIOD EQUITY
\end{abstract}

by

Yongqing Cong

Florida International University, 2014

Miami, Florida

Professor Howard A. Frank, Major Professor

The issue of increasing unfunded pension liabilities of state and local governments has drawn increasing attentions in the last few years, especially after the 2008 stock market downturn. To maintain sustainability many state and local governments have put public pension reform at the top of their priority list. Previous research and practices provide two strategies to reform the current pension systems: Incremental changes to amend the existing defined benefit plans (DB plans), and the pension model switch from the DB model to defined contribution plans (DC plans).

This study aims to uncover reform strategies to cope for public pension systems. It first examined the appropriateness of the incremental reform strategies by identifying the determinants of the financial solvency of DB plans, utilizing the existing panel data of 151 local DB plans in Florida municipalities. Second, it gathered the primary data through the surveys and interviews with the Finance and HR directors in Florida local governments to analyze their perceptions of public pension reform and reveal their 
readiness to conduct the public pension paradigm switch. These approaches revealed the critical interperiod equity issue along with the impact of the two-tier benefit structure during the recent pension reform.

The results suggest that incremental reform strategies that reduce benefits and increase contributions are not effective in improving the financial solvency of public DB plans. The alternative reform approach — the DB-to-DC transition-is attractive to local governments because it will relieve the employer of the pension cost burden and transfer the investment risk to employees themselves. The transition is also politically palatable because the taxpayer sentiment is not supportive of what are perceived to be generous retirement benefit of public employees. Meanwhile, local governments are hesitant to implement the paradigm switch due to prohibitive transition costs, political pressure, and perhaps more importantly, the potential negative impacts to public recruitment and retention. Local officials do not perceive a reduction of morale with the two-tier benefit structure at the present time; they believe this issue will solve itself along the retirement of senior employees. 


\section{TABLE OF CONTENTS}

CHAPTER

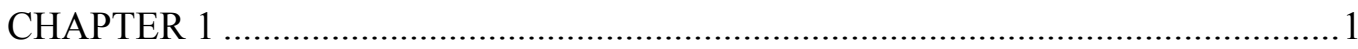

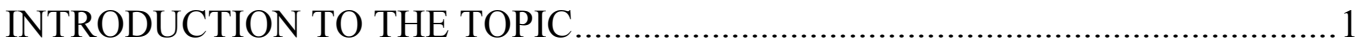

1.1 Introduction to the Public Pension System in the United States ......................... 1

1.2 Public Pension Reforms since the Economic Downturn in 2008....................... 3

1.3 Introduction to the Public Pension Systems in Florida ........................................6

1.4 Controversy over the Current DB plans in Florida Public Pension System........ 9

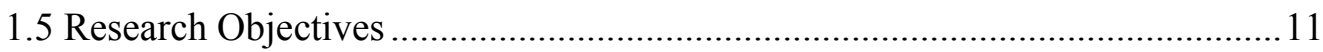

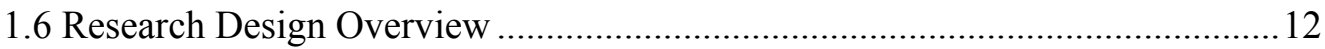

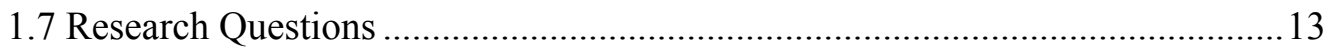

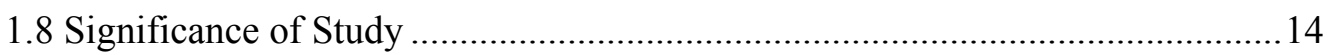

1.9 Justification of the Restricted Research Subject ............................................ 16

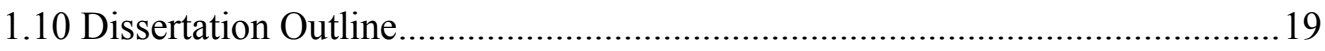

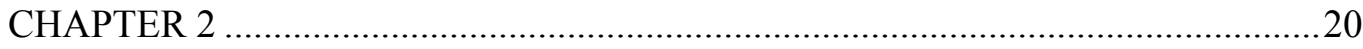

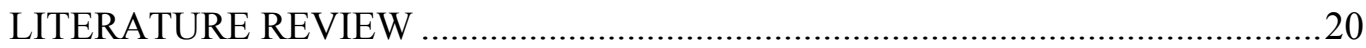

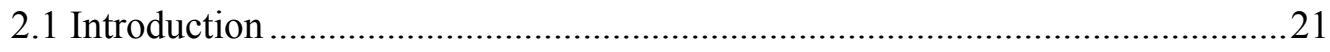

2.2 The Theoretical Framework of the Financial Solvency of DB Plans ................21

2.2.1 Measurement of the Financial Solvency of Public DB plans......................22

2.2.2 Determinants of the Financial Solvency of Public DB Plans......................24

2.3 The Public Pension Paradigm Switch from DB Plans to DC Plans ....................37

2.3.1 Drivers to Conduct Pension Model Transition ...............................................38

2.3.2 Impediments to Conduct the Pension Paradigm Switch.............................40

2.4 The Interperiod Equity Issue of Public Pension Reform...................................46

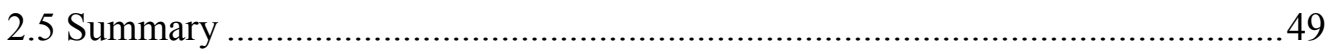

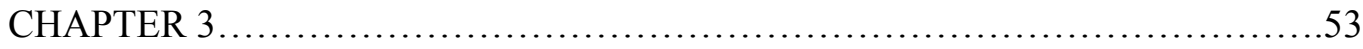

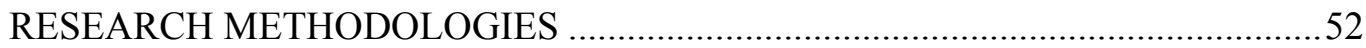

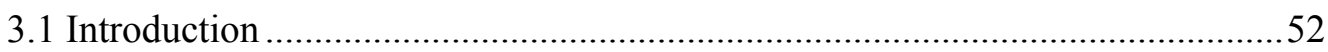

3.2 The Research Design for the Financial Solvency Issue ..................................53

3.3 The Research Design for the Issue of Public Pension Paradigm Switch ............56

3.3.1 The Survey Research Design................................................................56

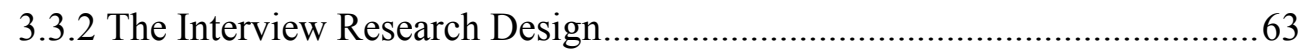

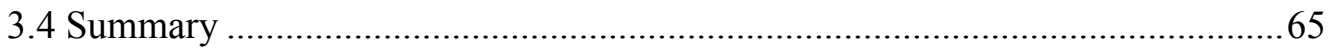

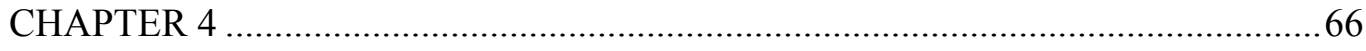

THE DETERMINANTS OF THE FINANCIAL SOLVENCY OF PUBLIC DB

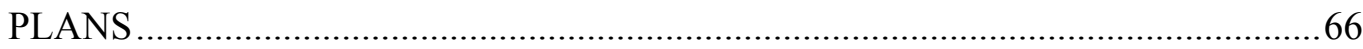

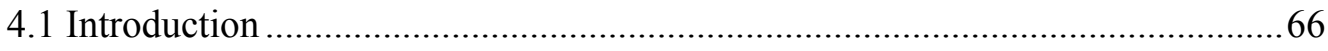

4.2 The Continuous Underfunding of Florida Municipalities DB Plans..................68 


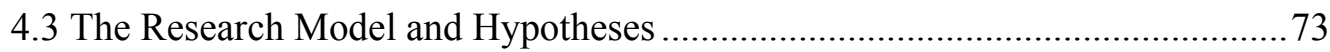

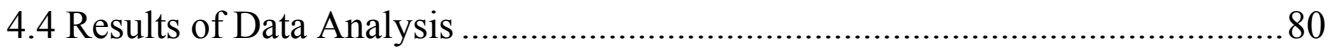

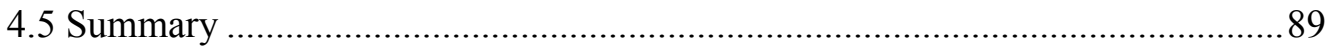

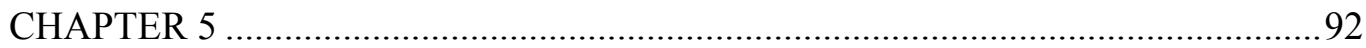

THE PERCEIVED ISSUES OF PUBLIC PENSION PARADIGM SWITCH

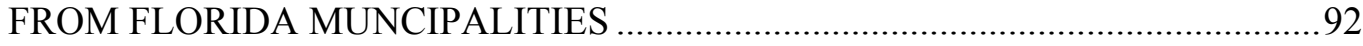

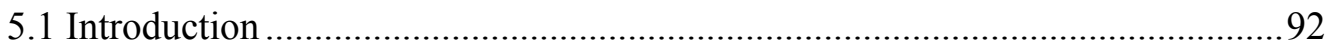

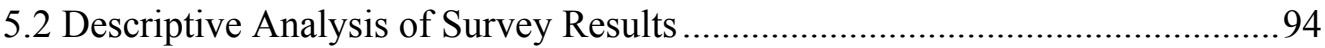

5.2.1 The Congruence of Finance and HR Respondents .....................................94

5.2.3 Summary Report of Survey Items ..........................................................98

5.3 Attitude Structure of Survey Responses: A Principal Component

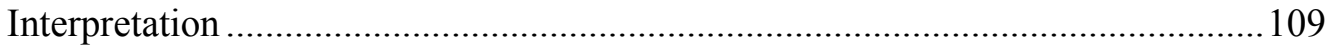

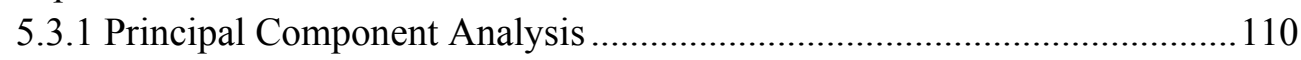

5.3.2 Indexes Creation and Regression Results.............................................. 113

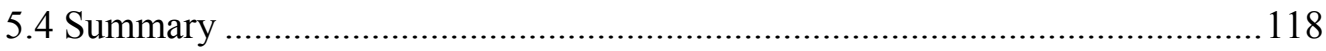

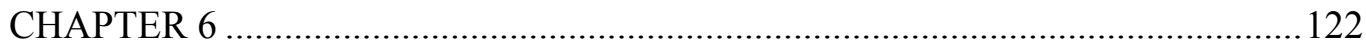

PUBLIC PENSION REFORM: MORE THAN FISCAL SUSTAINABILITY ....... 122

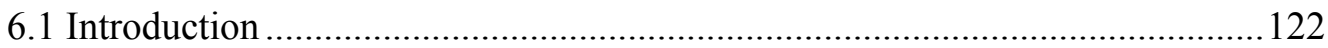

6.2 Quote Analyses of Interview Questions ...................................................... 123

6.2.1 The Financial Viability of Public Pension System................................... 123

6.2.2 The Human Resources Perspective of Public Pension Reform................. 132

6.2.3 The Pros and Cons of the Public Pension Model Shift.............................. 145

6.2.4 The Shared Mindset of Finance and HR Directors................................... 158

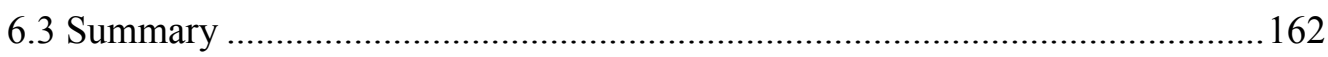

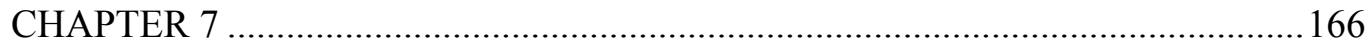

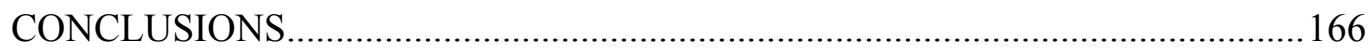

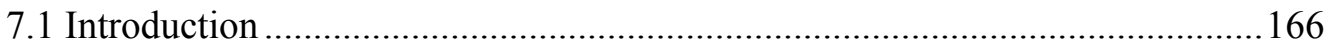

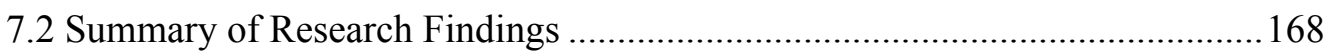

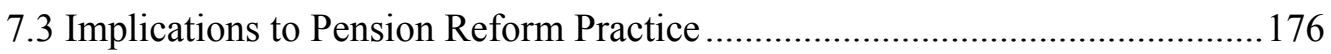

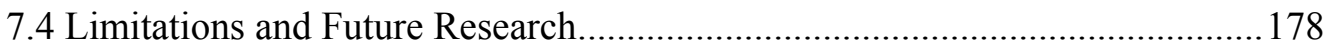

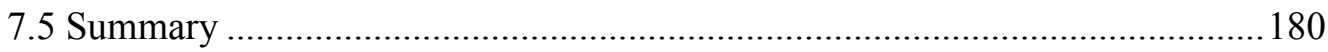

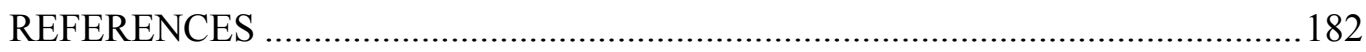

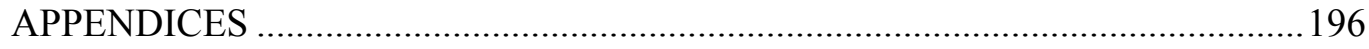

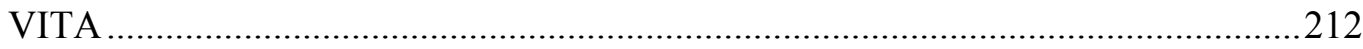




\section{LIST OF TABLES}

TABLE

PAGE

1.1 Comparisons between Previous and Current Public Pension

Law in Florida. ... 9

3.1 Explanatory Variables for the Regression Model.........................56

3.2 The Composition of Interviewees..................................66

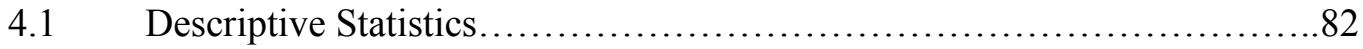

4.2 Regression Results............................................... 84

5.1 Individual Characteristics of Survey Respondents.......................96

5.2 Comparison of Means of Survey Questions ( $t$-test): Five Questions with Significant Difference among Finance and HR Directors...................98

5.3 General Questions Related to Pension Model...........................101

5.4 Organizational Impacts of DB Reform.............................. 104

5.5 Potential Impacts of a Two-Tier Pension Structure on Operations..........106

5.6 Perceived Drivers in the Public Pension Crisis.......................... 109

5.7 Scales Derived from Principal Component Analysis......................114

5.8 Descriptive Statistics of Indexes and City Level Characteristics............116

$5.9 \quad$ Regression Results............................................... 118

6.1 The Sustainability of Current Public Pension Model.......................129

6.2 The Ultimate Solution to the Public Pension Crisis.......................133

6.3 The Impact of Pension Paradigm Shift to Public Recruitment.............138

6.4 The Impact of Pension Paradigm Shift to Public Retention............... 142

6.5 The Impact of the Two-tier Benefit Structure............................ 146 
6.6 The Drivers of Public Pension Paradigm Switch......................... 151

6.7 The Impediments to Public Pension Paradigm Switch....................156

6.8 The Necessity of Financial Literacy Training............................160

6.9 The Congruence of Finance and HR Perceptions....................... 163 


\section{LIST OF FIGURES}

FIGURE

PAGE

1.1 Notable Changes to State-Sponsored Pension Plans,

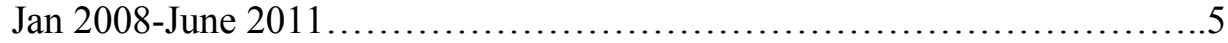

3.1 Number and Types of the Public Pension Plans for General

Public Employees in Florida Municipalities by $2011 \ldots \ldots \ldots \ldots \ldots \ldots \ldots . . . . .59$

4.1 Funded Ratios of Florida Local DB Plans for Public General

Employees (Entry Age Normal Funding Method Only)..................71

4.2 UAAL Percentages of Employee Payroll in Florida Local DB Plans.........72

4.3 Annual Contributions to Florida Municipal DB Plans.......................74

4.4 Research Model for the Determinants of the Financial Solvency of the Public DB Plans for General Employees................................75 


\section{LIST OF ABBREVIATIONS}

\begin{tabular}{|c|c|}
\hline AAA & American Academic of Actuaries \\
\hline $\mathrm{AFC}$ & Average Final Compensation \\
\hline AGG & Aggregate \\
\hline $\mathrm{ARC}$ & Annual Required Contribution \\
\hline COLA & Cost-Of-Living Adjustment \\
\hline DB & Defined Benefit \\
\hline $\mathrm{DC}$ & Defined Contribution \\
\hline Dept. & Department \\
\hline DMS & Department of Management Services \\
\hline EAN & Entry Age Normal \\
\hline EFA & Exploratory Factor Analysis \\
\hline ERISA & Employee Retirement Income and Security Act \\
\hline FIL & Frozen Initial Liability \\
\hline FPPTA & Florida Public Pension Trustee Association \\
\hline FRS & Florida Retirement System \\
\hline GAO & Government Accountability Office \\
\hline GASB & Government Accounting Standards Board \\
\hline HR & Human Resources \\
\hline IAFF & International Association of Fire Fighters \\
\hline ICMA & International City/County Management Association \\
\hline LCI & Leroy Collins Institute \\
\hline
\end{tabular}


NCPA The National Center for Policy Analysis

NCPERS National Conference on Public Employee Retirement Systems

NCSL National Conference of State Legislatures

No. Number

Obs. Observation

OLS Ordinary Least Square

PBA Police Benevolent Association

PCA Principal Component Analysis

PEW The Pew Center on the States

PPA Pension Protect Act

PPCC Public Pension Coordination Council

R-sq R-square

SD Standard Deviation

Sig. Significance

Std. Dev. Standard Deviation

UAAL Unfunded Actuarial Accrued Liability

UC United Credit 


\section{CHAPTER 1}

\section{INTRODUCTION TO THE TOPIC}

\subsection{Introduction to the Public Pension System in the United States}

Following the genesis of military pensions, which was the first public sector pension plan, retirement plans were disseminated to state and local employees in the late nineteenth century (Clark, Craig \& Wilson, 2003). The original purpose of these plans was to increase the competitiveness of the public sector employment with guaranteed retirement benefits, compared to the private sector, which often offered higher salaries for the comparable placement (National Conference on Public Employee Retirement Systems [NCPERS], 2008).

Broadly speaking, pension plans can be characterized as either defined benefit (DB) or defined contribution (DC) plans. Unlike the private sector, where employers switched from DB plans to DC plans over the past three decades, DB plans remain the predominant pension model providing retirement benefits to public employees. In 2011, about 78 percent of public sector employees participated in DB plans, compared with only 18 percent of private sector employees (Government Accountability Office [GAO], 2012). Typically, state and local government pension models include a DB plan and a supplementary DC option for voluntary savings (GAO, 2007). In addition to DB and DC plans, some entities offer "hybrid plans" which contain characteristics 
of both DB and DC plans, another distinguishing characteristic compared to private sector practice.

In the public sector, DB plans, with very few exceptions, provide employees a retirement benefit calculated by a formula that is "a function of a benefit multiplier, years of service, and the final average salary"(Papke, 2004, p. 330). The benefit is paid in the form of a lifetime annuity, i.e., participants receive benefit payments over their lifetime or the lifetime of beneficiaries. State and local government frequently offer postretirement cost-of-living adjustments (COLAs) under DB plans.

State and local government employees are generally required to contribute a percentage of their salaries to their DB plans, unlike private sector employees with DB plans. All assets accumulated from both employers and participants' contributions to DB plans are invested by the retirement board or a central agency responsible for managing government funds to fund the retirement benefits (Matson \& Dobel, 2006). Therefore, the investment risk is generally borne by the employer-state and local governments. Any unexpectedly high return on the assets may lead to reductions in the amount of employers' future contributions, while unexpectedly low investment return make it necessary to increase future contributions and/or reduce retirement benefits.

By contrast, in a DC plan, the key determinants of the amount of benefits are the contribution rates of the employee and employer to the employee's individual account, and the rate of investment return gained from the assets available in the 
account over time. Under a DC plan, employees steer the investment of their pension assets and take over the investment risk and fees. There are no COLAs for DC plan participants; however, after retirement a DC account balance could continue to earn investment income on their remaining assets until depleted. During tight financial time, the DC account can be liquidated to offer budgetary relief at the cost of taxes on the withdrawn amount plus an early-withdrawal penalty.

In general, DC plans are advocated because of their greater payout flexibility and portability, potentials for higher returns through investment, and the ability to continue to accrue earnings after retirement (Giertz and Papke, 2007). Compared with DC plans, DB plans usually provide more generous benefits through guaranteed lifetime income and automatic COLAs. Generally, DB plans are more useful to attract and retain risk-adverse, less mobile, public workforce with more tolerance of vesting requirements and limited portability of accrued benefits. From the operational perspective, a DB plan is a safer option since it is relatively immune to economic fluctuation and it theoretically allows for any unfunded liabilities to be resolved in 20 to 30 years (Frank, Gianakis, \& Neshkova, 2012).

\subsection{Public Pension Reforms since the Economic Downturn in 2008}

Prior to the recession, public pension plans were generally deemed well funded, so there was no immediate pressure to reform public pension systems by either increasing contributions or curtailing benefits, although some scholars argue that this 
is a misleading belief (Clark \& Sabelhaus, 2009; Giertz \& Papke, 2007; Novy-Marx \& Rauh, 2008). However, the stock market crash in 2008 exacerbated the public pension crisis and forced state and local governments to rethink the funding status of DB plans and to acknowledge certain risks associated with their pensions. During fiscal years 2008 and 2009, state and local pension plans lost more than $\$ 672$ billion in investment earnings, based on the data from Census Bureau. Although most plans still have enough assets to cover their benefit liabilities in the near future, there is a widening gap between public pension assets and liabilities. In fiscal year 2010, the shortfall between state pension assets and obligations was $\$ 757$ billion, which posed serious long-term fiscal challenges (The Pew Center on the States [Pew], 2012).

Since the economic downturn of 2008, many states and localities have taken action to counter fiscal pressures and increasing annual required contributions. Various reform strategies have been implemented to increase the financial status of current public pension systems, i.e., DB plans. Generally there are two streams of pension reforms: One is to reform the plan design of DB plans to alleviate the fiscal burden to plan sponsors by reducing pension benefits and increasing participants' contribution; the alternative is to include a DC component to transfer cost and risk to employees. Figure 1.1 reveals the notable changes to state pension plans due to the multiple reform measures after the stock market plunge (GAO, 2012).

On the basis of the GAO's analysis of state legislative changes reported by National Conference of State Legislatures (NCSL), during 2008 to 2011, 35 states 
reduced pension benefits through at least one of the following three actions: 1) adjusting the benefit formula used to calculate provided benefits; 2) raising the age or years of service required before retiring; 3) limiting the annual COLA increases. Benefits reductions mainly apply to future employees due to the legal protection to the retirement benefits of current employees and retirees.

Figure 1. 1 Notable Changes to State-Sponsored Pension Plans, 2008- 2011

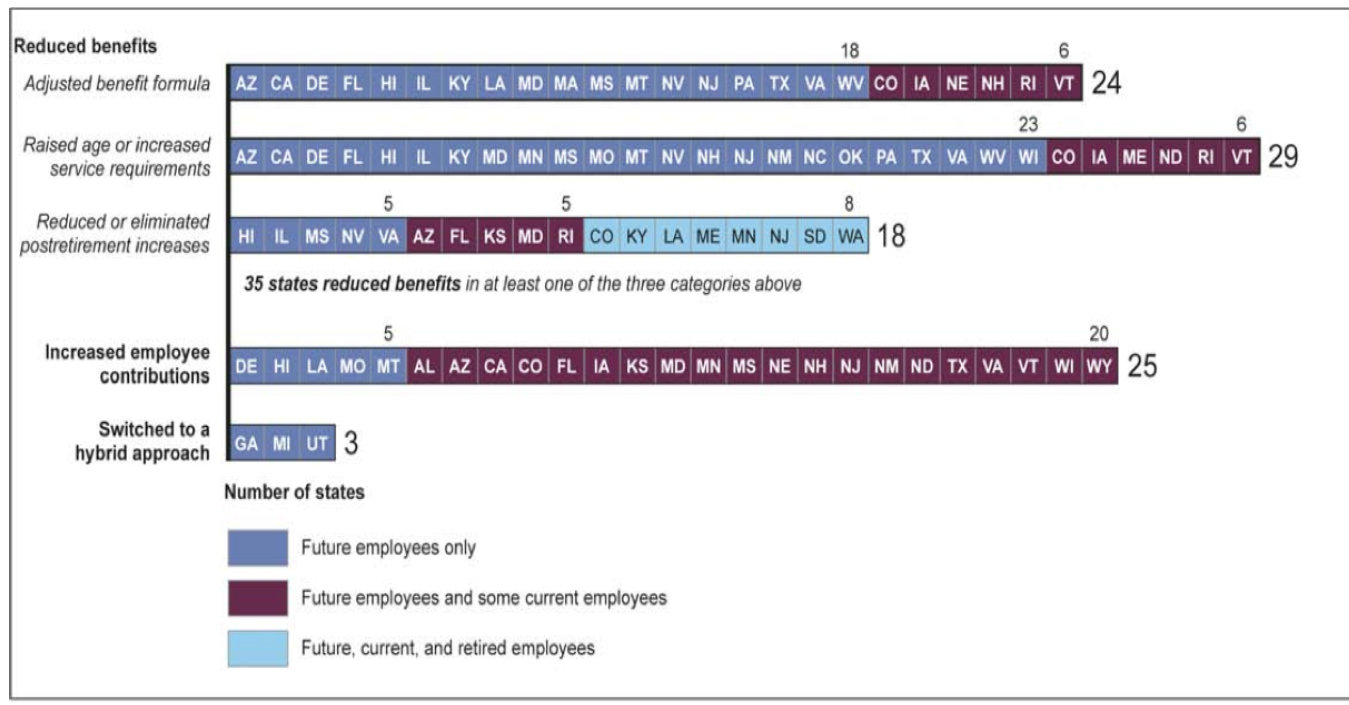

Source: GAO analysis of annual NCSL reports, 2012.

Twenty-five states required members to contribute a larger amount to the pension fund, in doing so the states transferred the pension costs from sponsors to employees. Georgia, Michigan, and Utah have pursued more comprehensive reforms by implementing hybrid approaches, which incorporate a DC component, ensuring their retirement systems will not become a future cause of fiscal distress. In addition to the states that GAO analyzed, Rhode Island in 2011 and Virginia in 2012 also approved hybrid approaches to their state-sponsored pension plans (Pew, 2012). 
Besides the reform strategies highlighted in Figure 2, in 2010 and 2011, 14 states lowered their investment return assumptions to reflect greater uncertainty in the stock markets, because these states realized their previous return assumptions were unlikely to be achieved in the short term and underestimated their true pension obligations (Pew, 2012).

\subsection{Introduction to the Public Pension Systems in Florida}

Sponsored by 249 local governments, Florida State currently has 492 DB municipal and special district retirement plans. Besides the municipal plans, in Florida there is a statewide DB plan for state and county employees (and local governments may opt into) called the Florida Retirement System (FRS). The State retirement systems in Florida, including the FRS, are the fourth largest public pension systems in the nation. Since inception, FRS has been recognized as a well-run DB model (Munnell, 2012). It frequently appears in the top-four list, evaluated by many study and research institutions (Pew, 2010a; Pew, 2012; The National Center for Policy Analysis [NCPA], 2010).

Although compared to other state sponsored pension plan, FRS fares better, yet the Great Recession in 2008 struck the pension funds heavily and exposed the nationwide problem of wicked unfunded pension liabilities. Even before the 2008 economic downturn, there was latent underfunding of pension plans due to that states tend to underestimate its unfunded obligations by using unrealistically high return 
assumptions. For instance, the State of Florida calculated that its pension systems were 100 percent funded, while according to NCPA (2010), actually it was about 10 percent underfunded.

While the state's plan is well funded, at the local level, there is long-existing underfunding of Florida municipal pensions, and the recent stock market plunge worsened the problem. The typical funding level of municipal pension plans have been below the 80 percent benchmark since 2004 and have continually declined every year since 2001 (Leroy Collins Institute [LCI], 2012). Increasing pension liabilities as a larger portion of the municipal budget have imposed significant fiscal stress to local governments.

The lagged impacts of 2008 economic downturn have put Florida public pension plans under increased scrutiny. In recent years, the sustainability of public pensions has become a prominent policy topic at both state and local level. Governments targeted pension reforms to get a relief from the fiscal burden of snowballing pension obligations. The most significant reform attempt is the new pension law enacted after July $1^{\text {st }}, 2011$, aiming to create a public pension system that is viable for years to come.

In 2011, mimicking the practice in the private sector, Florida State Governor Rick Scott led a coalition of Republican legislators to replace the DB plan of the FRS and other public-sectors plans in the state with DC plans for all new employees in order 
to reduce future obligations, which would free governments from paying predetermined pension benefits, and would save significant pension entitlements because the annual contributions would not be calculated as the required amount to cover future pension payments.

Scott's pension reform proposal ignited vehement opposition from various stakeholders, such as rank-and-file employees, police and fire unions, and teacher unions (Klas, 2011a; Resmovits, 2011; Ward, 2011). These groups asserted that publicsector employees became the victims of budget deficits and governments lay the fiscal burden on the back of all public employees. After furious debates and concessions, the pension reform law implemented after July $1^{\text {st }}, 2011$ is a much milder modification of the previous pension law. The new law includes strategies to increase employee contributions, reduce pension benefits, and establish a two-tier benefit system (see Table 1.1).

At the local level, Florida cities experienced the similar painstaking process of pension policy reform. Nevertheless, many municipalities have successfully adjusted their pension systems in the form of either modifying their current DB plans to reduce outlays or shifting to DC plans to transfer costs. For instance, Bradenton, Cape Coral, and Vero Beach increased their required contribution from employees; Hollywood, New Smyrna Beach and Temple Terrace eliminated or reduced their COLAs; Coral Gables, Winter Springs, and Miami reformed their pension benefit formula to decrease pension obligations; Lakeland, South Miami, Palm Beach Gardens and Fort Lauderdale 
switched from DB plans to DC plans (Florida League of Cities, 2012 \& 2013; Florida

TaxWatch \& LCI, 2013).

Table 1.1 Comparisons between Previous and Current Public Pension Law in

\section{Florida}

\begin{tabular}{|c|c|c|}
\hline Item & Previous Pension Law & Changes After July 1, 2011 \\
\hline Contributions & $\begin{array}{l}\text { - No contribution from employees; } \\
\text { - 100\% paid by employers. }\end{array}$ & $\begin{array}{l}\text { - Employees contribute 3\% pre-tax salaries } \\
\text { - All FRS Members (either DB or DC plans) } \\
\text { contribute. }\end{array}$ \\
\hline COLAs & $\begin{array}{l}\text { - Collect COLAs based on years of } \\
\text { service when retire } \\
\text { - Members who retire before July } 1 \text {, } \\
\text { 2011, receive a } 3 \% \text { annual COLA. }\end{array}$ & $\begin{array}{l}\text { - During July 1, } 2011 \text { and July 1, 2016, no } \\
\text { years of service credits for COLAs } \\
\text { - Members who retire after July 1, 2011, } \\
\text { receive lower percent annual COLA }\end{array}$ \\
\hline DROP* & $\begin{array}{l}\text { - Members who enter DROP before } \\
\text { July } 1,2011 \text {, will earn } 6.5 \text { percent } \\
\text { interest on the money set aside under } \\
\text { the retirement program. }\end{array}$ & $\begin{array}{l}\text { - Members who enter DROP after July } 1,2011 \\
\text { will earn } \mathbf{1 . 3} \text { percent interest on the retirement } \\
\text { money set aside in the program. }\end{array}$ \\
\hline $\begin{array}{l}\text { New hires - } \\
\text { vesting and } \\
\text { retirement age }\end{array}$ & $\begin{array}{l}\text { - Vesting period: } 5 \text { years; } \\
\text { - Regular class, senior management } \\
\text { class and elected officials class: } \\
\text { retire after } \mathbf{6 2} \text { years of age or } \mathbf{3 0} \\
\text { years of service; } \\
\text { - Special-risk class: retire after } 55 \\
\text { years of age or } 25 \text { years of service; } \\
\text { - The average final compensation } \\
\text { will be calculated on the best } 5 \text { years } \\
\text { of salary. }\end{array}$ & $\begin{array}{l}\text { - Vesting period: } \mathbf{8} \text { years; } \\
\text { - Regular class, senior management class and } \\
\text { elected officials class: retire after } \mathbf{6 5} \text { years of } \\
\text { age or } \mathbf{3 3} \text { years of service; } \\
\text { - Special-risk: retire after } \mathbf{6 0} \text { years of age or } \\
\mathbf{3 0} \text { years of service or, with } \mathbf{4} \text { years in the U.S. } \\
\text { military: retire after } \mathbf{5 7} \text { years of age and } \mathbf{3 0} \\
\text { years of service; } \\
\text { - The average final compensation will be } \\
\text { calculated on the best } \mathbf{8} \text { years of salary. }\end{array}$ \\
\hline
\end{tabular}

Source: Edited from Breaking Down Florida's Pension Reform Changes (Klas, 2011b)

\subsection{Controversy over the Current DB plans in Florida Public Pension System}

The reforms mentioned above intensified the discussion regarding sustainability of the current public DB plans in Florida. There are two groups of contradictory opinions towards the DB model. One espoused by reform advocators is 
that the existing DB plans are unsustainable and the pension model shift is necessary to reduce the financial burden of promised pension obligations to governments. These reforms are supported by conservative tax-watchers who incite voter anger by promoting the idea that most public employees enjoy more generous pension benefits and ought to join the ranks of private sector covered by DC plans. Facts from research institutions also provide evidences supporting that such change is imperative (Holcombe, 2011; LCI, 2012).

However, there is another fairly strong voice from scholars and research institutions that DB plans should be preserved because there is compelling evidence that the current DB plans in Florida public pension system have a clear cost advantage over DC plans (NCPERS, 2008). In addition, the inadequacy of 401(k) accounts in providing confidence in retirement reveals the inefficiency of DC plans to finance employee retirement plans (Florida Public Pension Trustees Association [FPPTA], 2010). Furthermore, another stream of thought implies that unfunded pension liabilities are misunderstood as a ticking time bomb by interest groups, because most retirement systems have a plan to pay down the unfunded liabilities in 20 to 30 years, therefore there is no immediate need for local governments to take drastic and instant actions to reduce or pay off the plan's unfunded liabilities (FPPTA, 2011).

The above discussion shows two distinct attitudes towards the reforms of DB plans in Florida's public pension systems. The contradictory standpoints pose a paradox about the continued viability of current DB plans, which inspired the author 
with the research interest in the pension reforms in Florida Municipalities and the sustainability of the public pension system. This conflict is one that is taking place in many venues.

\subsection{Research Objectives}

The main purpose of this study is to offer a better understanding of public pension systems in Florida local governments and to uncover the effective reform strategies that maintain the sustainability, while attracting and retaining a competent workforce. It investigates the effectiveness of incremental changes through examining the financial solvency of current DB plans in Florida municipalities. Further it explores the potential organizational impacts of pension model changes on the daily operations of Florida local governments; and reveals the major drivers and impediments for local governments to conduct the pension model switch from DB to DC plans in the public sector. Objectives of the study include:

- $\quad$ Providing a thorough analysis of the financial status of the current DB plans in Florida cities;

- Assessing the effectiveness of the incremental strategies to enhance the financial solvency of the current DB plans by identifying the major determinants of the fiscal health of DB plans; 
- $\quad$ Evaluating the potential impact of pension paradigm switch to the government operations and the public sector recruitment and retention in Florida municipalities;

- $\quad$ Exploring the readiness of Florida municipalities to conduct the pension model switch from DB to DC plans by identifying the major impetus and impediments to the transition.

\subsection{Research Design Overview}

The study employs a triangulated research design to carry out a full-scale examination of the public pension plans in Florida local governments. First, the study utilizes secondary data sources of Florida local retirement systems to conduct a descriptive analysis to provide an overview of the fiscal standing of current DB plans in Florida supplemented with a regression analysis that identifies the factors determining the financial solvency of DB plans. The analysis lays the ground of the arguments about the efficiency of the incremental reform strategies. Another leg of the study is the survey methodology to local government officials to collect the primary data regarding potential impacts of the pension model switch and their readiness to conduct this transition. Survey results provide a direct illustration of organizational impacts of implementing the pension paradigm shift. On the basis of principal components derived from survey responses as well as city-level secondary data, a regression model supplements the qualitative inquiry about the indicators of government officials' opinions on the issue of public pension reform. Third, to improve 
the validity of the survey results, the author conducted interviews of experts to crossverify the findings from survey responses and to gain in-depth and elaborate viewpoints that cannot be wholly grasped through surveys.

\subsection{Research Questions}

The study is not going to test the DC diffusion regarding pension reform, which would be premature given that only 10.5 percent of Florida's 410 cities adopt the DC plan as their default pension model for general employees (Florida Department of Management Services [DMS], 2012). Instead, the study aims to answer the following overview question in regard to the current public pension system for the general employees in Florida local governments:

- Whether the incremental changes exemplified in the 2011 pension law to preserve the DB model really make it sustainable? If not, how ready are Florida municipalities to adopt the alternative approach — the DB-to-DC transition?

This is broken into the following sub-questions:

o Will the incremental changes such as enacted reform strategies in 2011 enhance the financial solvency of the current DB plans for the general public employees in Florida local governments?

o How would the public pension paradigm switch impact government operations and the recruitment-retention of public employees?

o Whether the interperiod equity issue created by rollout of the two-tier pension reforms is perceived as an issue for Florida local governments? 
o What are perceived impetuses and potential impediments to conducting the pension model transition for Florida municipalities?

The impacts of public pension reform incorporate influences on financial solvency of public pension plans, as well as the quality of public services via recruitment and retention of qualified public employees. Possible morale impacts of the two-tier benefit structure are another central concern. By examining the efficiency of incremental changes to the fiscal status of pension plan, the author also investigates the potential organizational impacts of pension model switch, and the pros and cons of the DB-to-DC transition, this study seeks to reveal the current standing of the pension systems in Florida cities and the inclination of local governments to conduct the pension paradigm shift from DB to DC plans.

\subsection{Significance of Study}

The significance of the study is reflected by its original contribution to the academic research, and its triangulated approach is designed to supplement and augment prior studies that look solely at drivers of pension solvency. Although many scholars and research institutes have argued that pension reforms are imperative and introduced numerous reform strategies by altering the plan design feature of DB plans, the effectiveness of the incremental changes have not been highlighted as an important topic in previous academic discussion. The study fills an important knowledge gap in 
the scholarly literature by providing a thorough examination of Florida local pension plans to identify the determinants of the financial solvency of public DB plans.

The study also addresses the readiness of Florida local governments in conducting the pension paradigm switch, which has not been investigated on the basis of empirical evidences in previous studies. The discussion of employee interperiod equity derived from the public pension plan design is another original contribution of this study because the issue has not drawn enough attention in previous literature. Finally, the study utilizes the triangulated research methods with local level secondary data, responses from self-administrated surveys and structured interviews, which provide the primary empirical evidences absent in previous literature of public pension reforms.

By investigating the potential drivers and impediments of pension paradigm switch, as well as perceived organizational impacts, the study is intended to inform pension policy discussion in Florida. It will provide decision-makers of pension reforms with instructive references about the pros and cons of pension model changes and the possible consequences of the transition. The implications from this study will shed light on the current issues in the process of public sector pension reforms and the perceptions from Florida local governments will offer inspirations to other state and local governments since the public pension crisis is a nationwide epidemic. 


\subsection{Justification of the Restricted Research Subject}

The study concentrates on Florida's pension reform for the following two reasons. First, prior research has recognized Florida as a political and demographic trendsetter for the nation (Naisbitt, 1982; Shrestha \& Heiser, 2011; Watson, 2005). Second, the Florida domicile ensures that our survey respondents are operating under a uniform legal and administrative framework.

The research focus is restricted to general employee pension plans in Florida local governments. The reasons for selecting the public pension plans at the local level are as follows. First, compared to state government employees, more local government employees participate in public pension systems (about 14 million compared with 5 million). While some local governments participate in state-administered pension plans, generally local governments reserve responsibility for the required share to fund their pension plans providing their employees with retirement benefits. Thus, local governments have more fiscal burden than state governments in terms of annual contributions (GAO, 2012). In Florida, the state pension plan, i.e., the FRS, although experiences fiscal stress, has been and is still well funded. However, local pension plans in Florida have grappled with underfunded pension plans even before the 2008 economic downturn. Therefore, targeting local pension plans may provide better understanding of the pension reform imperatives. Second, research at the local level is more suitable for this study because in Florida state and counties employees are mandated to participate in the traditional DB model, i.e., FRS, while Florida cities have 
the freedom to opt into FRS or to retain its own type of pension plans with modifications, which could be DB, DC or the hybrid approach. Hence it is more feasible to analyze the possibility and readiness to conduct a pension paradigm shift at the local level.

The study selects the pension plans for general public employees in Florida local governments. Firstly, the research is restricted to the civilian, non-uniformed public employees in order to avoid the sensitivity of pension reforms in the context of contentious collective bargaining. According to the Bureau of Labor Statistics (2013), local government employees had the highest union membership rate in the public sector, 41.7 percent, and furthermore, this cohort includes employees in heavily unionized occupations, i.e., teachers and police officers, and firefighters. Secondly, the pension plans for teachers and public safeties have different design characteristics from those of general employees. For example, police officers and firefighters usually enjoy more generous benefits with younger retirement age. The uniqueness of pension plan design features for teachers and special risk employees cannot be fully enclosed by this study, therefore, the research focus lies in the pension plans for general public employees.

Although this study avoids some sensitivities regarding unions by limiting the focus on general employees' pension plans, the impact of unions is inevitably incorporated. Generally, public sector unions support the retention of DB model (Ferlauto, 2002; NCPERS, 2007). Munnell, Golub-Sass, Haverstick, Soto and Wiles (2008) found that a highly unionized pension plan is less likely to convert from the DB 
to DC model. The controversial issue of unions' impacts will be implied by responses to the anonymous surveys and interviews.

In addition, the study does not make an ideological statement about the public pension model switch. The public pension crisis is a nationwide phenomenon and reforms are likely nationwide regardless of whichever party is in power, although Republicans advocate the advantage of DC plans and Munnell (2012) identified the importance of Republican control of the legislature and governorship as a significant driver of introducing the DC model to the public sector. The universality of skyrocketing costs of public pension systems not only urged the Republican Governors such as Rick Scott in Florida to endeavor to replace DB plans with DC plans, but also forced the Democratic Governors, e.g., Jerry Brown in California, to propose a mandate that new employees direct a substantial portion of their retirement money in $401(\mathrm{k})$ style accounts, which turned to faded efforts with amendments of DB design (York \& McGreevy, 2012). Furthermore, the sweeping influences of the pension model switch make it difficult to reach an agreement even within the same Party. For instance, in 2013, the Republican House Speaker Will Weatherford could not even convince his own party members in the Florida Senate that the DB model should be terminated for new employees (Sickler, 2013). Thus, the study does not include partisanship as a factor of pension paradigm shift. 


\subsection{Dissertation Outline}

This dissertation is comprised of seven chapters. Chapter One provides an introduction of the public pension systems in state and local governments and in Florida, the research topic, the purpose and objectives of the study, an overview of the research design, the research questions, and the significance of the study. Chapter Two delivers the theoretical framework of the research with a literature review of public pension plan management and indicates the contribution of the current study to previous studies. Chapter Three lays out the triangulated research design and associated methodologies to carry out this study. Chapter Four presents the analysis of the fiscal standing of public pension plans for general employees in Florida local governments with trend analyses, and identifies the determinants of the financial solvency of public DB plans to estimate the efficiency of the incremental reform strategies in improving sustainability of public pension system. Chapter Five describes the survey results about the perceptions of Florida local officials towards the alternative reform approach, i.e., the DB-to-DC transition, and indicates the potential impacts of switch and the major drivers and impediments of pension paradigm shift. Chapter Six provides content analysis of interview data to further explore the rationale behind the survey responses and in-depth explanation of the viewpoints derived from survey participants. The last chapter, Chapter Seven, provides the conclusion of this research and addresses implications for policy makers and future studies. 


\section{CHAPTER 2}

\section{LITERATURE REVIEW}




\subsection{Introduction}

Public pensions not only provide for retirement benefits but also bring broader impacts on financial and human resources system. On the one hand, pensions overcome the "wage penalty" of public sector jobs. On the other hand, if poorly managed, they threaten the long-term sustainability of government operations. Therefore, the literature review revolves around the financial and organizational functions and impacts of public pension systems on governments.

Chapter 2 consists of three sections. First, it lays out previous studies about the financial solvency of public sector DB plans. Second, it shows the theoretical framework in the scholarly literature regarding the pension paradigm switch from DB to DC plans. The last part includes the omissions in the previous literature and the contribution of the study.

\subsection{The Theoretical Framework of the Financial Solvency of DB Plans}

The underfunding of pension funds has long plagued the public sector DB pension plans. Because the investment gains or losses of pension funds could bring profound influences to the long-term fiscal health of state and local governments, the continued underfunding of DB plans has posed great administrative concerns (Giertz \& Papke, 2007). Along with the looming public pension crisis, many scholars have examined the financial standing of state pension plans, especially under the circumstances of the recent economic downturn (Giertz, 2003; Novy-Marx \& Rauh, 
2009; Peng, 2004; Rauh, 2010). The increasing unfunded pension liabilities due to steep investment losses and consequent fiscal stress continue to appear as headlines in recent years, which has forced a group of researchers to consider responding strategies to improve the financial solvency of DB plans. In addition to the review of the previous literature about the recommendations to amend the DB plans, this section also provides a theoretical rationale that explains why public sector DB plans are mired in fiscal stresses.

\subsubsection{Measurement of the Financial Solvency of Public DB plans}

Careful study of the financial status of DB plan requires selection of appropriate financial measures. One of the most recognized techniques to determine the financial status of a DB plan is the funded ratio. It indicates the proportion of the plan's liabilities covered by its assets (Steffen, 2001), which provides a snapshot of the plan's health at a given moment of time. Therefore, it has the advantage of incorporating prior funding practices reflected by actuarial gains and losses, but it does not implicate the long-term vision of whether the plan is experiencing growth or decline (DMS, 2012; McCue, 1994).

To account for the drawbacks of funded ratio, another proxy of the financial solvency is often employed as an indicator of funding status, which is the unfunded actuarial accrued liability (UAAL). UAAL represents the difference between the actuarial accrued liability and the actuarial value of assets accumulated to finance that 
obligation at a particular point of time. Unlike the funded ratio, the magnitude and the trend of UAAL could reveal whether the plan's status is improving or declining (Berne \& Schramm, 1986), because it shows the variation between the projection and the reality of a pension plan fund.

The funded ratios and UAAL are not really comparable across the pension plans because they can be heavily influenced by each plan's actuarial assumptions and costing methods (McCue, 1994; Mitchell, McCarthy, Wisniewski, \& Zorn, 2001; Munnell, Aubry, \& Haverstick, 2008). However, the standards for accounting and financial reporting for state and local governments established by the Government Accounting Standards Board (GASB) since the 1980s have greatly improved the comparability of the funded ratio and UAAL. State and local governments must include the actuarial methods and assumptions in the actuarial reports for public plans, which help to standardize the rating of funded status about pension plans.

Many research institutes, such as the Pew Research Center, Wilshire Consulting, Wisconsin Retirement Research Committee, etc., and researchers adopt the funded ratio to illustrate the financial status of state and local pension plans (Munnell, Aubry, \& Haverstick, 2008; Munnell, Aubry, Hurwitz, Medenica, \& Quinby, 2012; Novy-Marx \& Rauh, 2009). Some experts select the unfunded pension liabilities to demonstrate the financial solvency of retirement system (Chaney, Copley, \& Stone, 2002; Coggburn \& Kearney, 2010). More frequently, agencies (e.g. GAO) and scholars 
incorporate both the funded ratio and unfunded liabilities in actuarial base to reflect the fiscal stress of public pension plans (Giertz \& Papke, 2007; McCue, 1994; Peng, 2004).

\subsubsection{Determinants of the Financial Solvency of Public DB Plans}

This section focuses on the contribution of the empirical literature on the examination of the funding status of DB plans in the public sector. The reviewed studies identify some determinants of the fiscal health of public DB plans, which are classified into three categories: the individual features of each plan design, the financial indicators, as well as the political factors of the financial solvency of DB plans.

\section{Plan Characteristics}

The unique characteristics associated with each DB plan have the most direct and profound impacts on its financial health. Previous literature suggests three plan features may affect the funding status of public sector DB plans: the generosity of pension benefits, the payment of contributions, and the plan demographics.

Generosity of Benefits

In DB plans, the amount of retirement benefits is calculated by a formula that involves a benefit multiplier, years of service, and the average final compensation (AFC). AFC is the average salary of selected number of years of services. The shorter 
period is used to calculate the AFC, the more generous the plan becomes. The benefit multiplier is the percentage of AFC earned with each year of service. The calculation of years of services depends on the normal retirement age regulated by the organization and the required vesting period to be eligible for the retirement benefits. In addition to the benefit formula, two other factors can increase the generosity of public sector DB plan: whether the organizations offer COLAs and the regulation of the minimum required years of service for early retirement.

More generous plan design characteristics will affect pension costs and consequentially influence the funding status of DB plans (Winklevoss, 1977). Liberal plan benefits will lead to greater future liabilities, so the funded ratio will decline and/or unfunded liabilities will increase (Munnel et. al., 2008). Ill-considered and unfunded benefit increases have resulted in the drop of funded ratio and then a widening gap between the states' pension assets and their obligations (Pew, 2010a).

McCue (1994), using a Chowdhury's incomplete covariance panel data analysis of 173 local government pension plans in Florida from 1987 to 1992, found that enhanced pension benefit packages led decreased funded ratio and increased unfunded liabilities for local governments. Similarly, a increase in normal retirement age was associated with higher funded ratios and lower unfunded liabilities, because they provide "longer time horizons to amortize benefit obligations" (p. 116). Giertz and Papke (2007) utilized the state-level data of 85 public pension plans from 2000, 2002, and 2004 surveys of actuarial reports by the Wisconsin Retirement Research 
Committee, to build a pooled ordinary least square (OLS) and fixed effect regression to model determinants of the funded ratio of public DB plans. They find that more generous plans, indicated by higher formula multipliers, tend to have higher funded ratios. Nevertheless, although the association is economically important, it does not hold statistically significant in their complete model.

\section{Fulfillments of Contributions}

Actuaries in each public pension system calculate the annual required contribution (ARC) that needs to be paid from the operating budget to keep the plan on a steady path toward full funding. The ARC, as defined by GASB, includes the normal cost, i.e., the present value of newly accrued pension liabilities in a given year, and amortized payments to make up unfunded actuarial liabilities over a 30-year period (Munnell et. al., 2012; Rauh, 2010). Therefore, increases in pension benefits will result in additional yearly cost, and thus lead to higher ARC.

Typically, contributions are made as a percentage of participating employee payroll by employer and employees. State and local government employees are generally required to contribute annually a percentage of their salaries to their DB plans. The percentage of contribution is determined in accordance with legislative requirements. Because the Employee Retirement Income and Security Act (ERISA) of 1974 does not apply to the public sector, there is a lower threshold of fiduciary responsibility in public pension management. Governments are not required to fully 
fund their ARC. In the vast majority of states, the amount that is set to be paid by legislatures may be considerably less than the actuarially required amount (Pew, 2010a). During economic downturns, limited payments to ARC may be preferred by legislatures because pension contributions do not possess the same priority and urgency as other government expenditures (Peng, 2004).

On the other hand, the strong financial performance will make public employers more prone to give themselves a funding holiday: Instead of putting extra funds aside for rainy days, it seems more palatable for politicians to reduce contributions because of the illusion that high investment returns are sufficient to fund the plans. McCue (1994) found evidence that there is negative relationship between the funded ratio of Florida local pension plans and their contributions from both employers and employees. The results suggest that as the funding status improves, governments tend to reduce the percentage of contributions from both sponsors and participants. By deferring the required payments to contributions, the governments merely shift the pension benefit costs to future generations (McCue, 1994; Peng, 2004).

Previous literature suggests the solvency of ARC is the key to maintain a sound funding pension plan. Falling behind required payments to required contributions is a significant factor of the declining funding status of public pension plans (Pew, 2010a). With examination of the survey data for 84 large public plans from 38 states, Munnell et al. (2008) conducted a linear regression to investigate the effect of fulfilling ARC to the financial health of locally administrated pension plans. The authors find that plan 
sponsors fulfilling their ARC would have significantly better-funded plans than those failing to make their ARC.

With a regression model using state-level data drawn from the Pew Center on the States' 2007 report Promises with a Price, Coggburn and Kearney (2010) found a significant positive relationship between the employer contributions and the unfunded pension liability, which is counterintuitive at the first glance. McCue's study (1994) also reveals the same association between contributions and UAAL. One of the explanations may be that plans with liberal contribution requirements are likely to accrue higher unfunded liabilities in the past than those less generous plans (Coggburn \& Kearney, 2010). Another reason is from the actuarial perspective: since the ARC is actuarially calculated, a higher contribution percentage indicates a wider gap between pension assets and liabilities (Eaton \& Nofsinger, 2004; Peng, 2004). Therefore, plans with more unfunded liabilities are required to assume higher contribution rates in order to ameliorate the poor funding practices in the past.

Previous literature does not yield consistent evidence of the significance of plan design features to the funding status of public pension plans. Munnell (2012) points out this could be explained by the unique pension culture of each state. For example, Florida and Delaware are clustered in the category of less generous pension benefits. The former has been famous of well-funded pension plans while the latter suffered from the unfunded pension liabilities. By contrast, some states like Kentucky and 
Illinois are located in the group of liberal pension benefits, but differ widely in funding status of their pension plans.

\section{Plan Demographics}

The number of elderly in the United States increased from less than 5\% in 1900 to about $12.4 \%$ in 2000 . Beginning in 2010 , the elderly population increased dramatically, which is caused by the "graying" of baby boomers (Frankfort-Nachmias \& Leon-Guerrero, 2011). In every state, the elderly population grows faster than the total population (ConagaRetna, 2004). The demographic change will exert greater pressure on both public and private pension systems and impact their funding status. Coggburn and Kearney's study of state pensions (2010) shows that the growth of public employee density, measured as the number of state government employees per 10,000 state population, will lead to the increase of state governments' unfunded pension liabilities.

The plan demographic information includes the numbers of active members and beneficiaries of the pension plan. Previous studies have shown that the demographic figures influence the financial solvency of public pension plans. Munnell et al. (2008) find a significantly positive relationship between the number of plan participants and the funding ratio of locally administered pension plans. The authors explain this finding with the economies of scale in running plans and greater scrutiny to larger plans. Giertz \& Papke (2007) use the ratio of active members to beneficiaries to reflect the plan 
demographics and they find that "the ratio of actives to beneficiaries is statistically significant and suggest that plans with a one unit higher ratio have a funding ratio that is 4.5 percentage points higher" (p. 321).

\section{Financial Factors}

Both the external economic performance and the internal fiscal status of state and local governments will endow great influences to the financial solvency of public pension plans. The discussion below summarizes two financial elements affecting the funding status of pension plans: the fiscal stress that governments experience and the investment strategies of public pension assets.

\section{Fiscal Stress of Governments}

The fiscal condition of state and local governments will affect the funding of public pension plans. During recessions, the lower-than-expected economic growth rate will result in revenue shortfalls and cyclical budget pressures (Peng, 2004). These fiscal stresses will force governments to balance their budget sheet by either increasing tax revenues or reducing expenditures. Because of the theoretically prefunded nature of pension funds, they can be viewed as a source of ready cash for legislatures (Giertz \& Papke, 2007). Therefore, when governments encounter a significant fiscal stress, legislators may believe it is legitimate to reduce or postpone pension payments to shore up their financial solvency. However, this provisional strategy will only increase the ultimate costs when the pension bill is due in future, which hurts the funding status of 
pension plans and transfers the financial obligations to future taxpayers (Inman, 1982; Mitchell \& Smith, 1994; Peng, 2004; Peng, 2008; Romano, 1993).

In previous studies, researchers select numerous indicators of fiscal stress to examine its impact on the funding status of public pension plans. The frequently used empirical gauges of fiscal stress are the current year general fund surplus (or deficit) and the year-end general fund balance (Reck, Wilson, Gotlob, \& Lawrence, 2001; Wilson, 1983; Wilson \& Howard, 1984). Chaney, Copley, and Stone (2002) utilize these two measures standardized by population to run an OLS model with the pension data of 44 states. Their results show states with fiscal stress that have balanced budget requirements at the same time fund their pensions at significantly lower level than others. Pagano (1993) extends the measure of current year fund balance by creating an imbalance index, which is the difference of current revenues and current expenditures divided by total current expenditures. Adopting the imbalance index to examine the funding status of Florida local pension plans, McCue (1994) finds that when cities face fiscal stress, policymakers typically defer the funding for UAAL, which would worsen the funding status of public pension plans.

Eaton and Nofsinger (2004) employ two different indicators of fiscal constraints: one is a flow variable calculated with each state's annual interest payments divided by its total revenue; another is the amount of total public debt divided by total revenue. Utilizing a panel data from five surveys of state and local government pension systems conducted by the Public Pension Coordination Council (PPCC) for the years 
1990-1992, 1994, and 1996, the authors uncover that states with higher fiscal constraints have significantly lower funding level than those states with less fiscal constraints. Following the measurement of Eaton and Nofsinger (2004), Coggburn and Kearney (2010) also select the flow variable of fiscal constraints. Their results indicate “a significant positive relationship between a state's level of fiscal constraint and unfunded liabilities" (p. 103), because the pension payments become the easy victim in the competition of expenditure allocations with other government programs.

Investment of Pension Assets

Since public pension plans rely heavily on the investment earnings to fund benefit obligations, the market volatility of pension fund investment returns could significantly affect the financial solvency of the plans. Severe investment losses of public pension funds in the 2008 bear market is the most direct root for the current public pension crisis (Pew, 2010a). Therefore, the strategies to sustain an adequate investment return are imperative to improve the funding status of pension plans. One of the important approaches is to ensure the pension asset allocation to different investment instruments.

Back in the 1970s, because of the requirements associated with state law, state pension systems generally relied on more conservative instruments that avoided investment losses and delivered a low but stable rate of return, e.g., fixed income, cash and equivalents, etc. Nevertheless, in the following decades, public pension systems 
loosened up their restrictions on investment in high-risk instruments such as equity, real estate and private equity. According to the Pensions \& Investments Annual Plan Sponsor Survey, in 2007 equity investments accounted for $60 \%$ of public plan assets, compared with that in 1990 s, only $38 \%$ of public pension assets were placed in equities. In bull markets, the aggressive investment strategies could generate considerable returns and result in reducing contribution rate because of the over-funded pension funds. But the downside is that the negative investment returns during the market plunge, along with reduced revenue collections due to bad economy, would require governments to contribute substantially more to their pension plans (Peng, 2004).

The review of literature suggests the importance of prudent pension assets investment to the financial solvency of public pension plans. Peng (2004) conducts a case study of three states (West Virginia, New York, and New Jersey) to illustrate the best practice in handling pension investment and finds that diversified assets among a broad array of pension assets allocation in both high and low risk instruments may ensure the long-term healthy and steady investment returns. Novy-Marx and Rauh (2009) refute the belief that the investment in equity is less risky in the long run than in the short-term, because of its intrinsic fallacy of equity investment (Bodie, 1995; Merton \& Samuelson, 1974; Ross, 1999). Albrecht and Hingorani (2004) find that investment in equities would negatively affect the risk adjusted financial performance of public pension funds, although Nofsinger (1998), Abrecht, Shamsub, and 
Giannatasio (2007), Weller and Wenger (2009) do not find it brings a statistical significant impact.

Stalebrink, Kriz and Guo (2010) examine public pension asset allocation by comparing it with an optimal portfolio, as defined by Modern Portfolio Theory (MPT), which claims that diversification across asset classes will lower the investment risk at a given level of expected return. With data from 94 pension plans from the 2007 Public Fund Survey, the authors conduct the comparisons between the expected volatility of the funds' return and that of the optimal asset allocation at the target rate of return. Their results indicate the plans in the sample "are taking on far more risk than the optimal portfolio would incur given their target returns. The excessive risk taking is driven by an unexplainable reliance on equity investments" (p. 42).

\section{Political Factors}

Since most state and local governments do not have prescribed actuarial assumptions and funding methods to prepare actuarial reports for public pension funds, the selection of these variables rests in the political preference of each plan board of trustees. This section provides explanations about the influences of the political selections of these two factors on the financial solvency of public pension plans.

\section{Funding Methods}


Funding methods are the budgeting schemes or the payment plans in which the pension benefits are to be financed. The choice of funding methods does not affect the true over-all costs, but serve as "a controlling factor in determining how much of the eventual cost is to be paid at any particular point of time" (Trowbridge, 1952, p. 17). State and local governments primarily use one of the four funding methods to determine their normal costs, which are: Entry age normal (EAN), frozen initial liability (FIL), aggregate (AGG), and united credit (UC). AGG is the most conservative method used by public employers. With the AGG method, the normal costs are calculated as the amount of the difference between the present value of future obligations and the assets needed to pay it down over time (Munnell et. al., 2008). The FIL method is grouped with AGG cost plans. Under the FIL method, the unfunded obligations are amortized over a fixed period. After calculating the initial unfunded liability, the AGG method is employed (Munnell et. al., 2008). The EAN method is also relatively conservative because the benefit costs are recognized early in a participant's career at which the pension funds allow for greater investment returns to fund the obligations (Trowbridge \& Farr, 1971). The UC method is the least conservative funding regime because the pension liability is calculated later in the participant's career when the investment return is amortized over a shorter period (McCue, 1994).

The review of literature suggests mixed results about the impact of funding method choice to the financial solvency of public pension plans. Munnell, et al. (2008) find the employers that opt for the cheaper funding method, i.e., the projected UC, may 
be less committed to funding their obligations, which leads to lower funding ratios. However, there are studies that do not find evidence that the plans using UC method are worse funded than those using the more stringent methods (Giertz \& Papke, 2007; McCue 1994; Munnell et. al., 2008). One of the explanations for the latter could be that although the political choice of funding method results in difference of required contributions in the short term, in the long run every approach will generate sufficient obligation payments. Hence in aggregate the adoption of funding method should have no significant impact on the long-time financial soundness of public pension plans (McCue, 1994).

\section{Actuarial Assumptions}

Another two key economic assumptions in public pension funding refer to the interest assumption, also named as the earning assumption, and the assumption of the wage inflation rate. The difference between the interest assumption and the wage inflation assumption, which is often referred as the "economic spread", is the assumed real return on invested assets over the wage inflation rate (Giertz \& Papke, 2007). The economic spread is one of the most critical decisions made by policymakers regarding ultimate pension costs (Tilove, 1977). When the assumption of interest rate is higher than the projected wage inflation rate, the pension benefit obligations would be reduced. On the contrary, when the salary growth rate is higher than the earning 
assumption, the public pension plans would incur more benefit costs. Therefore, the larger economic spread is assumed, the less pension costs governments would pay for (Mitchell \& Smith, 1992).

Since most state and local governments do not have mandatory actuarial assumption rates, the assumed economic spread can serve as a useful tool for policymakers to manipulate the pension costs. Especially when governments perceive the fiscal pressure or recession, by raising the assumption of interest rate unrealistically, the plan sponsors could reduce the required pension expenditure to balance the budget sheet (Giertz \& Papke 2007), thus making pension plans appear well funded. Munnell (2012) argues that the investment return rate at eight percent, assumed by many governments, is unrealistic and leads to the illusion of less pension costs. McCue (1994)

finds strong supporting evidence that the increase of the assumed economic spread is associated with the increase in the funding ratio. However, since the UAAL is calculated based on actual events not forecasting increased rates, the actual economic spread, instead of the assumptions, positively affect the amount of UAAL.

\subsection{The Public Pension Paradigm Switch from DB Plans to DC Plans}

Some scholars appear committed to tinkering strategies that preserve the DB model. Meanwhile, some researchers have started considering the imperative of replacing the DB plans with DC plans. Other scholars not only criticize the vulnerability and inefficiency of DB plans, but also advocate the DB-to-DC transition. 
Although just a few state and local governments have experience of DC plans, existing literature details potential issues with implementing public pension paradigm switch (Frank et al., 2012; Lechance and Mitchell, 2002; Munnel et al., 2008; Munnel et al., 2010; Papke, 2004). The section will present previous studies about the drivers and impediments to conduct the public pension model transition.

\subsubsection{Drivers to Conduct Pension Model Transition}

The steep fall of public pension assets resulting from the stock market plunge in 2008 has incurred a widening gap between the public pension assets and liabilities. At the same time, the relatively poor post-recession performance has tightened revenues, and thus fewer resources for state and local governments to allocate to public pension funds. The increasing unfunded pension liabilities in recent years have shattered the long-held illusion that public sector enterprises are relatively more immune to the market fluctuation than private entities (Hays, 1996; Giertz \& Papke, 2007; Munnell, Haverstick, \& Soto, 2007). The outstanding costs associated with DB pension plans have forced governments to acknowledge the financial risk of sponsoring them is unacceptable to taxpayers and elected officials. Under the DC model, the annual contribution cost is stable, in contrast to the inconsistent $\mathrm{ARC}$ required by DB plans based on their market performance. Therefore, the switch from the DB to DC model is offered as a means of reducing the fiscal burden of snowballing pension costs from governments. Thus, the basic affordability issue of the DB plans becomes the most direct incentive for state and local governments to conduct the DB-to-DC transition. 
The changes in GASB's accounting rule make the solvency issue of public pension funds more visible. In 1999, GASB issued new accounting and financial reporting standards that required government entities to provide more comprehensive accrual-basis financial statement (Funkhouser, 2013). State and local governments are required to report the amount of UAAL, which represents a funding liability rather than the financial condition of individual plans (Frank et. al., 2012). Since then, GASB has continued to set higher standards to improve the accounting and financial reporting of public pension plans by state and local governments, which reflects a more accountable representation of pension benefit obligations. The recently approved GASB Statement 68 requires governments with DB plans to report net pension liabilities, which provides citizens with a clearer picture of the size and nature of the financial obligations for past services rendered (Norwalk, 2012). These new accounting rules are likely to reveal an increasingly weak financial position of pension funds, hence the perception of unhealthy public pension system will force politicians to embrace pension policy changes (Lambert \& Byrnes, 2012).

Other than the financial and budgetary pressure from the pension costs and GASB's transparency initiatives, the Great Recession also imposes political pressures on state and local governments to lean towards the pension paradigm switch (Boivie \& Weller, 2012). Under the DB regime, the only option available for state and local governments to reduce the unfunded liabilities is to improve the funding level (Clark \& Sabelhaus, 2009; Munnell, Aubry, \& Quinby, 2010). The resources to improve the 
funding would primarily come from the tax revenues rather than from increased employee contributions, because usually there are legal constraints on changing the benefit formula for current employees (Manahan, 2010). "The debate over increased funding is likely to trigger a significant battle for resources between plan participants and taxpayers" (Clark \& Sabelhaus, 2009, p. 494). Thus, taxpayer sentiment may cause policy-makers to make politically palatable decision about pension reform. The increased popularity of anti-tax movements further fuels the oppositions to public DB pension plans (Barstow, 2010). The increasingly visible disparity between the compensation level and DB coverage of public employees and that in the private sector may incur the voter anger, which argues for elimination of DB plans in the public sector (Reilly, Schoener, \& Bolin, 2007).

\subsubsection{Impediments to Conduct the Pension Paradigm Switch}

Those advocating a DB-to-DC switch recognize serious issues in the transition. This section identifies several potential financial and organizational impediments during the transfer.

\section{Transition Costs}

One of the thorniest issues in dealing with a DB-to-DC transition is that governments still need to deal with costs of existing DB pension plans in terms of accrued liabilities (Boivie \& Weller, 2012; Munnell, Golub-Sass et al., 2008). Because many states have legal restrictions of changing benefits of current employees, the newly 
employed DC plans would only apply to the new-hired employees. Thus, the governments still have to cover the accrued benefit obligations for past services. To making matters worse: Although the new employees on DC plans will not accrue any benefits, they also will not make contributions, which means the employer will solely bear the fiscal burden without incoming new dollars to fund the old DB plan. Therefore, the higher the previous unfunded liabilities the DB plan has (i.e., the lower the funding ratio), the more substantial costs governments will encounter at the beginning of pension model transition. However, in the long run, through paying down the unfunded liabilities in the past without newly accrued obligations, governments would be able to survive with gradually decreased fiscal stress after the painful liquidation for the first several years.

Munnell and Golub-Sass et al. (2008) examine the factors that affect the decision to introduce a DC plan for state governments with an ordered probit regression using annual data of pension plans for state employees and teachers from 1992 to 2006. Their findings do not reveal the actuarial funded ratio is a significant cue for the introduction of a DC plan. However, with the financial data from 1998-2010, Thom (2010) examines the effect of Michigan's decision to close DB plans for new employees and replace with DC plans. The results show the transition could reduce both the long-term benefit obligations and state budget costs. Especially, when comparing the contribution rate for both plans, the new DC plan has more stable annual 
contribution rate and is less expensive than DB plans, except for the first few years after the introduction of DC plans.

\section{Adequacy for Recruitment \& Retention}

One of the major deterrents relating to the public pension paradigm switch is the concern that the DC model is less adequate as a recruitment-retention tool (American Academic of Actuaries [AAA], 2006; Boivie \& Weller, 2012). In part, this based on the belief that DB makes up for the so-called "wage penalty". The long-held belief is that employees prefer the guaranteed retirement benefits of DB pensions to higher salaries (Ippolito, 1997). Whether or not the employers offer DB plans is a deciding factor that affects the applicant's choice of organizations (Nyce, 2012). However, the argument that DB pension is necessary to reward retirement benefits for relatively lower wages is doubtful given today's job market (Frank et al., 2012; Fletcher, 2010). On the basis of the 2013 data from the Bureau of Labor Statistics, the hourly pay for public employees is on average about one-third higher than that for private employees. In June 2013, the average total compensation cost per hour for public sector employees is $\$ 42.09$, compared with $\$ 29.11$ for private sector workers. Many researchers have revealed the similar trend that in the last three decades, public employees at all levels have started enjoying higher salary than private sector workers (Bender, 2003; Borjas, 2003; Krueger, 1988; Smith, 1977). 
Another advantage of the DB model from the human resources perspective is reflected through public employee retention. There seems to be lower employee turnover rate with DB plans than that under the DC regime. Munnell, Haverstick, and Sanzenbacher (2006) find evidence of lower attrition with DB plans, which suggests that better turnover rates starting from 1990s correlate with the reduced DB coverage and increased DC adoption since then. Public employees, who have longer tenure than private workers, prefer DB plans over alternative plans because the DB plan features favor long-term service (Dulebohn, Murray, \& Sun, 2000; Munnell et al,, 2007; Olleman, 2009). Therefore, DB plans can enhance the probability to attract and retain employees with long-term commitments to their employers (Ippolito, 1997; Nyce, 2007). By contrast, DC plans are less capable than DB plans of instilling employee loyalty to younger employees (Nyce, 2007). They are more attractive to those who focus more on current rewards rather than the deferred pension benefit with long tenure offered by DB plans. Younger workers, particularly those with college degrees, prefer the portability of DC pensions and are increasingly reluctant to commit in the long service period required under the public sector DB model (Bowman \& West, 2006; Dolan, 2007).

Thus, it is possible that the public sector would attract a different labor force if they conducted a DB-to-DC transition. Those higher-income, better-educated plan enrollees will prefer the DC option, whereas the lower-income participants with shorter life expectancies will stick to the safer DB model (Bodie, Marcus, \& Merton, 1988; 
Clark \& Pitts, 1999). The midcareer employees will suffer most from the pension paradigm shift, while younger and mobile workers may favor the conversion and those near-retiring are unaffected by the change (Munnnell, Golub-Sass et al., 2006). The experience in the private sector suggests that closing DB plans has little adverse effects on the capacity to recruit and retain qualified workers. Similarly, based on the examination of academic researches, Frank et al. (2012) contend that the "adoption of DC plans per se do not affect long-term human resources planning in government" (p. 11). Moreover, in both Florida and Michigan the introduction of DC model even originated partly from governments' concern for their ability to attract and retain competent employees (Huntley, 2001; Rehfeld, 1998).

Financial Illiteracy of Public Employees

Another critical issue regarding the DB-to-DC transition rests in the transfer of risks of investment, longevity, and inflation from employers to employees. Under the DB model, state and local governments assume these risks and manage the assets for employees, which has a clear cost advantage in the investment and administration over DC plans (AAA, 2006; Bovie \& Weller; 2012; Brainard, 2005). The guaranteed annuity structure offered by traditional DB plans provide the retirement security to those who lack the necessary knowledge of financial planning. By contrast, with a DC plan the contributions to the individual accounts are invested by the own will of employees, so 
all the risks are shifted to the plan participants. Unfortunately, most Americans are not financially literate enough to manage their savings or allocate assets across investment classes (Frank, 2009; Lusardi \& Mitchell, 2005; United States Congress, 2008). According to the 2003 John Hancock Financial Services Retirement Survey of 800 DC plan participants, nearly half have little or no investment knowledge and less than $20 \%$ consider themselves relative knowledgeable (Carmichael, 2003). The survey concludes that many respondents have a skewed opinion about the way that investment works across-the-board, not to mention the advanced skill of financial planning of pension assets. To make it worse, many employees have limited enthusiasm to learn about the pension fund investment. One study of the Pension Research Council shows a large proportion of workers lack the serious interest in maximizing their investment returns and retirement security (McFarland, Marconi, \& Utkus, 2003).

The damage to 401(k) accounts associated with the 2008 stock market crash reinforces the impact of illiteracy. The poor performance of 401(k) accounts has raised widespread concerns about their capacity to provide retirement security. In the private sector, the average return rate of $401(\mathrm{k})$ assets is $1 \%$ less than that of DB assets during 1988-2004, even with a higher percentage of 401(k) assets invested in equities during the bull market of 1990s (Munnell et al., 2006). In the public sector, concern with the huge disparity between the investment returns of DB plans (11\%) and DC plans (6.5\%), in 2002, Nebraska replaced the DC plans for state and county employees with a cash balance plan, where employers took back the responsibility to management of pension 
assets (Munnell, Golub-Sass et. al., 2008). Experience in both the private and public sectors reveal the same difficulty for individual participants to manage their pension asset investments and generally they could not do a pleasing job.

Another factor contributing to the need for enhanced financial literacy is the fact that unlike the private sector DC participants, the public employees are not covered by the Pension Protection Act (PPA) of 2006, which addresses the financial illiteracy and undersaving issues of 401(k) plans in the private sector (Frank et al., 2012). The PPA offers the qualified default investment alternatives of asset allocations to private DC participants in order to facilitate controls over their retirement income. Without the protection of PPA, the public DC enrollees may suffer from poor decisions and make reckless investment decisions that fail to secure adequate retirement benefits (Yakoboski, 2011). The upshot is during the process of pension paradigm shift from DB to DC plans, state and local governments cannot ignore the reality that most employees lack the basic knowledge of investment concepts and practices. Thus, the financial training is crucial in order to avoid the possible indigence of retired employees.

\subsection{The Interperiod Equity Issue of Public Pension Reform}

Another issue worthy of consideration is the intergeneration inequity. Many researchers have raised their questions about this aspect of pension underfunding. By delaying pension obligation payments, the governments simply shift the financial burden from the current taxpayers to the future generations, which violates the 
interperiod equity principle (Clark \& Sabelhaus, 2009; Creedy, Li, \& Moslehi, 2010; Peng, 2004; Peng, 2008). Interperiod equity is a term in the governmental accounting literature, which has originated from Rawls' (1971) conception known as "justice between generations" (p. 284). As Frederickson (1994) advocates, public officials have the obligations towards future generation to ensure the intergenerational fairness. However, the current shortfalls of DB plan funding suggest an unfair transfer of wealth from the future taxpayers to the current generation (Mahoney, 2000; Novy-Marx \& Rauh, 2008). This wealth transfer is revealed by the fact that the subsequent generations not only need to pay extra taxes to finance the accrued pension promise for previous public services, but also expect to receive lower returns in terms of reduction in public services. (Mahoney, 2000; Mittelstaedt, 2004). Thus, a pension windfall awarded to the previous generations is coming at the expense of future taxpayers. Furthermore, recent poor investment returns suggest this issue is unlikely to be ameliorated by future bull markets (El-Erian, 2008; Mittelstaedt, 2004).

Failing to assume the responsibility of interperiod equity may result in a moral hazard issue of managing DB plans, that is, governments have less intention to fully fund their DB pension benefits (Giertz \& Papke, 2007; Yang and Mitchell, 2005; Peng, 2008). Promises of guaranteed pension benefits enforce plan participants' belief that their benefit are cast in stone regardless of the funding status. Since ERISA does not apply to the public sector employees, politicians tend to be indifferent to the long-term funding needs either because of the urgency to address immediate budget priorities, or 
because of their relatively short horizon of operation. Similarly, legislatures would give themselves a funding holiday in good times by deferring pension contributions or increase the benefit level ignoring the long-term effects. These practices echo the public choice theory, which assumes that elected officials and public administrators act in their self-interest, not in the public interest (Buchanan \& Tullock, 1962). Mismanagement due to the moral hazard issue exacerbates the underfunding of the DB model. By design, DC plans minimize this moral hazard problem - the governments are required to pay their constant proportions of pension contribution in a timely manner. Switching from DB to DC not only could limit the moral hazard of underfunding pension plans, but also could address the transfer of pension costs to all stakeholders of DB plans.

Before the recent public pension reform, the transfer of pension costs among different generations was just implicitly manifested within the DB system. However, the two-tier benefit system created in the recent public pension reform makes the interperiod equity issue more relevent. Hesitant to conduct the DB-to-DC transition in totality, many state and local governments adopted the incremental strategy to improve their pension funding status. New hired employees will face elongated retirement age and vesting periods, reduced benefit multipliers and COLAs, and/or mixed pension plan portfolios. Therefore, under the two-tier structure the new hires enjoy less generous retirement benefits. State and local governments hope to reduce their future pension costs by hiring new employees at lower pension costs than incumbent workers. 
Practice in the private sector suggests the two-tier benefit structure is more appealing to companies with higher rates of turnover among new hires and with a large group of rich-benefit, high-skilled senior employees due to retire soon (Harrison \& Bluestone, 1990). A two-tier system also causes the problems of higher turnover rate of new hires and a demoralized workforce (Bewley, 2007). But given enough time, this issue may be self-solvent along the retirement of senior employees leaving only one tier with lower benefits left in the entire industry (Harrison \& Bluestone, 1990).

The issue has not drawn much attention in the literature of public pension reform given its recency. The study investigates the impact of the two-tier benefit structure from the perspective of ethics and equity, because when conducting political reforms, elected officials should not just fix their attentions exclusively on methods but also consider the ultimate goal of governments (Adams, 1902).

\subsection{Summary}

The literature review provides a theoretical framework of developing public pension reform strategies to solve the current retirement crisis. If state and local governments plan to improve the funding level of the DB model, it is necessary to identify the significant factors that may affect the financial solvency of public DB plans. The review of empirical studies showcases the rationale behind the underfunding of public sector DB plans, which includes the plan design features, financial factors and political influences. Previous studies fail to consistently address the impact of these 
determinants on the financial solvency in their totality and generate controversial results about the significance of these indicators. There are also methodological issues among the literature that need to be tackled. Previous studies provide partial explanations of the financial solvency of the public DB model with different measurements. The study incorporates more indicators in a comprehensive examination of the financial status of local DB pension plans. In addition, most of the reviewed studies relied heavily on the data of state sponsored plans or large local plans. The study will delve into the DB plans at the local level, which are equally problematic.

The chapter also reviews the literature about the incentives for state and local governments to conduct the pension paradigm switch from DB to DC model, as well as the critical issues that need to be taken into consideration during the transition, which consists of the potential transition costs, effects of DC plans on recruitment and retention, and workforce literacy training. The interperiod equity issue also remains during pension reform. The literature review reveals a dissonance among the researchers' attitudes towards the pension paradigm shift. The DB advocators praise the advantages of DB plans and raise questions regarding the effectiveness of the DC model from both financial and human resources perspectives, whereas another group of scholars believe in the capacity of the DC model in attracting and retaining public workforce and appreciate its lower costs in the long run. The bifurcation calls for empirical evidence to circumstantiate either argument. The interperiod equity issue, 
especially with regard to the two-tier benefit structure, is emergent and also begs for investigation.

On the basis of the discussion above, the contribution of the study to the previous literature about the public pension reform strategies manifests as follows. First, it addresses the methodological issue of the financial solvency of public DB plans by incorporating more variables and measurements with available data of Florida DB plans at the municipal level, which establishes an integrated model for identifying key determinants of the financial solvency. Second, the study utilizes primary data needed about the perceptions of the public pension paradigm switch through surveys and interviews with Florida local government officials. In doing so, it will reveal the drivers and potential obstacles of the pension model transition. Third, it examines the matter of interperiod equity regarding the public pension reform with empirical data from surveys and interviews, a topic that has not drawn enough attention in previous studies. Finally, the study fills an important gap in previous literature by delivering a comprehensive analysis of the efficiency of pension reform approaches in the public sector. Its practical implications will facilitate policymakers to develop feasible reform strategies in order to maintain the sustainability of the public pension system. 


\section{CHAPTER 3}

\section{RESEARCH METHODOLOGIES}

\subsection{Introduction}

Chapter 3 overviews the research approaches utilized in this study, and it is organized according to the research techniques driven by tests of hypotheses. The first part outlines the research design for the examination of the financial solvency of Florida local DB plans with a longitudinal research using the existing data. Second, it describes the research design exploring public pension reform strategies and qualitative data collection. This section provides the details of the survey data analysis approaches, including the comparisons of means, principal component analysis, and a crosssectional regression model; and the interview research design and the data analysis plan.

The study utilized a triangulated research approach to conduct investigations. Triangulation is a "method of cross-checking data from multiple sources to search for 
regularities in the research data" (O’Donoghue \& Punch, 2003). Given the complexity of pension reform and the contrasting views of many stakeholders, triangulation is the appropriate technique. Single research methodology is not sufficient to fully reveal the panorama of the complex phenomenon and may incur intrinsic biases. To overcome the shortcomings of single method and single data source, the incorporation of multiple observations, methodologies, and empirical data sources is essential to facilitate the validation of findings.

\subsection{The Research Design for the Financial Solvency Issue}

The first overarching research question for the study is to examine whether the incremental reform strategies to preserve the DB model could really enhance the financial solvency of public DB plans and thus ensure the sustainability of public pensions in Florida local government. The incremental reform strategies are exemplified by the pension laws enacted in Florida in 2011. The reforms included a series of actions to improve the funding level of the DB regime by changing the plan design features in terms of reducing benefits and increasing contributions. Therefore, it is necessary to prove that the characteristics of DB plan design are the most significant factors in determining the financial status of DB plans, thereby justifying the effectiveness of the incremental reform approach. The literature suggests the underfunding of public sector DB plans not only results from generous benefits or insufficient contributions, but also results from the political pressure. With evidence that changing plan design features may not be sufficient to remedy the public DB model, 
it would make sense to further explore the alternative reform strategies such as the pension paradigm switch from DB to DC plans.

This study utilizes existing data of 151 local DB plans for general public employees collected from the Local Government Annual Reports of Retirement Plans to assess financial solvency, which are prepared by the Florida State Department of Management Services from 2005 to 2012. On the basis of the literature, the study selects the combination of actuarial funded ratio and UAAL percentage of the participating employee payroll as indicators of the financial solvency. The higher the funded ratio is, or the smaller the UAAL percentage is, the better condition the DB plan is in. The trend analyses of these two dependent variables will be provided in Chapter 4 to deliver a general idea of the financial status of Florida local pension plans.

Utilizing panel data, this study includes the elements discussed in the literature review as explanatory variables for the financial solvency, which include the plan design of benefits and contributions, financial factors, and political impacts. The plan demographic information, measured as the ratio of retirees to active members, is included as a control variable. A year dummy of 2012 is also added to separate the effect of the pension reform after 2011. Table 3.1 shows the detailed measurements of the explanatory variables.

A fixed-effect regression model will be tested with the data analysis and statistical software Stata. Fixed-effect models are frequently applied to the panel data 
analysis when researchers are only interested in the impact of variables that vary over time. The purpose of using fixed-effect models is to control the unobserved heterogeneity (i.e., the unobserved individual differences across the entities being studied) when the heterogeneity is time-invariant and correlated with other individual characteristics (Wooldridge, 2013).

Table 3.1 Explanatory Variables for the Regression Model

\begin{tabular}{|c|c|}
\hline Variables & Description \\
\hline \multicolumn{2}{|l|}{ Plan Design Characteristics } \\
\hline \multicolumn{2}{|l|}{ Benefit } \\
\hline Retirement Benefit Rate & $\begin{array}{l}\text { Percent of Average Final Compensation (AFC) earned with } \\
\text { each year of service }\end{array}$ \\
\hline AFC Period & The number of years used in determining the AFC \\
\hline Normal Retirement Age & Normal retirement age for full pension \\
\hline Vesting & $\begin{array}{l}\text { Whether members have rights to benefit computed on years } \\
\text { of service prior to completion of normal retirement age and } \\
\text { credit }\end{array}$ \\
\hline COLA & $\begin{array}{l}\text { Whether the plan has an automatic cost-of-living provision } \\
\text { for retirees }\end{array}$ \\
\hline Early Out & The minimum required years of service for early retirement \\
\hline \multicolumn{2}{|l|}{ Contribution } \\
\hline Member Percent & $\begin{array}{l}\text { The percent of participating employee payroll which is } \\
\text { paid by employees }\end{array}$ \\
\hline City Percent & $\begin{array}{l}\text { The percent of participating employee payroll which is } \\
\text { paid by plan sponsor }\end{array}$ \\
\hline \multicolumn{2}{|l|}{ Financial Factors } \\
\hline $\begin{array}{l}\text { Balance of Revenue and } \\
\text { Expenditure }\end{array}$ & $\begin{array}{l}\text { Excess/Deficiency of revenue over/under expenditure } \\
\text { (total account at city level year end) per } 1,000 \text { population }\end{array}$ \\
\hline Pension Asset Investment & $\begin{array}{l}\text { The percentage of pension assets invested in equities and } \\
\text { fixed incomes }\end{array}$ \\
\hline \multicolumn{2}{|l|}{ Political Factors } \\
\hline Funding Method & $\begin{array}{l}\text { The actuarial cost funding method used to calculate normal } \\
\text { contribution: EAN, FIL, AGG, UC }\end{array}$ \\
\hline Assumed Economic Spread & $\begin{array}{l}\text { The difference between the interest rate assumption and the } \\
\text { salary growth rate assumption }\end{array}$ \\
\hline Actual Economic Spread & $\begin{array}{l}\text { The difference between the actual interest rate and the } \\
\text { actual salary growth rate }\end{array}$ \\
\hline
\end{tabular}

\section{Control Variables}


Plan Demographics

Year Dummy of 2012
The ratio of number of retirees and/or beneficiaries to number of active members in the plan Measure the impact of the 2011 pension law

When using the fixed-effect model, researchers could remove the effect of any time invariant components of the model thus greatly reduce the threat of omitted variable bias (Kohler \& Kreuter, 2012). This study focuses on the cause of changes in the financial solvency within the individual public DB plans, not the effect of constant features of each pension plan. Therefore, it's appropriate to adopt the fixed-effect models in the investigation. The regression results will be presented in Chapter 4 to uncover the key determinants for the fiscal viability of public DB plans.

\subsection{The Research Design for the Issue of Public Pension Paradigm Switch}

\subsubsection{The Survey Research Design}

In addition to the quantitative analysis of the financial solvency of public DB plans, this study also probes into the public pension reforms with the analysis of primary data collected by survey questionnaires. Although the examination of the secondary data lays the ground of arguments about the effectiveness of incremental reform strategies, more evidence is needed to understand the alternative reform approach — the DB-to DC transition. Through the survey results, this study endeavors to uncover the potential impacts of the pension paradigm switch and the attitudes of state and local governments towards this emerging trend. With the quantitative analyses of the survey responses, this study aims to establish indexes of their perceptions to the public pension reform to better understand the rationale behind their thoughts. 
The study collects primary data through a self-administered survey questionnaire sent to the Finance and Human Resources (HR) directors of Florida municipalities. The survey was sent out via e-mail and regular mail, followed by phone and fax reminders. Multiple waves of surveys from August 1st to October 25th, 2012 were administered aiming to enhance the response rate. Given its exploratory nature, the survey is the appropriate method to gather consistent primary data and to assess thoughts, opinions, and feelings, since no prior studies have collected such kind of data relating the public pension reform.

The survey research design is adopted because it enables descriptive contentions about a population by analyzing a representative sample of respondents' attitudes (Axinn \& Pearce, 2006; Creswell, 2003; Shaughnessy, Zechmeister, \& Jeanne, 2011). This study employs a structured survey instrument to elicit consistent measures of perceptions from public officials towards public pension reform. The response format to the survey questions is a five-point Likert scale, ranging from "strongly disagree" to "strongly agree" with a neutral midpoint. Questions are framed in the context of the DB system as the default pension model and restricted to civilian, non-uniformed employees in local governments.

The target population for the survey consists of public officials from all the municipalities in Florida that offer a public pension plan for general employees because they are the focus of this study. The potential survey respondents were selected by the technique of cluster sampling. First, the author selected all the municipalities that 
provide either a local plan for their public general employees or participated in the FRS, since not all of the 410 municipalities in Florida offer pension plans for their general employees (See Figure 3.1). This selection leaves 305 municipalities qualified for the survey. Second, the municipalities with population less than 5,000 were filtered to enhance the generalizability of the research finding, which ends up with the public officials from 176 municipalities as the potential survey respondents.

\section{Figure 3.1 Types of the Public Pension Plans for General Public Employees in}

Florida Municipalities by 2011

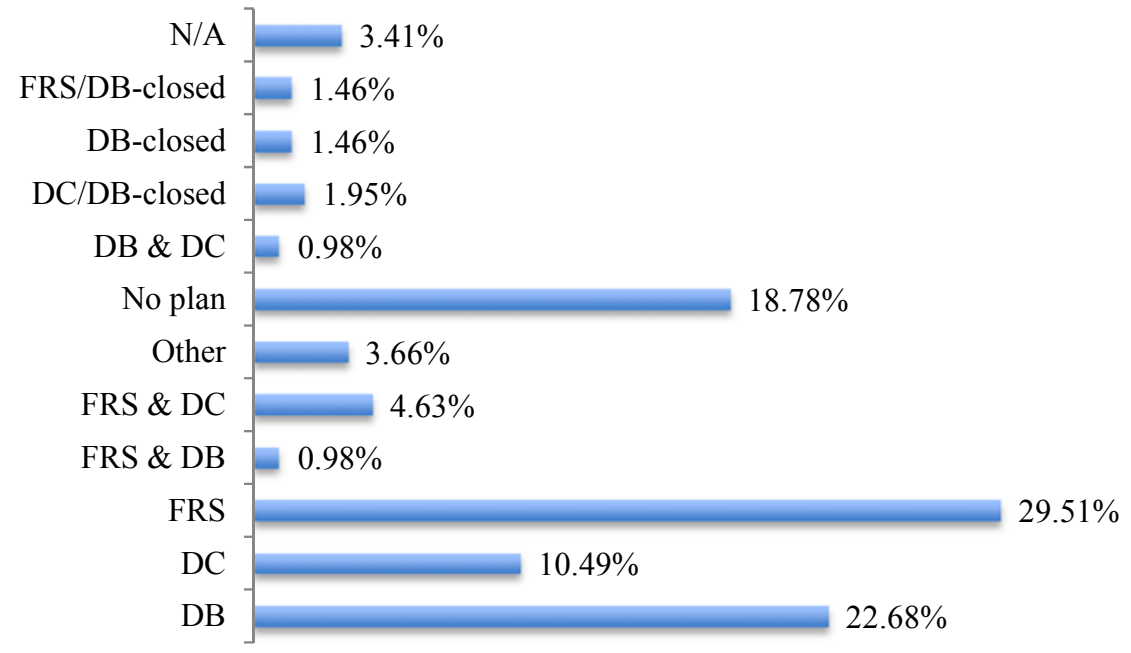

Source: summarized from the 2011 Local Government Annual Reports of retirement plans, Florida State Department of Management Services

The target audience of the survey instruments includes the Finance and HR directors of the selected municipalities in Florida. Finance directors are targeted because the status of pension funds has great impacts on finance and budgeting, hence finance directors would have a direct interest in the issues of pension reform. Pension 
reform would also influence the recruitment and retention of public employees, thus the human resources directors would provide the first-hand insights into the impact of the pension paradigm switch and the newly established two-tier system. The current literature about retirement is segmented between finance and HR management; nonetheless, the research of public pensions should be holistic and integrative. Confronting the current public pension crisis requires exploratory reform strategies that integrate financial adjustments with HR planning considerations (Frank et al., 2012). Thus, the inclusion of both Finance and HR directors from one municipality also serves as a tactic to enhance the overall survey response rate.

The survey instrument is specifically developed for this study based on the critical issues regarding public pension reform identified in the literature review. The questionnaire for Finance directors is partially different from that for HR directors, but the majority of the survey questions are common for the two groups. The 36 common questions for both department heads ask about their perceptions to the public pension model shift, the potential impacts of the public pension reform, and drivers and impediments regarding the public pension paradigm switch. The version for finance directors also asks about the financial sustainability of the public pension plans in order to find out the reasons for underfunding of public pension plans. The extra questions for HR directors inquire the importance of financial literacy training and recent changes of individual pension plan. The survey instruments are attached as Appendix 1. 
Before sending out the survey questionnaire, the instrument was pilot tested with six knowledgeable experts on the research subject, which improved the content validity and format of the survey questions. The self-administered survey was sent out online and via mail for multiple waves. The first two rounds include an on-line survey launch thorough www.fiu.qualtrics.com with the author's account on August 1, 2012. The mailed version was sent out on September 10, 2012 with phone and fax reminder. The last wave was also online through the FIU Qualtrics on October 25, 2012. When administering both online and mailed survey questionnaires, the study follows the guideline of Neuman (2004) to enhance the response rate by accompanying the instrument with a cover letter, which explains the purpose and participants of the survey, the statement of confidentiality and voluntary participation, a small amount of monetary stimulus, and detailed contact information of the researchers. For the mailed version, the cover letter was printed on paper with the letterhead of Department of Public Administration at Florida International University. Along with the cover letter and survey questionnaire, each mailed survey also includes a prepaid, self-addressed envelope for mailing back the responses.

The survey findings are derived from 57 Finance Directors and 56 Human Resources Directors, which comprises a response rate of 33\%. Among the 176 surveyed cities, in 21 cities both the Finance and HR directors responded to the survey; in 36 cities only Finance directors took the survey; in other 35 cities only HR directors answered the questionnaire. In total, the survey yielded responses from 92 cities, 
representing $52.0 \%$ of all the surveyed cities. The response rate is realistic since these days the average response rate in social science is 40 to $50 \%$, especially when considering the high refusal rates in the United States (Neuman, 2004).

Crosstablulations of responses by taxes levied in 2011 as well as city locations indicate there is no significant difference between respondents and non-respondents by tax revenue or region. However, the average population of respondent cities is about 20,000 lower than the non-respondent cities, which could be explained by the fact that some of the largest cities fall into the non-respondent category (the standard deviation of the population for non-respondents is 3 times of that for respondent cities). The composition of pension plan types for general employees (DB, DC, and FRS) of the respondent cities is almost the same as the distribution of pension plan type in all Florida cities. For example, in Florida, $10.5 \%$ of all the 410 cities adopt the DC model to provide retirement benefits, the same as the sample $(10.9 \%$ of respondent cities provide DC plans only.) The comparisons of means between the responses of Finance and HR directors indicate the congruence between these two professions: only five out of the thirty-six common questions have significant differences. Therefore, the survey results can be viewed as a collective attitude towards pension reform.

The data analysis plan of the survey results includes a comparison of means between the responses of Finance and HR directors, a descriptive summary of survey results, a principal components analysis, and a multiple regression analysis with supplementary secondary data. Since the survey questions are designed with five-point 
Likert scales, this study treats the survey responses as quantitative data. First, in order to unveil the similarities and differences of the perceptions from the Finance and HR directors in Florida local governments towards the public pension reform issues, the study compares the means of the two groups through the independent-samples $t$-test. A median score of responses will be provided as a fact-at-a-glance indicator of how perceptions are distributed. By displaying of the frequency distributions of survey items, the survey findings will be discussed question by question.

The second step of the analysis of survey results is a Principal Component Analysis (PCA), which is a way to identify patterns in data by “...generating a reduced set of variates that account for most of the variability in original data..." (Dillon \& Goldstein, 1984, p. 47). The congruence of Finance and HR directors' perceptions allows sufficient numbers of observations to undertake the PCA. Since there is no theory of diffusion of DC plans in the public sector and the study does not test any specific hypotheses regarding the public pension reform, the study conducts an exploratory factor analysis (EFA) of the survey results in order to highlight any underlying variates that affect the observed pattern of responses (Long, 1983). Some issues regarding the DB-to-DC transition are still relatively new to state and local governments, this procedure could facilitate to investigate whether respondents have an internally valid manner in answering the survey questions or they simply check the box. 
On the basis of the results of the EFA, five indexes reflecting the perceptions in the public pension reform from local government officials are developed by calculating the average of the factor scores of survey items comprising the five factors. The indexes are employed as the dependent variables in a multiple regression analysis with the individual characteristics of respondents and city-level data as explanatory variables. The regression results will show which variables may impact the perceptions of survey respondents towards the public pension reform issues.

\subsubsection{The Interview Research Design}

The survey results provide the evidence about the perceptions of Florida local government officials towards public pension reform issues. However, solely relying on the survey responses is not enough to explain the rationale behind the revealed attitude. Since the survey process may not cover all aspects of pension transition, the validity of the survey results needs to be verified by another method. Therefore, another qualitative method, i.e., interview, is employed to gather in-depth thoughts about the subject of public pension reform. This qualitative approach could take a non-linear route to better comprehend the details of a particular context (Neuman, 2004).

The study develops and administrates ten structured phone interviews to inquire further elaborations on the survey findings and to gather in-depth insights into the issues from May to July 2013. The interviewees, who are drawn from the survey respondents in purpose, split almost equally by department, gender, and plan coverage 
for general employees (DB, DC, and FRS). Table 3.2 shows the composition of interviewees. The selection of interview participants provides valuable information since the composition of interviewees cover almost all the stages in the process of public pension reform, such as preserving DB by modifications, switching to the State pension plan, and transitioning to the DC model. The non-random sampling is adequate because it allows the researcher to select critical cases that are rich in information pertaining to the research topic (Kuzel, 1999).

The structured interviews were conducted based on an interview schedule with the same nine questions in the same order to each participant, which insures the consistency and reliability of the aggregated answers (See Appendix 2). The structured interviews are best suited for studies that need compare participants' responses in order to answer a research question (Lindlof \& Taylor, 2002). In order to uncover the reasons behind the survey response and profound viewpoints about the public pension reform, the interview questions contain the following topics: the sustainability of DB plans, the major drivers and obstacles to conduct the DB-to-DC transition, the impacts of the paradigm shift to the recruitment and retention in public sector, the necessity of financial literacy training with the transition, the issue with newly established two-tier benefit system; and the possible solutions to the current public pension crisis. The interviews were recorded with consent of the participants and documented by transcripts. The interview questions and findings of the interview data will be presented 
in Chapter 6. The results are reported collectively to keep confidentiality of individual interviewees.

Table 3.2 The Composition of Interviewees

\begin{tabular}{|c|c|c|c|c|c|}
\hline ID & Dept. & Gender & $\begin{array}{l}\text { Current Plan Type } \\
\text { for General } \\
\text { Employee }\end{array}$ & $\begin{array}{c}\text { Current } \\
\text { Funded Ratio of } \\
\text { General } \\
\text { Employee DB } \\
\text { plan }\end{array}$ & Recent Pension Plan Changes \\
\hline 1 & Finance & Male & DB & $97.40 \%$ & $\begin{array}{l}\text { Adopted a second tier of benefits } \\
\text { for newly hired general employees }\end{array}$ \\
\hline 2 & Finance & Female & DB & $64.10 \%$ & N/A \\
\hline 3 & Finance & Female & DB & $90.40 \%$ & $\begin{array}{l}\text { Moved from a DB plan to a hybrid } \\
\text { plan; reduced the benefits of } \\
\text { general employees in the DB plan }\end{array}$ \\
\hline 4 & Finance & Male & $\begin{array}{c}\text { DB (closed to } \\
\text { new hires) \& FRS }\end{array}$ & $66.20 \%$ & $\begin{array}{l}\text { Increased retirement age; closed the } \\
\text { DB plan for general employees and } \\
\text { switched to FRS }\end{array}$ \\
\hline 5 & Finance & Male & $\begin{array}{l}\mathrm{DB} \text { (closed to } \\
\text { new hires) \& DC }\end{array}$ & $84.10 \%$ & $\begin{array}{l}\text { All new hires switched to } 401(\mathrm{a}) \\
\text { plan; reduced benefits of employees } \\
\text { in the DB plan }\end{array}$ \\
\hline 6 & HR & Male & $\begin{array}{c}\text { DB (closed to } \\
\text { new hires) \& FRS }\end{array}$ & $72.00 \%$ & $\begin{array}{l}\text { Closed the DB plan for general } \\
\text { employees and switched to FRS }\end{array}$ \\
\hline 7 & HR & Male & $\mathrm{DB} \& \mathrm{DC}$ & $76.70 \%$ & $\begin{array}{l}\text { Reduced benefits for general } \\
\text { employees in the DB plan }\end{array}$ \\
\hline 8 & HR & Female & DC \& FRS & NA & $\begin{array}{l}\text { For general employees, switched } \\
\text { from FRS to a } 401 \text { (a) plans }\end{array}$ \\
\hline 9 & HR & Female & DB & $65.60 \%$ & $\begin{array}{l}\text { Adopted a second tier of benefits } \\
\text { into the police pension plan }\end{array}$ \\
\hline 10 & HR & Male & DC \& FRS & NA & $\begin{array}{l}\text { For general employees, switched } \\
\text { from FRS to a DC plan }\end{array}$ \\
\hline
\end{tabular}

\subsection{Summary}

This study employs a triangulated research design to conduct a full-scale examination of the public pension plans in Florida local governments. First, this study provides an overview of the fiscal standing of current DB plans in Florida local governments by analyzing the existing data of 151 local DB plans from 2005 to 2012. A fixed-effect regression model is established with the panel data to identify the crucial 
indicators determining the financial solvency of DB plans, which paves the way for the arguments about the efficiency of the incremental reform strategies. Second, the author adopts a survey of local government officials designed to collect the primary data of the potential impacts of the pension paradigm switch and their readiness to conduct the model transition. A descriptive analysis of the survey results will be delivered to illustrate the organizational impacts of public pension reform issues and the drivers and impediments of conducting the pension paradigm shift. Quantitative analyses on the basis of the indexes, derived from the principal components analysis of survey responses, supplements the qualitative inquiry with numerical data, which enables identification of the determinants impacting government officials' opinions on pension reform issues. Third, in order to improve the credibility and validity of the survey results, interviews are conducted to cross-verify the survey findings and to gain indepth and elaborate viewpoints that cannot be wholly grasped through surveys.

\section{CHAPTER 4}

THE DETERMINANTS OF THE FINANCIAL SOLVENCY OF PUBLIC DB

\section{PLANS}

\subsection{Introduction}

The most direct incentive for state and local governments to reform the public pension system is to improve the financial health of public pension plans and thus, 
relieve the fiscal burden of skyrocketing pension costs. In order to efficiently enhance the funding status of public pension plans, reform strategies should be developed based on the examination of the roots for the pension crisis. Therefore, it is necessary to investigate the critical determinants of the financial solvency of public pension plans to prescribe targeted therapies.

Recent history has shown that most state and local governments have tried to reform their pension plans with incremental changes to the DB plan design. The new pension law enacted in 2011 in Florida can serve as such an example. The reform utilized strategies to increase the employee contribution rate and reduce benefits by decreasing COLAs, lengthen the vesting period, extend the AFC period, and increase retirement age and required years of service. However, the literature review suggests that the financial solvency of public DB plans is not only determined by the plan design characteristics, but also is greatly affected by shifting political, economic, and demographical realities. Hence, Chapter 4 aims to identify the significant determinants of the financial health of pubic DB plans. Furthermore, the results would provide evidence to argue whether the incremental reform strategies for DB plans are effective to sustain the current public pension system.

The following discussion is organized into four sections. The first part provides a description of the financial solvency of Florida local DB plans with trend analyses from the perspectives of the funded ratio, UAAL percent as employee payroll, and annual contribution to local DB plans. Second, it introduces the research model of the 
financial solvency of public DB plans as well as the research hypotheses based on the literature review. The third component is a regression with discussions. Finally, a summary will be presented to contend the effectiveness of the incremental reform strategies.

\subsection{The Continuous Underfunding of Florida Municipalities DB Plans}

The section utilizes the 2005 to 2012 Annual Reports of Florida Local Government Retirement Systems, published by the Florida Department of Management Services (DMS), to explore three important trends of the 151 local DB plans. The analysis will provide insight on the health of DB plans in Florida with an eye to their post-Great Recession prospects.

DB Plans' Underfunding is Not New to Florida Municipalities

The funded ratio of pension plan assets to plan liabilities is the most frequently used benchmark assessing the financial health of the DB plans in public sector. The widely held threshold of 80 percent funding level is a useful yardstick to tell whether the public DB plans are in trouble or not. Figure 4.1 displays the trend in funded ratios of Florida local DB plans for public general employees from 2005 to 2012. Since the funded ratios can be affected by the actuarial methods to calculate them, this figure 
only includes the local DB plans using the entry age normal cost method, which is the most common cost method in Florida municipalities. Figure 4.1 shows that the typical funding levels of Florida municipal DB plans for general employees started dropping even before the 2008 stock market strike.

In 2004, the typical municipal DB plan for public general employees was over 80 percent (meaning more than half of the plans were more than 80 percent funded). After 2004, the funded ratio began to drop in almost every year and the funding level in almost each following year was below $80 \%$, except for 2007 as a consequence of the relatively strong market returns. The plunge in funding status after 2007 reflects the fiscal crisis associated with the 2008 stock market downturn. By 2011, almost three quarters of Florida municipal DB plans for general employees were below the 80 percent threshold, and the typical DB plans approached the 70 percent funding level. This trend line indicates that the funding crisis predated the recent stock market downturn. The nearly decade-long trend suggests that there were structural issues in the public DB pension system that required analysis and remediation.

\section{Figure 4.1 Funded Ratios of Florida Local DB Plans for Public General}

\section{Employees (Entry Age Normal Funding Method Only)}




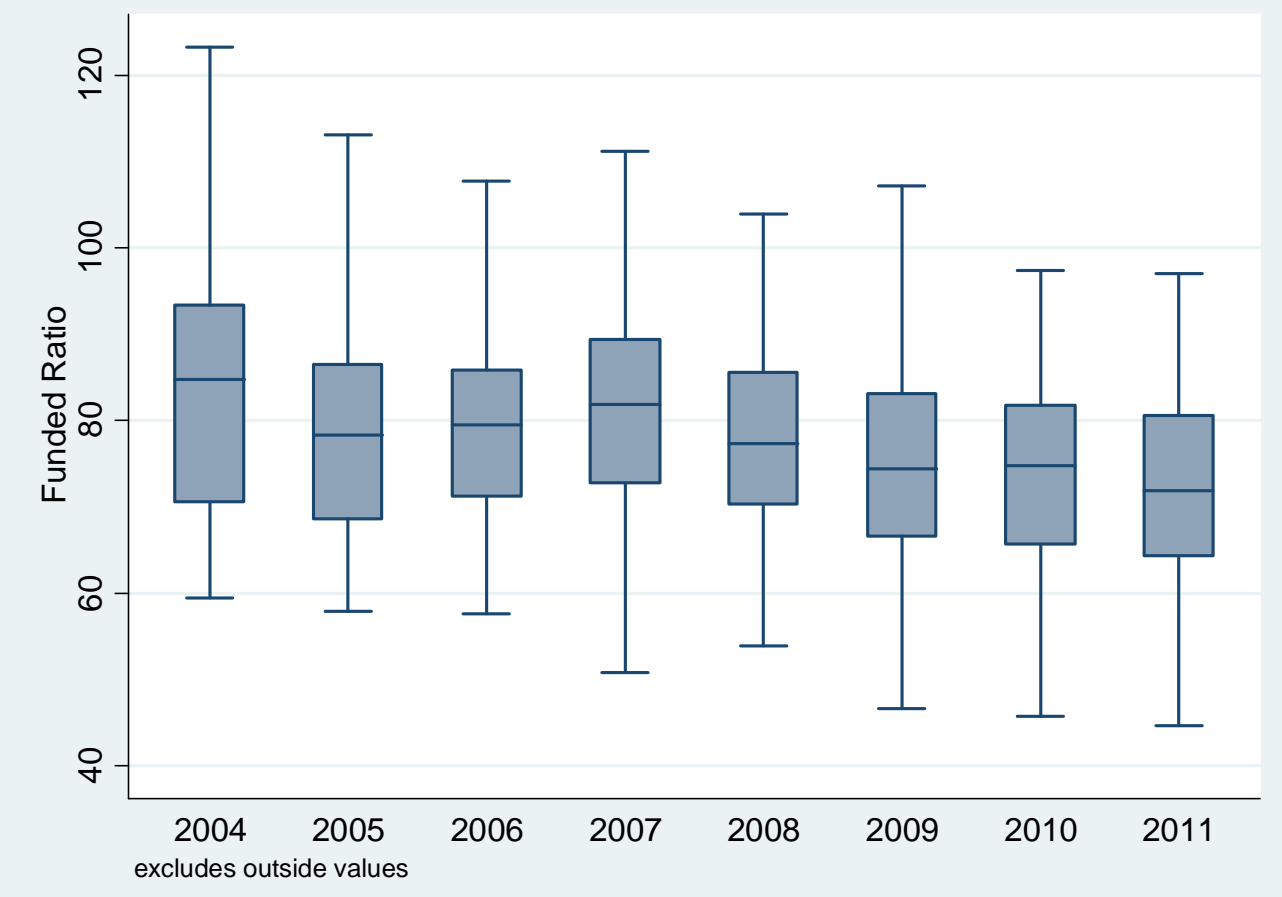

Increasing Liabilities of DB Pension Plans for Florida Municipalities

Unlike the funded ratio, which adopts a ratio to reflect the extent to which the pension obligations are funded, the UAAL gives a direct view of the accrued unfunded pension liabilities at the actuarial base. Figure 4.2 shows the change of UAAL percentages as the participating employee payroll in Florida municipal DB plans for general employees, which shows a steady growth of the UAAL percent since 2004 . The drastic increase after 2007 demonstrates the severe impacts of 2008 depression.

The growing UAAL percent indicates the funding status of the 151 public DB plans for general employees in Florida municipalities has declined since the start of stock market downturn, which resulted from the decrease in the actuarial values of assets accumulated to finance the accrued actuarial liability. Figure 4.2 further suggests 
reduced investment returns from stock market and fewer revenues collected during the economic recession. The upshot is that most Florida municipalities experienced financial challenges of funding pension liabilities even before the 2008 stock market plunge. The Great Recession exacerbated this situation.

Figure 4.2 UAAL Percentages of Employee Payroll in Florida Local DB Plans

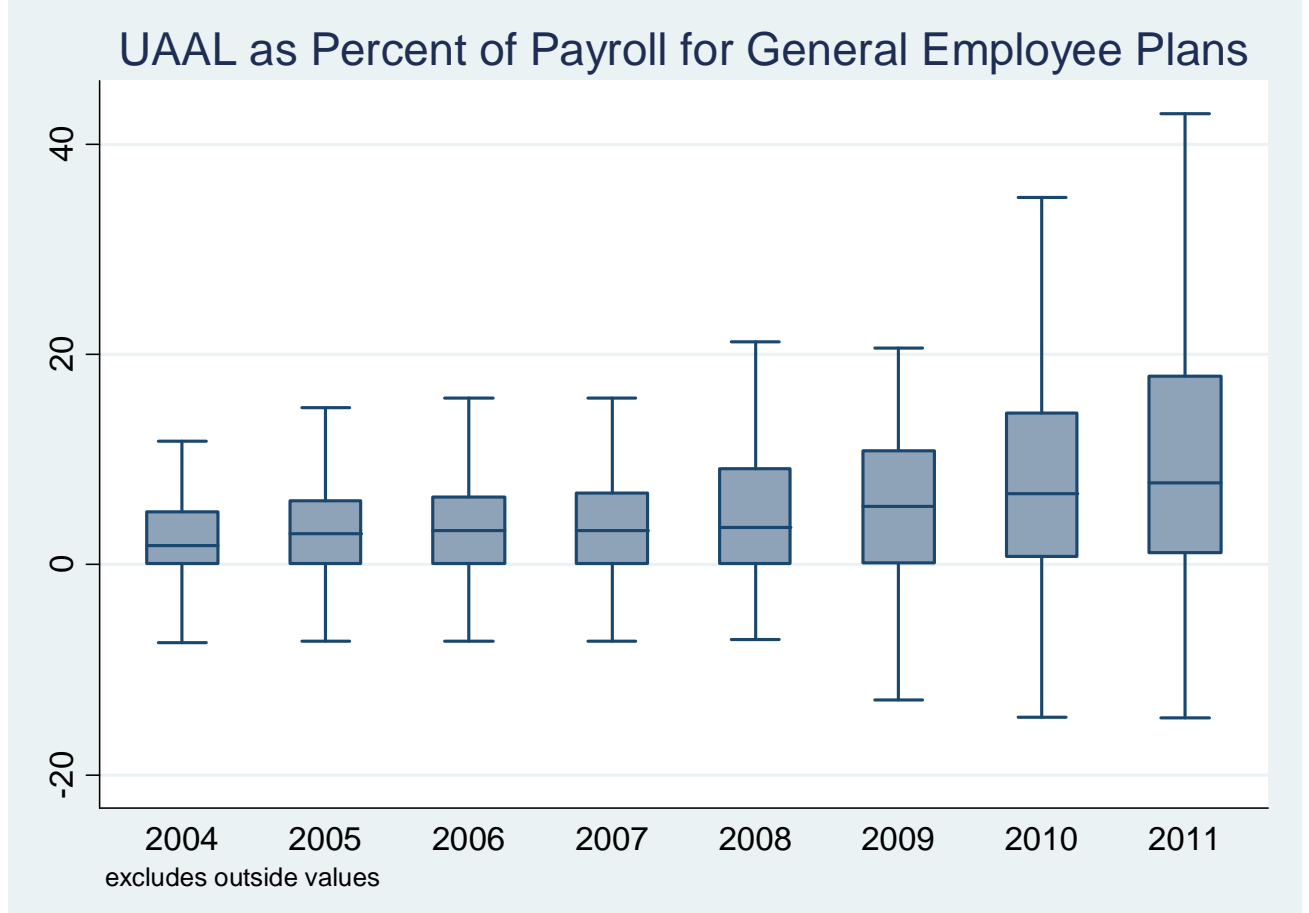

Florida Municipalities are Paying More to Fund their DB Plans

If the UAAL percent is considered as the future obligation to be amortized in the next 20 to 30 years, the annual contributions from DB plans sponsors reveal the annual responsibility of governments for municipal pension plans. Figure 4.3 displays the trend of the allocations of payment of Florida municipalities for their general employee DB plans between employee and municipalities. It demonstrates that the 
employee contributions to DB plans from 2004 to 2011 remains consistent. So did the city’s portion from 2004 to 2007.

However, after the Great Recession, municipal contributions as a percentage of employee payroll for the typical general employee DB plans climbed significantlyfrom $15 \%$ in 2007 to $23 \%$ in 2011 . The analysis illustrates Florida local governments are picking up the increase in annual pension costs and bear more responsibility in funding the DB plans in the public sector. The fiscal stress of the growing pension contribution percentage to municipalities is intensified by the curtailed revenues and increasing demand for services during the tough economic times. Therefore, the urgency to relieve soring pension costs currently plays an important role in the decision making process of public pension reform.

Figure 4.3 Annual Contributions to Florida Municipal DB Plans 


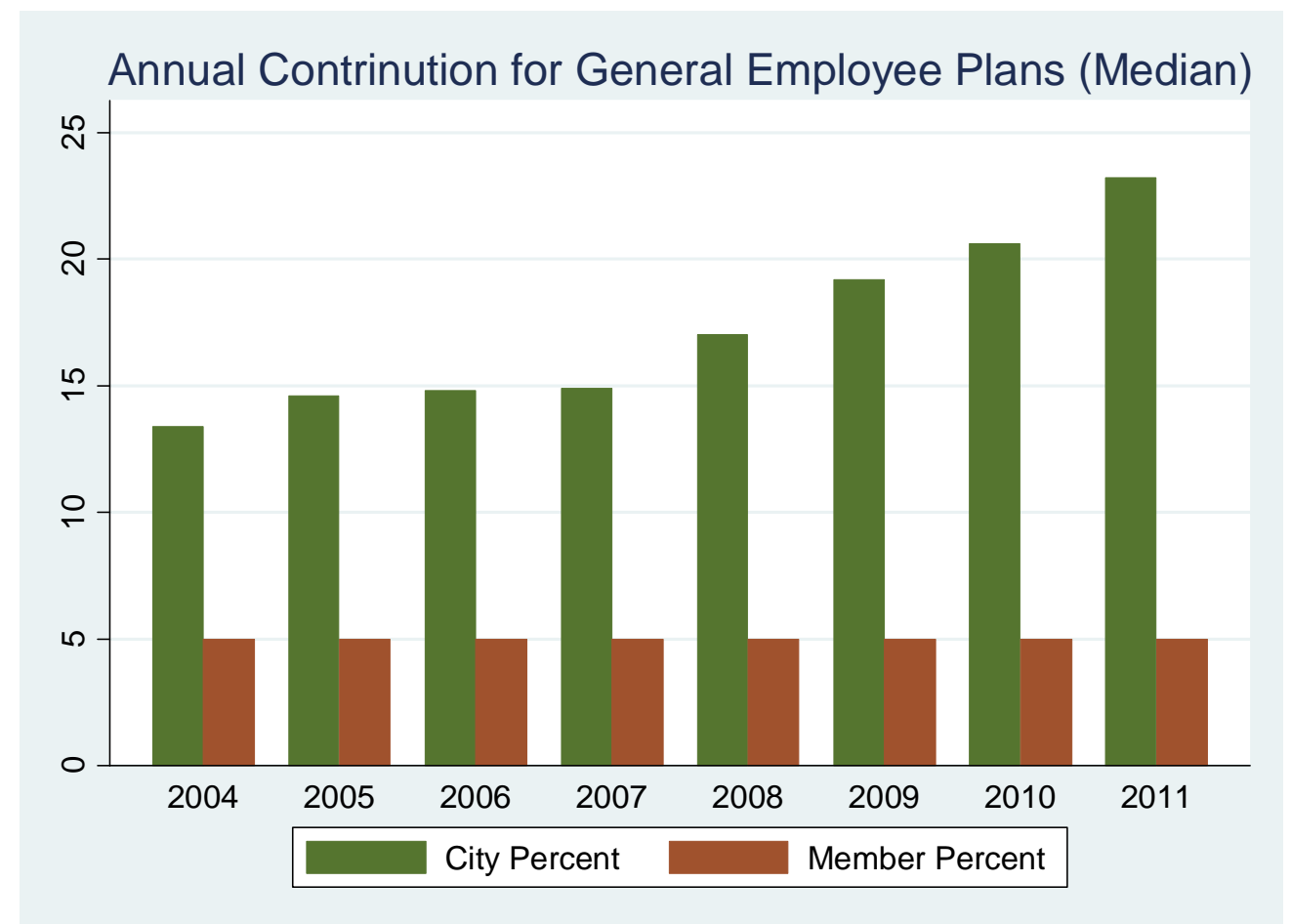

\subsection{The Research Model and Hypotheses}

Figure 4.4 sets forth the conceptual model of the financial solvency of public DB plans. It is based on the literature provided in Chapter 2. The study employs the Funded ratio and UAAL percent of payroll as the dependent variables to indicate the financial status of Florida local pension plans. The funded ratio is calculated in a similar manner as the Governmental Accounting Standards Board (GASB) Statement 25 calculation, that is, the actuarial value of assets divided by actuarial liabilities. Instead of using market values of asset and liabilities, this formula provides a relative longterm view about the financial solvency of public DB plans. Factors that may affect the fiscal health of public pension plans are grouped into four categories, which are exhibited in Figure 4.4. 
Figure 4.4 Research Model for the Determinants of the Financial Solvency of the

Public DB Plans for General Employees

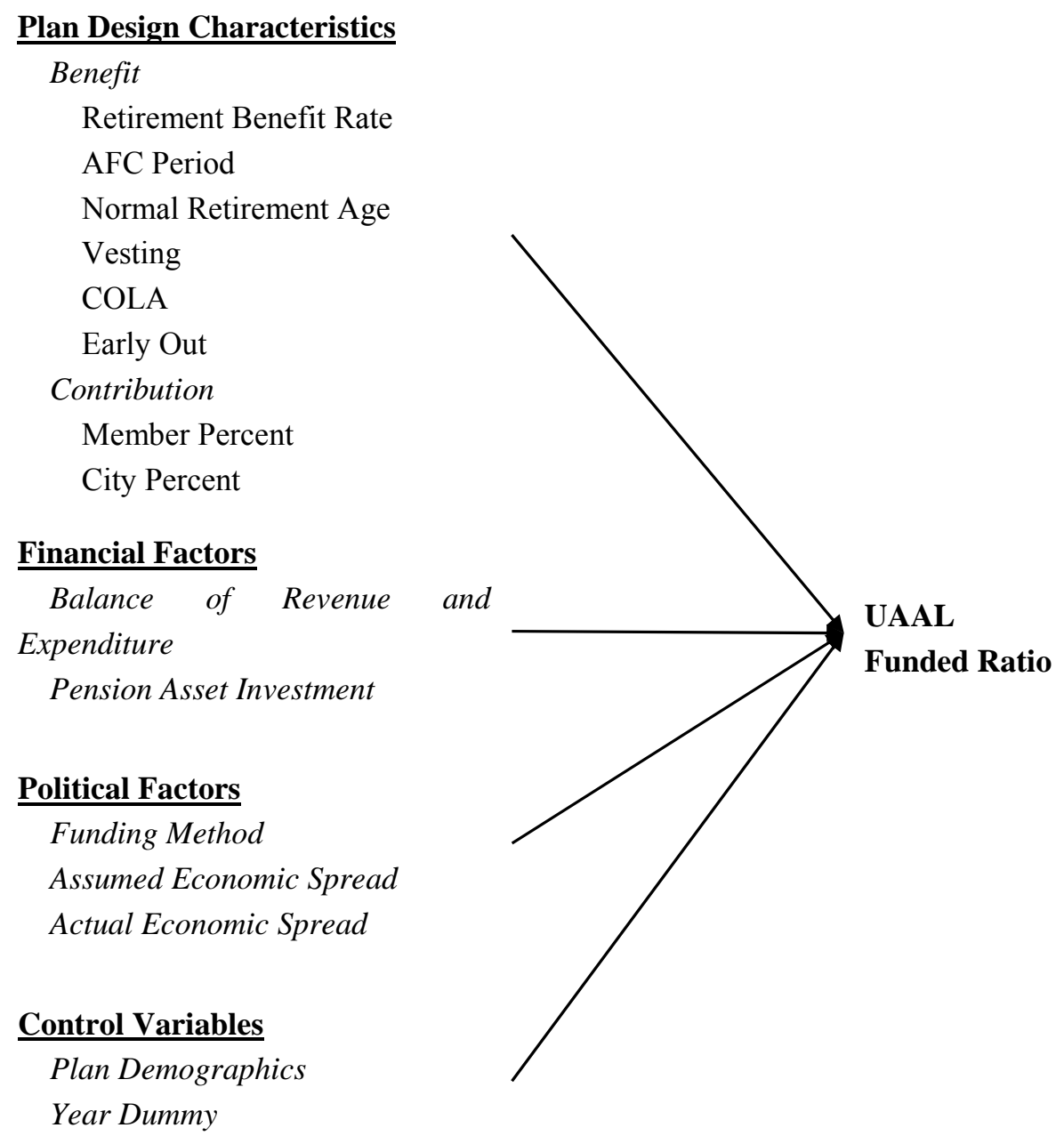

Plan Design Characteristics 
The major focus of this chapter is to explore whether incremental changes exemplified by the 2011 reform could improve the financial solvency of Florida local pension plans. Therefore the design characteristics of individual pension plan are critical components of the independent variables. Previous studies provide inconclusive evidence about the relationship between plan designs and fiscal health of public pension system (Coggburn and Kearney, 2010; Giertz and Papke, 2007; McCue, 1994; Munnel et. al., 2008). Therefore, in this study the hypotheses of plan design characteristics and the financial solvency of public pension plans are stated as below:

Hypothesis 1: Reducing pension benefits will not improve the financial solvency of the local DB plans.

Hypothesis 2: Increasing pension contributions will not improve the financial solvency of the local DB plans.

The improvement of the financial solvency of the local pension plans are indicated by increased funded ratio and decreased UAAL percent. The strategies to reduce pension benefits include the direct changes to the benefit formula such as reducing retirement benefit rate, elongating the AFC period to calculate the final average salary, and increasing the normal retirement age; and the decrease of indirect benefits, such as lengthening vesting period to be eligible for retirement benefits, limiting the provision of COLAs, and strengthening the requirement of early retirement.

Financial Factors 
The study also examines the internal fiscal stress of governments and the external economic development that may impact the financial solvency of public pension plans. Based on the literature review, the governments that are under higher fiscal pressure tend to fund their pension plans at lower levels, which would worsen the financial status of public pension systems (Chaney, Copley, \& Stone, 2002; Coggburn \& Kearney, 2010; Eaton \& Nofsinger, 2004; McCue, 1994). Followed the previous practices (Reck, Wilson, Gotlob, \& Lawrence, 2001; Wilson, 1983; Wilson \& Howard, 1984), the indicator selected in this study for the fiscal stress is the excess/deficiency of revenue over/under expenditure (total account at city level year end) per 1,000 populations. The gauge is standardized by population in order to control the impact of city size differences.

In addition to the fiscal status of governments, the market performance of pension fund investments also plays an important role in determining the funding status of public pension plans. Pension assets could be allocated into investment instruments with low but stable rate of return, e.g. fixed income, and high-risk instruments such as equities, which may bring considerable investment returns in bull markets and may also incur severe losses during the market plunge. Previous studies suggest the necessity of a prudent investment strategy of pension assets to maintain the financial solvency of public pension plans (Albrecht and Hingorani, 2004; Novy-Marx and Rauh, 2009; Peng, 2004; Stalebrink, Kriz and Guo, 2010). The higher risk of investment in equities must be taken into consideration when measuring the financial solvency of public 
pension plan funds. The study selects the percentages of pension assets allocated in fixed income and equity, which are the two major investment instruments in Florida cities, to examine the impact of investment portfolio to the funding status of public pension plans.

Hypothesis 3: Higher fiscal stress will decrease the financial solvency of public DB plans.

Hypothesis 4: Riskier investment of pension assets will decrease the financial solvency of public DB plans.

\section{Political Factors}

The research model also includes the political factors that could affect the financial solvency of public pension plans. The political preference of funding methods would determine the amount of normal cost of public pension plans. The more conservative budgeting schemes is chosen, the more estimated cost would be calculated. Therefore, the choice of funding methods would affect the funding status of public pension plans. The primary four funding methods adopted by governments, from the most to the least conservative, are AGG, FIL, EAN, and UC. Although the literature review does not provide consistent evidence that whether the cheaper funding method will lead to the decline of funding status (Giertz \& Papke, 2007; McCue 1994; Munnell

et. al., 2008; Munnell, Haverstick, \& Aubry, 2008), this study examines the hypothesis that the pension plans using the less conservative funding methods will be associated 
with declined financial solvency because cheaper funding regimes may make plan sponsors less committed to funding their pension plans.

Another political factor utilized by the plan board of trustees to determine the ultimate pension costs is the actuarial assumptions in public pension funding. State and local governments often rely on the economic spread, the difference between the interest assumption and the wage inflation assumption, to control the actuarial amount of pension costs. Preceding research demonstrates that by increasing the assumed economic spread, the governments could effectively reduce their pension costs, thus create the actuarial illusion that their pension plans are better funded, whereas the actual economic spread may tell a different story (Giertz \& Papke 2007; McCue, 1994; Mitchell \& Smith, 1992).

Hypothesis 5: Choosing a less conservative funding method choice will reduce the financial solvency of public DB plans.

Hypothesis 6: Larger assumed economic spread will actuarially improve the financial solvency of public DB plans.

\section{Control Variables}

The study employs key demographics as control variables in assessing financial, which is expressed in the ratio of retirees and/or beneficiaries to the active member in 
the plan. The literature contends that the dramatic increase in elderly population and growth in public employees will impose heavier fiscal pressure on pension systems (Coggburn and Kearney, 2010; ConagaRetna, 2004). According to the statistics of U.S. Census Bureau (2011), Florida had the greatest share of population that was 65 years and over in both 2000 and 2010 (17.6 percent and 17.3 percent, respectively). It is reasonable to assume that this population composition would bring additional fiscal burden on local pension systems. Previous studies also reveal the positive relationship of active plan participants and the funding status of public pension systems (Giertz and Papke, 2007; Munnell et al., 2008). Therefore, higher ratio of retirees to active members implies more pension liabilities, which may result in declined funding status of pension plans.

The study aims to investigate the effectiveness of the incremental reform strategies such as the 2011 pension law. Therefore, the year dummy of 2012 is included in the model to see whether provisions could improve the financial solvency of the public pension system at the local level. Although the target of the 2011 pension law is FRS, yet in essence FRS is a DB system. Given that $60 \%$ of Florida local governments use the FRS as their primary scheme to provide pension benefits, by examining the DB pension systems at the local level, this study will explore the preliminary outcome of the incremental reform strategies and try to provide evidence that the tinkering measure to preserve the current DB plans may not be sufficient to solve the public pension crisis. 
Hypothesis 7: The higher ratio of retirees to active members will decrease the financial solvency of public DB plans.

Hypothesis 8: The 2011 pension reform strategies did not improve the financial solvency of public DB plans at the local level.

\subsection{Results of Data Analysis}

Information used for this portion of the study were gathered from data issued from Local Government Annual Reports of Retirement Plans launched by Florida State Department of Management Services from 2005 to 2012. This study gathered the data from 151 DB plans in Florida municipalities and prepared the panel dataset for the research. Table 4.1 presents the descriptive statistics of the included variables. Most of the key variables are measured at interval-ratio level except for the funding method and vesting requirements. The summary statistics suggest currently Florida municipalities use the entry age normal method most often, followed by the aggregate cost method, the frozen initial liability method, and finally the unit credit method. The vesting requirements are assigned values to quantify the magnitude of the strictness of regulations about the vesting period, hence indicating the generosity of retirement benefits. According to the annual report, from high to low, a "yes" signifies that prior to completing of required normal retirement age and credits, plan members have rights to benefit computed on years of service; "partial" indicates a vesting schedule (e.g. $20 \%$ of benefit with 3 years of service); "no" implies plan members must complete 
requirements (e.g. 30 years of services) otherwise they would lose all rights to any benefits.

Table 4.1 Descriptive Statistics

\begin{tabular}{lrrrrr}
\hline \multicolumn{1}{c}{ Variables } & Obs. & Mean & Std. Dev. & Min & Max \\
\hline FundedRatio & 1001 & 81.19 & 17.72 & 0 & 211.1 \\
UAALPercent & 1185 & 7.19 & 13.20 & -31 & 150.1 \\
MemberPercent & 1189 & 4.86 & 3.52 & 0 & 19.7 \\
CityPercent & 1185 & 21.66 & 24.28 & -23 & 269 \\
RetireActiveRatio & 1168 & 60.59 & 90.71 & 0 & 914.29 \\
\hline BenefitRate & 676 & 2.68 & 2.16 & 1 & 30 \\
AFCYear & 1097 & 4.06 & 1.14 & 1 & 5 \\
NormalRetireAge & 1049 & 59.46 & 4.35 & 50 & 65 \\
Vesting & 1176 & 2.78 & 0.42 & 1 & 3 \\
YearsEarlyOut & 1027 & 11.04 & 5.71 & 2 & 30 \\
\hline Equities & 1182 & 54.51 & 21.37 & 0 & 107.75 \\
FixIncome & 1182 & 31.91 & 15.90 & 0 & 99.56 \\
AssumedSpread & 1157 & 2.13 & 1.22 & -4.9 & 8 \\
ActualSpread & 1123 & -0.98 & 5.79 & -30.54 & 26.1 \\
BalancePer1000 & 1069 & 105.66 & 464.16 & -9694.48 & 1000 \\
\hline Dummy Variables & & \multicolumn{5}{c}{ Ordinal Variable } & & \\
Fund Method & Frequency & Percent & Vesting & & \\
AGG & 241 & 20.29 & Label/Value & Frequency & Percent \\
EAN & 694 & 58.42 & No/1 & 4 & 0.34 \\
FIL & 230 & 19.36 & Partial/2 & 247 & 21.00 \\
UC & 23 & 1.94 & Yes/3 & 925 & 78.66 \\
\hline
\end{tabular}

Because of the missing data for retirement benefit rate, this variable is dropped

in the data analysis because its inclusion will severely reduce the total number of observation for the regression model. Table 4.2 provides the fixed-effect OLS regression results with standard errors. Before running the regression, the author diagnosed whether there is multicollinearity issue among the variables to avoid its negative impact to size of $\mathrm{R}$, the importance of the predictor, and the variance of regression coefficients (Stevens, 1996). By examining the simple correlation among variables from the correlation matrix, one variable, the AFC period, is omitted due to 
its intercorrelation is higher than the general accepted level of 0.80 (Stevens, 1996, p. 77).

The OLS model assumes that the variance of error terms is constant. If there are error terms that do not have constant variance, it is called heteroskedasticity. The possible existence of heteroskedasticity could result in non-BLUE OLS estimates and biased standard errors (Wooldridge, 2013). In order to avoid these negative impacts of heteroskedasticity, this study use robust standard errors to correct the problem. The regression results and standard errors are robust to heteroskedasticity.

The Hypotheses of Plan Design Characteristics

Amid the hypotheses of plan design characteristics, the benefit hypothesis just gets partial support, whereas the contribution hypothesis achieves strong statistical significances. Only one of the benefit indicators, the normal retirement age, in the UAAL model is statistically significant. As an important component to count the years of services when calculating the retirement benefit, increased normal retirement age implies less generosity of the pension plans. However, the positive relationship indicated by the results between the normal retirement age and UAAL percent of payroll support the hypothesis that the reduced retirement benefits are not associated with the improvement in the financial solvency of local public DB plans.

Table 4.2 Regression Results 


\begin{tabular}{|c|c|c|c|c|}
\hline & \multicolumn{2}{|c|}{ Funded Ratio } & \multicolumn{2}{|c|}{ UAAL \% of Payroll } \\
\hline & Coefficient & $\begin{array}{c}\text { Standard } \\
\text { Error }\end{array}$ & Coefficient & $\begin{array}{l}\text { Standard } \\
\text { Error }\end{array}$ \\
\hline \multicolumn{5}{|l|}{ Plan Design Characteristics } \\
\hline \multicolumn{5}{|l|}{ Benefit } \\
\hline AFC Period & \multicolumn{2}{|c|}{ Omitted } & -5.40 & 6.00 \\
\hline Normal Retirement Age & 0.19 & 0.42 & $0.60 * *$ & 0.25 \\
\hline Vesting & 4.64 & 6.73 & -0.87 & 4.33 \\
\hline COLA & -1.57 & 1.90 & 0.57 & 1.14 \\
\hline Early Out & 0.25 & 0.18 & -0.03 & 0.11 \\
\hline \multicolumn{5}{|l|}{ Contribution } \\
\hline Member Percent & $-0.84 * *$ & 0.42 & $0.77 * * *$ & 0.25 \\
\hline City Percent & $-0.33 * * *$ & 0.06 & $0.45^{* * *}$ & 0.03 \\
\hline \multicolumn{5}{|l|}{ Financial Factors } \\
\hline $\begin{array}{l}\text { Balance of Revenue and } \\
\text { Expenditure }\end{array}$ & 0.00 & 0.00 & 0.00 & 0.00 \\
\hline Investment in Equities & $0.06 * *$ & 0.03 & -0.03 & 0.02 \\
\hline $\begin{array}{l}\text { Investment in Fixed } \\
\text { Incomes }\end{array}$ & $0.08 * *$ & 0.04 & -0.03 & 0.02 \\
\hline \multicolumn{5}{|l|}{ Political Factors } \\
\hline \multicolumn{5}{|l|}{ Funding Method } \\
\hline EAN & 1.34 & 1.93 & $7.40 * * *$ & 1.13 \\
\hline FIL & 1.04 & 2.79 & $3.58 * *$ & 1.63 \\
\hline $\mathrm{UC}$ & $12.12 *$ & 7.29 & $10.96^{* *}$ & 4.68 \\
\hline Assumed Economic Spread & 0.75 & 0.54 & $-0.78 * *$ & 0.32 \\
\hline Actual Economic Spread & 0.00 & 0.07 & 0.06 & 0.04 \\
\hline \multicolumn{5}{|l|}{ Control Variables } \\
\hline Plan Demographics & $0.03^{* *}$ & 0.01 & $-0.04 * * *$ & 0.01 \\
\hline Year Dummy & $-3.26 * *$ & 1.20 & $2.04^{* * *}$ & 0.71 \\
\hline Constant & 55.22 & 32.00 & -15.69 & 32.07 \\
\hline No. of Obs. & \multicolumn{2}{|c|}{672} & \multicolumn{2}{|c|}{771} \\
\hline No. of Groups & \multicolumn{2}{|c|}{110} & \multicolumn{2}{|c|}{112} \\
\hline R-sq: Within & \multicolumn{2}{|c|}{0.1617} & \multicolumn{2}{|c|}{0.4458} \\
\hline F Value & \multicolumn{2}{|c|}{$F(16,546)=6.58$} & \multicolumn{2}{|c|}{$F(17,642)=30.38$} \\
\hline Prob $>$ F & \multicolumn{2}{|c|}{0.0000} & \multicolumn{2}{|c|}{0.0000} \\
\hline
\end{tabular}

Note: Bold characters indicate that variables are significant at $.005(* * *), .05(* *)$, or $.10(*)$. AFC Period is omitted due to multicollinearity.

Standard errors are robust to heteroskedasticity.

Although the increase in normal retirement age provides "longer time horizons to amortize benefit obligations" (McCue, 1994, p. 116), at the same time there are probably more chances to confront latent risks from the investment loss or inflation, 
which would inversely incur greater pension liabilities to the DB plans. The results could be explained that along with the fluctuation of stock markets, the DB system may not be immune to the market downturn, even if the pension liabilities are supposed to be paid down in longer time period.

The contribution hypotheses are supported by significant and consistent empirical results in both models. The negative sign of both the member percent and city percent suggests that the increase of funded ratio of DB plans is associated with decline in the contributions by both employers and employees. This implies that during good economic times, the illusion that high investment returns are enough to fund the pension plans will make governments less keen to fulfill their contributions and it is more popular for politicians to reduce the share of employee contribution, indicated by the magnitude differences of the two coefficients.

In the UAAL model, the results are consistent with previous study about the contribution hypothesis (McCue, 1994; Coggburn \& Kearney, 2010). With the increase of contributions by both plan sponsors and participants, there is an associated increase in UAAL percent of employee payroll. This lends support to the argument that plans with liberal contribution requirements are likely to accrue higher unfunded liabilities, that is, a wider gap between pension assets and liabilities.

The author admits that there is a potential endogenous issue with the key explanatory variable in the models. On the one hand, the plan design characteristics 
may cause the changes of the fiscal solvency of pension plans. On the other hand, governments could also alter the plan design features in response to the shifting financial status of public DB plans. Therefore, the results could also be interpreted the other way around: Plans with more pressure of UAAL would require higher rates of contribution to amortize the pension costs accrued in the past. The positive coefficients confirm what is expected: Employer contributions shift the risk and funding from employers to employees.

\section{The Hypotheses of Financial Factors}

The fiscal stress hypothesis does not yield any significant results in either model. In the model of funded ratio, the investment variables holds significant with results consistent with the hypothesis. The positive signs of the percentage of pension assets invested in both equities and fixed incomes imply that as the assets allocations in both instruments increase there is an associated increase in the funded ratio of pension plans. Whereas when local governments increase one percent of their pension assets in both instruments, the low risk one (i.e., the fixed incomes) will increase the funded ratio more than the riskier equities by 0.02 percent. Although the difference is small, the results suggest the investment in less risky instrument is somewhat more efficient than high risk ones in improving the financial solvency of local public pension plans, consistent with prior findings (Albrecht \& Hingorani, 2004; Novey-Marx \& Rauh, 2009; Stalebrink, Kriz, \& Guo, 2010). 
However, the considerable investment return with the high-risk instruments in bull markets is attractive to governments and the percentage of pension asset allocations into equities has greatly increased since 1990s. The results also demonstrate the positive relationship between the investment in equities and funded ratios of Florida local pension plans. Being aware of the drawbacks of the high risk of investment loss during market downturns, local governments should follow the advice suggested by Peng (2004) to diversify the investment portfolios with both high and low risk instruments.

\section{The Hypotheses of Political Factors}

By definition, pension plans adopting the most conservative funding method, i.e., the aggregate cost method, are 100 percent fully funded. Therefore, following the practice of Munnell, Aubry and Haverstick (2008), this study does not include those plans using AGG funding method. There is substantial evidence that the funding method hypothesis is supported by the findings, especially in the UAAL model. In the funded ratio model, only the UC method is significant with an expected positive sign, which can be explained that using the less stringent cost method, the pension costs will be cheaper with less benefit obligations, which leads to higher funded ratio.

In the UAAL model, it is evident that along with implementing less conservative funding method, the UAAL percent of payroll increases significantly (from FIL, EAN, to UC). This result is contradictory to the previous studies that suggest 
funding method choices have no impact of the funding status of pension plans (Giertz \& Papke, 2007; McCue 1994; Munnell, Aubry, \& Haverstick, 2008). As Munnell, Haverstick, and Aubry (2008) point out, the selection of cost method does not matter only if plans strictly follow their funding schedule, the funded ratio of assets to liabilities would achieve fully funded. However, the results in this study prove that when adopting the less stringent cost method, local governments will be misled by the illusion of cheaper costs with pension plans, and will be less committed to on a regular basis. Over time, the underfunded contributions to their pension plans would accumulate into huge fiscal burden of unfunded liabilities to local budgets and wither the financial solvency of DB pension plans.

The assumed economic spread hypothesis is supported in the UAAL model only. The negative sign of the coefficient indicates that with the increase of assumed economic spread, that is, a higher interest rate assumption than the projected wage inflation rate leads to an associated decline of the UAAL percent as employee payroll. This result is consistent with previous literature (Giertz \& Papke 2007; Mitchell \& Smith, 1992). As one of the crucial decisions made by elected officials, the assumed economic spread can be used to control the amount of future benefit obligations. The larger the assumed economic spread, the less pension costs for governments. Hence governments can leverage the assumed economic spread to reduce pension expenditure especially when they perceive the fiscal pressure to balance their budget sheets.

The Hypotheses of Control Variables 
Plan demographic variables are significant. The improved financial solvency of pension plans is associated with the increase in ratios of retirees to active plan members. With higher ratio of beneficiaries to participants, the funded ratio of pension plans increases and the UAAL percent of payroll declines. This result contradicts the discussions about plan demographics in previous literature (Coggburn \& Kearney, 2010; Giertz \& Papke, 2007; Munnell et al, 2008). By taking a glance at the descriptive statistics, one could find that in Florida municipalities, the ratio of retirees to active is fairly high (average 60.6 percent with standard deviation of 90.7 percent). This suggests that as a state with significant numbers of elder public employees, Florida municipalities are ready to deal with this issue. The fact that Florida retirement has been ranked among top well-funded pension systems implies that Florida cities have been doing well to cope with the demographic changes of the pension plans along with the graying of baby boomers.

The year dummy of 2012 is included to examine the effect of the 2011 pension reform law to Florida local public plans. Although the 2011 reform targeted the state retirement system, it had significant spillover the local level since over $60 \%$ of Florida municipalities adopt FRS/DB plans as their primary way to provide retirement benefit. The statistically significant results imply that after the 2011 pension reform, the financial solvency of Florida local pension plans did not improve, which is consistent with the hypothesis. On the contrary, in 2012 the funded ratio of Florida local DB plans 
declined and the UAAL percent increased. While one year is perhaps a short-test, it suggests that the 2011 reforms may be insufficient to address long-term funding trends.

\subsection{Summary}

Findings from the regression presented in this chapter provide a snapshot of eight years of data. The model examined four categories of explanatory variables: the plan design characteristics, the financial factors, the political impacts, and the selected control variables. Through the examination, this study aims to identify the critical determinants of the financial solvency of public DB plans, in order to further conduct investigations of the appropriate reform strategies to sustain the public pension systems.

The regression results suggest most of the factors affect the financial solvency of DB plans as expected and are consistent with the literature. Although most of the benefit variables are insignificant in either model, the normal retirement age is evident in the UAAL model, which implies the strategy to reduce the generosity of pension benefits, such as extending the normal retirement age, may not help to improve the funding status of public DB plans. The contribution hypotheses are strongly supported by the results. The increase in contributions, either from employer or from employee, will not be able to improve the financial solvency of DB plans. The findings about the plan design characteristics are the strongest argument that this chapter endeavors to state. The results suggest the conclusion that the incremental reform strategies to alter 
the plan design features, such as reducing benefits and increasing contributions, may not be effective tools in improving the financial solvency of the DB model. Incremental reforms may be insufficient to alleviate the fiscal pressures to state and local governments in the short-term and may not provide a viable public pension system.

Amid the financial factors, the way that pension assets are invested is proven to be critical to the funded ratio of the DB plans. Although both low- and high-risk allocations are to boost the funded ratio of the pension plan, more fixed income tend to be a bit more efficient to increase the funding status. This implies that state and local governments may need to take a balanced approach between equities and fixed income.

Both political factors get substantial supporting evidence from the results. The funding method choice will affect the financial solvency in different ways. The illusion created by the most liberal approach will reduce the pension costs and make the funded ratio of DB plans appear to climb. But the UAAL model tells the real story: over time the underestimated unfunded liabilities will be highlighted by avoiding conservative assumptions. The less conservative funding method governments select, the DB plan will incur higher pension obligations, which deteriorate the financial solvency of the pension system. Similarly, the assumed economic spread is also a useful leverage for political official to manipulate the pension costs. By overstating the differences between the interest rate and wage inflation rate, the assumed pension costs decline, as does the fiscal pressure to maintain funding. But the UAAL percent of payroll, the 
actuarial-based measurement of the financial solvency, will increase over time, thus governments will not be able to maintain a funding illusion eventually.

The results of control variables reveal the unique features of the Florida pension system. The plan demographics variables do not act in the expected direction to affect the financial solvency of DB plans. The municipalities with more retirees than active members are better at funding status. This could be explained by Florida's long history of an aging population in the country and the general high ratio of retirees to participants in the sample municipalities.

Florida municipalities have started dealing with the heavier pension obligations a long time ago and have been doing reasonably well with their retirement system. The state retirement system is always considered one of the healthiest systems compared with others. But Florida also suffered from the 2008 stock market plunge and political decision makers reduced the pension costs through reform strategies, in particular those put forward in 2011. Nonetheless, the year dummy variable shows that after the enactment of the 2011 pension law, in 2012 the financial solvency still went south with reduced funded ratios and increased UAAL. At the local level, Florida public DB plans are still struggling with the pension issues accrued from previous management decisions aggregated by the 2008 Great Recession, which requires governments to implement tactics to survive the perils of current public pension systems. 
CHAPTER 5

THE PERCEIVED ISSUES OF PUBLIC PENSION PARADIGM SWITCH FROM FLORIDA MUNCIPALITIES

\subsection{Introduction}

The dramatically increased costs of public pension plans after the 2008 economic downturn forced many state and local governments to reexamine the sustainability of the current DB model and to explore reform strategies. As noted 
earlier, generally the reforms can be classified into two categories: the incremental changes trying to preserve the status quo of the DB model and the paradigm shift from DB to DC. In Florida, the state retirement system adopted the former tactic in 2011 and effectively established a two-tiered benefit structure aiming at bolstering the DB plans via reduced pension costs. Florida municipalities also took actions to relieve fiscal burden of pension plans through a mix of both strategies. Through the analysis of research findings based on a survey of Florida local finance and human resource directors, this chapter attempts to investigate their perceptions of public pension reform approaches, and to discern their readiness to conduct the pension paradigm shift. This is addressed by two sub questions: What are the drivers for them to switch pension models and what are the potential impediments to implementing the transition?

The chapter is organized into three sections. It begins with a descriptive analysis of the survey results to reveal the perceptions of Finance and HR professionals towards the causes and potential impacts of public pension reform strategies. The second section presents the results of principal components analysis and descriptions of the five factors generated, which serve as indexes to reflect the attitude to public pension reforms. The third section focuses on regression models with the indexes and individual characteristics of respondents and municipalities. The analysis will reveal the elements that may affect the perceptions of public officials to view pension reform issues. 


\subsection{Descriptive Analysis of Survey Results}

\subsubsection{The Congruence of Finance and HR Respondents}

As stated in Chapter 3, the target audience of the survey questionnaire included both the Finance and HR directors of the selected municipalities in Florida. Therefore it's necessary to first identify significant differences in responses between Finance and HR professionals prior to presenting the survey results, because it would determine the way to report and explain the survey findings. Besides the difference of departments, the survey participants are also differentiated by several individual characteristics, which include gender, age, professional designation, the pension model they are currently contributing to, and that provides the majority of their retirement income. Table 5.1 depicts the summary of the distributions for all the individual features. Since the survey participants split equally into the two departments, it also shows a decent comparison between Finance and HR directors.

Table 5.1 Individual Characteristics of Survey Respondents

\begin{tabular}{|c|c|c|c|c|c|c|}
\hline Variables & Tinance $(\%)$ & $\mathbf{N}$ & HR (\%) & $\mathbf{N}$ & Total (\%) & $\mathbf{N}$ \\
\hline Gender & & 53 & & 53 & & 106 \\
\hline Male & 54.7 & & 28.3 & & 41.5 & \\
\hline Female & 45.3 & & 71.7 & & 58.5 & \\
\hline Age & & 53 & & 53 & & 106 \\
\hline $26-35$ & 1.9 & & 5.7 & & 3.8 & \\
\hline $36-45$ & 17.0 & & 17.0 & & 17.0 & \\
\hline $46-55$ & 26.4 & & 26.4 & & 26.4 & \\
\hline $56-65$ & 39.6 & & 41.5 & & 40.6 & \\
\hline $66+$ & 15.1 & & 9.4 & & 12.3 & \\
\hline Plan currently contributing to & & 52 & & 52 & & 104 \\
\hline DB & 32.7 & & 55.8 & & 44.2 & \\
\hline $\mathrm{DC}$ & 28.9 & & 11.5 & & 20.2 & \\
\hline Hybrid & 30.8 & & 28.8 & & 29.8 & \\
\hline
\end{tabular}




\begin{tabular}{lrrrrrr} 
Others & 7.7 & 3.8 & & 5.8 & \\
Plan providing major retirement income & 53 & & 53 & & 106 \\
DB & 52.8 & & 69.8 & & 61.3 & \\
DC & 35.8 & 15.1 & & 25.5 & \\
Hybrid & 3.8 & & 3.8 & & 3.8 & \\
Others & 7.5 & & 11.3 & & 9.4 & \\
Professional Designation & & 53 & & 53 & & 106 \\
Yes & 52.8 & & 17.0 & & 34.9 & \\
No & 47.2 & 83.0 & 65.1 & \\
\hline
\end{tabular}

The gender composition of the directors suggests a significant difference between the two groups of professionals: $71.7 \%$ of the HR Directors are women, versus $45.3 \%$ of the Finance Directors, which suggests that women gravitate to the HR department. Similarly, the professional designation also indicates an evident disparity between the two departments: $83 \%$ of the HR Directors do not possess a professional certification, compared with only $47.2 \%$ of the Finance Directors. This implies a lower requirement of profession designation in HR than Finance domain.

The responses to age and plan types do not suggest significant differences between Finance and HR Directors. Survey respondents fall into different age categories with the pluralities of both groups are between 56 and 65. Averagely, the participants have 25 years of working experience; therefore, they know well about the pension system to answer the related questions. Overall, the DB model is their predominant personal public pension option that they are currently contributing to (44.2\%), while HR directors are more inclined to DB plans than Finance people $(55.8 \%$ versus $32.7 \%$ ). So does the pension choice that provides the majority of their retirement income. Most respondents rely on the default DB to provide their retirement security (61.3\%), whereas the Finance staff shows greater "hybridization" in their retirement 
savings than HR directors, who are more likely to be in DB only retirements: $35.8 \%$ of the Finance stuff opt for DC plans, versus only $15.1 \%$ of HR people.

Except for exploring the individual characteristics of survey participants, the differences in the perceptions between Finance and HR directors are also of interest to the author. The original expectation was that Finance and HR staff would consider the public pension reform issue through different prisms. The former would interpret pension issues with greater sensitivity to financial sustainability, while the latter would view the pension issues with insights leaning towards impact on public recruitment and retention. However, the expected differences in perceptions between the two professionals are not sighted in the results of comparing means of survey responses.

As indicated in Table 5.2, they differ on only five of thirty-six common questions.

Table 5.2 Comparison of Means of Survey Questions (t-test): Five Questions with Significant Difference among Finance and HR Directors

\begin{tabular}{|c|c|c|c|c|c|c|c|c|}
\hline \multirow{2}{*}{$\begin{array}{ll}\text { Survey Questions } & \text { with } \\
\text { Significant Difference } & \end{array}$} & \multicolumn{3}{|c|}{ Finance Director N=57 } & \multicolumn{2}{|c|}{ HR Director } & \multirow{2}{*}{$\begin{array}{l}\mathbf{N}=56 \\
\mathrm{SD}\end{array}$} & \multirow{2}{*}{$t$} & \multirow{2}{*}{ Sig. } \\
\hline & Mean & Median & SD & Mean & Median & & & \\
\hline \multicolumn{9}{|l|}{$\begin{array}{l}\text { Organizational } \text { Impacts: } \\
\text { Adoption of recent reforms } \\
\text { will... }\end{array}$} \\
\hline $\begin{array}{l}1 \text { Reduce pension outlays } \\
\text { as percentage of total } \\
\text { outlays }\end{array}$ & 3.88 & 4 & 0.764 & 3.50 & 4 & 0.831 & 2.485 & 0.014 \\
\hline $\begin{array}{l}2 \text { Make outsourcing easier } \\
\text { due to lower future } \\
\text { pension costs }\end{array}$ & 2.79 & 3 & 1.022 & 3.27 & 3 & 1.104 & 2.399 & 0.018 \\
\hline \multicolumn{9}{|l|}{$\begin{array}{l}\text { Drivers of Change in Public } \\
\text { Pension "Crisis" }\end{array}$} \\
\hline $\begin{array}{l}3 \text { Low returns of fixed } \\
\text { income securities }\end{array}$ & 4.22 & 4 & 0.815 & 3.72 & 4 & 0.968 & 2.843 & 0.005 \\
\hline $\begin{array}{l}4 \text { Lower than historical } \\
\text { returns on stocks }\end{array}$ & 4.38 & 4.5 & 0.753 & 3.91 & 4 & 1.005 & 2.698 & 0.008 \\
\hline
\end{tabular}




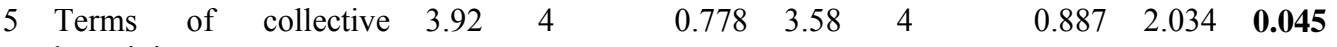
bargaining agreements

Table 5.2 lists the five questions highlighted with significant differences between Finance and HR directors. Two of them are in the section inquiring about the potential organizational impacts of the recent public pension reforms in Florida. Responses to Question 1 suggest that both groups acknowledge pension cuts will reduce "pension outlays as percentage of total outlays", while Finance directors are more mindful of this issue than HR staff. Question 2 is the only one that shows the opposite stances between the two groups. But both scores are close to the neutral point in either direction, which shows that participants do not see an association between pension costs and outsourcing. Finance directors are even less aware of this connection than their HR colleagues. For most of respondents, this aspect of pension reform may still be tangential.

The other three questions with statistically significant differences focus on the drivers of changes in public pension system. The scores suggest both groups of professionals see markets influencing reforms, but Finance directors view these drivers as more important than their HR counterparts, especially for the perceived impacts of shortfalls in fixed income and stock market return. The evident significances of the two drivers indicate these directors apprehend the nexus between investment returns and the long-term financial solvency of public DB plans. 
The last question deals with the impact of collective bargaining on public pensions. Responses to question 5 confirm that collective bargaining is observed to be a significant driver of public pension changes. Still, Finance directors are more sensitive to this issue than HR people. Through the negotiations with multiple stakeholders from the financial and political perspectives, the public pension systems get altered within a real world. Therefore, the relatively high mean and median score are to be expected.

The fact of only five out of thirty-six questions are significant different makes the author to speculate that the perceptions of the two professional groups towards the public pension issue may be similar. Except for the demographical differences between the two groups, the survey respondents averagely have 25 years' professional experience under the primary DB model. The findings imply that the professional domains have marginal impact on their opinions regarding public pension reforms. Hence, in the following sections the respondents will be treated as a collective group of senior directors rather than representatives of two professions with distinctive stances. The integrative survey findings will be reported to reflect the overall trend of perceptions to public pension reforms.

\subsubsection{Summary Report of Survey Items}

The main body of the survey questionnaire consists of thirty-six common items to both Finance and HR directors. The survey items are classified into four sections, 
which include the general questions of pension model, the organizational impacts of public pension reforms, the potential impacts of the two-tier benefit structure, and the drivers of the public pension crisis. The following parts will provide the survey findings for these themes in sequence by describing the percentage frequencies for each survey item, along with the analyses and discussions of the results.

\section{Overview Questions on Pension Model}

This section includes the questions serving as a "warm-up" to the subsequent more detailed questions about public pension reform. Following the practice of effective survey construction (Hoddinott \& Bass, 1986; Rea \& Parker, 2005), this study adopts the intellectual funneling from broad to specific perspectives of the issue for the purpose of establishing a common frame of reference, cueing participants to the substance ahead, diminishing non-response and maximizing their memory recollections. Table 5.3 sets forth the seven questions covered in this section.

Table 5.3 General Questions Related to Pension Model

\begin{tabular}{|c|c|c|c|c|c|c|}
\hline & Pension Model Questions & $\begin{array}{l}\text { Strongly } \\
\text { Disagree }\end{array}$ & Disagree & $\begin{array}{l}\text { Neither } \\
\text { Agree } \\
\text { nor } \\
\text { Disagree }\end{array}$ & Agree & $\begin{array}{c}\text { Strongly } \\
\text { Agree }\end{array}$ \\
\hline 1 & $\begin{array}{l}\text { Shifting to defined contribution for new } \\
\text { employees is difficult because of } \\
\text { unfunded pension liabilities under the } \\
\text { current defined benefit model }\end{array}$ & 11.6 & 19.6 & 19.6 & 32.1 & 17.0 \\
\hline 2 & $\begin{array}{l}\text { A younger workforce prefers defined } \\
\text { contribution plans to defined benefit } \\
\text { plans }\end{array}$ & 5.4 & 23.4 & 39.6 & 27.0 & 4.5 \\
\hline 3 & $\begin{array}{l}\text { Adoption of defined contribution plans } \\
\text { would foster greater employee mobility } \\
\text { between the public and private sectors }\end{array}$ & 3.6 & 8.0 & 25.9 & 47.3 & 15.2 \\
\hline
\end{tabular}


4 Adoption of defined contribution plans would foster greater employee mobility within the public sector

5 The steady erosion of defined benefit pension coverage in the private sector puts pressure on elected officials to reduce defined benefit coverage in the public sector

6 Political and social forces will eventually lead to the elimination of pensions for public sector employees, mirroring long-term trends in the private sector.

7 Taxpayer sentiment will eventually lead to the adoption of defined contribution plans as the default model in the public

5.4

13.5

32.4

40.5

8.1
1.8
13.4
10.7
$45.5 \quad 28.6$

7.1

29.5

16.1

39.3

8.0 sector

The responses to Question 1 suggest only half of the participants recognize the unfunded pension liabilities as a disincentive to the public pension paradigm shift. One of the major concerns raised by local governments to the original 2011 reform proposal of switching all new public employees covered by FRC to DC plans is that this strategy would obligate local governments to immediately pay off their unfunded pension liabilities when they opt to the FRS. Thus the results of Question 1 reflect an underestimation of the transition costs of the DB-to-DC switch. Question 2 yields the lowest response in this section, which suggests that participants may not be aware of the preference that younger workers have for DC plans (Bowman \& West, 2006; Dolan, 2007; Nyce, 2007). This could be explained that the respondents may believe the pension type is not a cue for prospective hiring especially under the current economy environment, or they simply infer this conclusion from their own previous experiences.

On the other hand, responses to question 3 and 4 indicate that adoption of DC plans would foster greater employee mobility either between the public and private 
sectors or within the public sector. It is of note that $62.5 \%$ of respondents agree or strongly agree that a DC model would foster greater mobility between the public and private sectors, which implies their potential recognition that the motivation to serve in the public sector is waning (Rose, 2013) and that portability of DC plans may enhance workforce development. Question 5,6 and 7 probe into the drivers of pension changes in the public sector. The respondents admit that "the steady erosion of defined benefit pension coverage in the private sector" and "taxpayer sentiment" will exert pressure on elected officials to reduce the coverage of DB plans and even to adopt DC plans as the default pension model.

Overall, responses suggest a DC model that fosters greater employee mobility may enhance the overall organizational productivity. They also realizes that pension practices and trends in the private sector, as well as taxpayer sentiment, may lead to substantive pension changes in the public sector.

\section{Organizational Impacts of Pension Reforms}

Under most circumstances, "reform" in the context of recent public pension system has become a euphemism for benefit reductions. This section of the survey items investigates the perceptions of the directors to the possible impacts of pension "reforms" in Florida local governments. The results are displayed in Table 5.4.

Responses to Question 1 and 2 indicate that public pension reforms may make it more difficult to recruit new employees and will have less impact on the retention of 
senior employees. The results are reasonable since the incremental reform strategies such as elongating vesting period or normal retirement age only affect new hires. Thus the answers reflect the new reality of a two-tiered workforce. These facts make directors realize that the enacted reforms may increase turnover of junior personnel (Question 3), and they clearly understand that recent pension changes may make the public sector less attractive to prospective employees: in Question 4 nearly $60 \%$ of respondents agree or strongly agree that the reforms will " decrease competitiveness of compensation with comparative private sector jobs". This is consistent with the notion that generous public pension benefits compensate for lower salaries for comparable private sector positions (Bender, 2003; Borjas, 2003; Fletcher, 2010; Krueger, 1988).

Table 5.4 Organizational Impacts of DB Reform

\begin{tabular}{|c|c|c|c|c|c|c|}
\hline & Adoption of recent reforms will... & $\begin{array}{l}\text { Strongly } \\
\text { Disagree }\end{array}$ & Disagree & $\begin{array}{l}\text { Neither } \\
\text { Agree } \\
\text { nor } \\
\text { Disagree }\end{array}$ & Agree & $\begin{array}{l}\text { Strongly } \\
\text { Agree }\end{array}$ \\
\hline 1 & $\begin{array}{l}\text { Make it more difficult to retain senior } \\
\text { personnel }\end{array}$ & 3.6 & 26.8 & 23.2 & 37.5 & 8.9 \\
\hline 2 & $\begin{array}{l}\text { Make it more difficult to attract well- } \\
\text { qualified applicants }\end{array}$ & 2.7 & 25.0 & 20.5 & 43.8 & 8.0 \\
\hline 3 & Increase turnover of junior personnel & 3.6 & 25.9 & 22.3 & 42.9 & 5.4 \\
\hline 4 & $\begin{array}{l}\text { Decrease competiveness of } \\
\text { compensation with comparable } \\
\text { private sector jobs }\end{array}$ & 3.6 & 24.3 & 12.6 & 38.7 & 20.7 \\
\hline 5 & $\begin{array}{l}\text { Make it more difficult to attract and } \\
\text { retain a diverse workforce }\end{array}$ & 3.6 & 29.5 & 26.8 & 34.8 & 5.4 \\
\hline 6 & $\begin{array}{l}\text { Ultimately reduce efficiency and } \\
\text { effectiveness of municipal operations }\end{array}$ & 9.8 & 30.4 & 31.3 & 24.1 & 4.5 \\
\hline 7 & $\begin{array}{l}\text { Obligate jurisdictions to educate } \\
\text { employees on the basics of asset } \\
\text { allocation throughout their lifetimes }\end{array}$ & 1.8 & 17.0 & 25.9 & 42.0 & 13.4 \\
\hline 8 & $\begin{array}{l}\text { Encourage jurisdictions to provide } \\
\text { access to low-or no-cost independent } \\
\text { financial planning }\end{array}$ & 1.8 & 15.2 & 25.0 & 48.2 & 9.8 \\
\hline 9 & $\begin{array}{l}\text { Encourage increased savings through } \\
\text { deferred compensation or other } \\
\text { voluntary Plans }\end{array}$ & 6.8 & 18.6 & 18.6 & 47.5 & 8.5 \\
\hline
\end{tabular}


However, respondents are less aware of the impacts of reforms on their jurisdictions' ability to "attract and retain a diverse workforce" in Question 5. This could be explained by limited awareness among managers of the relative appeal of pensions to women and minorities (Lewis \& Frank, 2002). In Question 6 barely onefourth of participants agree or strongly agree that these changes will adversely affect the efficiency and effectiveness of municipal operations. Our respondents may not see how pension benefit cuts or improved mobility may impact productivity.

Responses to Question 7 and 8 suggest respondents agree upon the necessity for their jurisdictions to assume their responsibilities to educate employees in regard to the basics of financial planning and asset allocations along with the advent of the DBto-DC transition. This recognition echoes the private sector organizational trends in the post-Pension Protection Act era, in which firms are increasingly offering workers lowor no-cost financial planning from independent financial planners. The efforts of independent workplace-based financial literacy programs could significantly improve public employees' knowledge of saving and investment (Holland, Goodman, \& Stich, 2008).

One of the changes enacted after July 1, 2011 is that FRS participants are required to contribute 3.0 to 10.41 percent of their salaries to their pension plans, which resulted in an effective reduction in earnings. Responses to Question 9 suggest over half of the respondents admit the change will stimulate saving elsewhere through deferred compensation or other voluntary plans to make up for this salary cut. 
In short, this section's results suggest respondents acknowledge the negative impacts of pension reforms are heavier on recruitment and retention of junior rather than senior employees and pension reforms necessitate financial literacy training or low- or no-cost financial planning to public employees.

Potential Impacts of the Two-tier Pension Structure

The recent pension reforms undertaken in Florida were applied in a manner that effectively tiers employees by date of hire. For instance, the normal retirement age for employees hired after July 1, 2011 is 65; previously it was 62 . Similarly, other changes such as vesting periods, benefit multipliers and COLAs are also tied to date of hire, which results in a two-tier benefit structure. This section inquires how Finance and HR directors perceive the potential impacts of the two-tier pension system to the organizational operations.

Table 5.5 Potential Impacts of a "Two-Tier" Pension Structure on Operations

\begin{tabular}{llccccc}
\hline $\begin{array}{l}\text { Establishment of a two-tier } \\
\text { retirement plan... }\end{array}$ & $\begin{array}{c}\text { Strongly } \\
\text { Disagree }\end{array}$ & Disagree & $\begin{array}{c}\text { Neither } \\
\text { Agree } \\
\text { nor } \\
\text { Disagree }\end{array}$ & Agree & $\begin{array}{c}\text { Strongly } \\
\text { Agree }\end{array}$ \\
\hline $1 \quad \begin{array}{l}\text { Fosters antagonism between younger } \\
\text { and older workers given differential } \\
\text { impacts of benefit cuts }\end{array}$ & 1.8 & 26.1 & 21.6 & $\mathbf{4 3 . 2}$ & 7.2 \\
\hline $\begin{array}{l}\text { Creates different levels of morale and } \\
\text { commitment between new hires and } \\
\text { existing employees }\end{array}$ & 0.9 & 22.5 & 14.4 & $\mathbf{5 1 . 4}$ & 10.8 \\
\hline
\end{tabular}


3 Makes hiring of the most talented prospects more difficult due to longer vesting

4 Makes hiring of the most talented prospects more difficult due to Increased retirement age

5 Will increase participation in supplemental retirement plans such as 457 plans among younger workers

6 Represents an issue that straddles traditional boundaries between human resources and finance

7 Receives little attention given the high unemployment rate

2.7

2.7

4.5

2.7

11.7

38.7

5.4

5.4

19.8

36.0

35.1

3.6

8 Becomes less problematic over time given the "graying" workforce and retirement of older workers

\begin{tabular}{lllll}
2.8 & 19.3 & 18.3 & $\mathbf{5 5 . 0}$ & 4.6 \\
\hline
\end{tabular}

Responses to Question 1 and 2 suggest a significant agreement upon the probability that the establishment of a two-tier pension structure "fosters antagonism between younger and older workers" and "creates different levels of morale and commitment between new hires and existing employees". This suggests that respondents acknowledge that the two-tier system may result in tensions in the work climate and that public sector should learn from the experiences of private sector in mitigating these negative impacts (Munnell, Golub-Sass, Soto, \& Vitaglinao, 2006).

Questions 3 and 4 deal respectively with the perceived impacts of increased time required for vesting and retirement on the public recruitment. Responses imply moderate agreement with the probability that lengthened vesting period and older retirement age could become deterrents to hiring the most talented employees. Question 5 tries to tap respondents' opinions on the saving habits of younger employees. Answers suggest that less than half of the respondents perceive the two-tier compensation structure would stimulate participation in supplemental plans such as the 
457. This may reflect the generally weak propensity of Americans to save, or it may reveal that the directors have not yet to digest the potential linkage between the cuts in employer's pension contribution and the sufficiency of post-retirement earnings.

Question 6 examines whether the issue related to date of hire is one that "straddles traditional boundaries between human resources and finance". Nearly $50 \%$ of respondents agree or strongly agree with this assertion. The two-tier issue clearly involves dollars and cents, with spillovers to workplace morale and recruitment and retention. Given the emergent nature of this issue, the connection between the two professional groups may yield new intellectual hints for respondents and researchers.

Questions 7 and 8 test the potential negatives of the two-tier benefit structure. One could argue that with high unemployment rates, prospective job seekers would be less care about the two-tier issue and feel fortunate enough to be hired. Likewise, one could argue that the potential undesirable impacts related to date-of-hire will effectively fade away as senior employees retire. Responses show little support for the former contention, but substantial agreements with the latter. Although participants recognize the negative impacts of the two-tier issue would exist even under high unemployment rate, they believe this issue is a self-correcting ailment that will be healed by time.

In summary, the survey respondents appear to admit that a two-tier benefit structure may negatively affect the workplace morale and hurt recruitment and 
retention. The answers imply that the retirement of older cohorts may mitigate the potential negatives related to date-of-hire.

\section{Drivers of Change in Public Pension Crisis}

This section assesses perceived drivers of change in the public pension system. Understanding the rationale behind responses may provide insights regarding the role of these drivers in a complex operating environment. Table 5.6 sets forth the answers to this subject. The findings suggest that all drivers get at least somewhat supported, whereas these factors carry different weights.

Table 5.6 Perceived Drivers in the Public Pension Crisis

\begin{tabular}{|c|c|c|c|c|c|c|}
\hline & & & & Neither & & \\
\hline & $\begin{array}{l}\text { Drivers of Public Pension } \\
\text { "Crisis" }\end{array}$ & $\begin{array}{l}\text { Strongly } \\
\text { Disagree }\end{array}$ & Disagree & $\begin{array}{c}\text { Agree } \\
\text { nor } \\
\text { Disagree }\end{array}$ & Agree & $\begin{array}{c}\text { Strongly } \\
\text { Agree }\end{array}$ \\
\hline 1 & $\begin{array}{l}\text { Changes in governmental } \\
\text { accounting rules }\end{array}$ & 5.0 & 26.7 & 28.7 & 36.6 & 3.0 \\
\hline 2 & $\begin{array}{l}\text { Decreasing defined benefit } \\
\text { pension coverage of the private } \\
\text { sector workforce }\end{array}$ & 3.9 & 13.7 & 19.6 & 54.9 & 7.8 \\
\hline 3 & $\begin{array}{l}\text { Decreasing overall pension } \\
\text { coverage of private sector } \\
\text { workforce }\end{array}$ & 3.9 & 14.7 & 22.5 & 50.0 & 8.8 \\
\hline 4 & $\begin{array}{lll}\text { Statutory } & \text { Property } & \text { Tax } \\
\text { Limitations } & & \end{array}$ & 2.9 & 14.6 & 30.1 & 36.9 & 15.5 \\
\hline 5 & $\begin{array}{l}\text { Changes in State Pension } \\
\text { Systems }\end{array}$ & 2.9 & 14.6 & 36.9 & 40.8 & 4.9 \\
\hline 6 & $\begin{array}{l}\text { Cuts in intergovernmental } \\
\text { revenue }\end{array}$ & 2.9 & 9.7 & 16.5 & 49.5 & 21.4 \\
\hline 7 & $\begin{array}{l}\text { Pension benefit changes in } \\
\text { neighboring communities }\end{array}$ & 1.0 & 12.6 & 41.7 & 39.8 & 4.9 \\
\hline
\end{tabular}

The relative low rate of agreement in Question 1 suggests respondents may view accounting rule changes as shedding light on an ongoing public pension crisis, 
rather than triggering it, since governments have had to deal with the operational impacts of Governmental Accounting Standards Board's accrual accounting model for over a decade. Drivers such as the stock market performance and collective bargaining attract higher scores in terms of impacts on public pension reforms, as introduced at the beginning of this chapter. Similar to the statement about stock market performance, questions 4 and 6 examine the impacts of scarce revenues to the public pension crisis. Responses confirm that both the property tax limitations and cuts in intergovernmental revenue are influential drivers of pension reforms. The economic downturn has fostered negative growth in these sources of revenues for many communities, which spurred plenty of reform reactions.

The high ratios of agreement in Questions 2 and 3 confirm the respondents' awareness of the impacts of changing pension realities in the private sector. These directors acknowledge that the decreased coverage of DB plans, as well as the overall decrease in pension coverage nationwide in the private sector, has precipitated policy changes in public pension plans. Overall, respondents recognize that the financial solvency of public pension plans is not immune to macroeconomic conditions or changes in American's retirement finance.

Responses to questions 5 and 7 indicate pension policies of the state or neighboring communities are not significant drivers of perceived impact. The former could be explained with the fact that only $27.2 \%$ of respondent cities participate in FRS, insulating them from direct impacts. Another possibility is that state's salary and 
benefit package is relatively low compared with many large local governments. The low rate of agreement in question 7 suggests respondents are more concerned with overcoming their own pension difficulties than benchmarking their pension practices to other jurisdictions. Thus, peer input on the organizational impacts of DB reforms may be limited.

In sum, there is no surprise in respondents' assessment of drivers for public pension changes. Respondents, who have average nearly 25 years of experience and whose primary retirement model is $\mathrm{DB}$, realize that market performances cannot be separated from the long-term fiscal sustainability of public pension plans. They imply that the DB model may not work as well now as in prior years if domestic economic growth remains subdued in the future.

\subsection{Attitude Structure of Survey Responses: A Principal Component Interpretation}

The second major section of reporting survey results involves a principal component analysis and generating indexes for the attitude structures with survey responses. This study utilizes exploratory factor analysis (EFA) to examine the significance of including selected items into the indexes. In addition to the purpose of reducing the number of variables, indexes tend to possess higher reliability and validity than individual variables (Babbie, 1990; Neuman, 2004). Based on the derived indexes, this study incorporates the individual characteristics of respondents and city-level 
information to establish regression models, which reveal elements that may affect the perceptions to public pension reform issues.

\subsubsection{Principal Component Analysis}

The similarity of the Finance and HR directors' perceptions facilitates the principal component extraction process to conduct the EFA of the survey results. Since the survey respondents can be viewed as an integrative group, it allows sufficient sample size to undertake the analysis. Out of the 36 common questions, 20 items with communalities of 0.40 or higher are preserved for extraction. The extraction employs a varimax rotation method. The assumption of varimax, one of the orthogonal rotation methods, is that the factors are uncorrelated (Gorsuch, 1983), which assumes no overlapping of the loadings among items and provides a clearer structure of attitudes. Findings were verified with the direct oblimin approach, an oblique rotation method that assumes factors are correlated. Results were virtually identical to those obtained with the varimax rotation.

The analysis generates a four-factor solution that explains $60.6 \%$ of the overall variation. These four factors exceed the traditional "Eigenvalues Greater than One" criterion for inclusion (Ficker, Kulzy, \& Appleget, 2012; Stevens, 1996). By examining the loadings of each variate, the four factors are labeled as follows to summarize survey findings: Shortcomings of reform, social drivers of reform, diffusion of private sector model, and financial literacy. For further analysis, the first factor is 
split into two subsidiary components, which results in five scales as displayed in Table 5.7. The Cronbach's Alphas for all the five scales are greater than the generally accepted 0.70 level, which suggest the internal consistency of each extracted factor. Overall, the results indicate these five factors are representative of the survey responses and the items about public pension reform issues.

The factors encapsulate survey results into a handful of identifiable concepts. The six items in the first factor, general shortcomings, relate to downsides of the introduction of the DC model. Respondents note the adoption of DC plans may bring challenges to public recruitment and retention, as well as turnover of junior personnel and municipal operations. The second factor deals with the negative organizational impacts related to the two-tier benefit structure that may cause antagonism between younger and older workers and make the hiring of prospective employee more difficult. The four items in the third factor, social drivers of reform, speak to the impacts of decreased pension coverage nationwide and lower stock market returns to the pension changes in public sector. The fourth factor, diffusion of the private sector model, speaks to the greater employee mobility fostered by the DC model and reform trends in the public sector tempted by the practices in the private sector. The two items in the last factor, financial literacy, address the necessity of educating employees about the basics of asset allocation and financial planning in order to prepare for the DB-to-DC transition. In short, these extracted factors show that survey findings demonstrate a fairly structured worldview. 
Table 5.7 Scales Derived from Principal Component Analysis

\begin{tabular}{|c|c|c|c|c|c|}
\hline \multicolumn{2}{|c|}{ Factors (Item Number) } & \multirow[b]{2}{*}{$\begin{array}{l}\text { Survey Items (Respective Loadings) } \\
\text { Make it more difficult to retain senior } \\
\text { personnel }(0.73) \\
\text { Make it more difficult to attract well- } \\
\text { qualified applicants }(0.80) \\
\text { Increase turnover of junior personnel }(0.74) \\
\text { Decrease competiveness of compensation } \\
\text { with comparable private sector jobs }(0.73) \\
\text { Make it more difficult to attract and retain a } \\
\text { diverse workforce }(0.78)\end{array}$} & \multirow{3}{*}{$\begin{array}{c}\begin{array}{c}\text { Eigenvalue } \\
\text { (Cumulative } \\
\%)\end{array} \\
\\
\\
\\
\\
5.20 \\
(26.01 \%)\end{array}$} & \multicolumn{2}{|c|}{$\begin{array}{c}\text { Cronbach's } \\
\text { Alpha }\end{array}$} \\
\hline \multirow{2}{*}{$\begin{array}{l}\text { Shortcomings } \\
\text { of Reform } \\
(10)\end{array}$} & $\begin{array}{c}\text { General } \\
\text { Shortcomings } \\
\text { (6) }\end{array}$ & & & \multirow[t]{2}{*}{0.89} & 0.87 \\
\hline & $\begin{array}{l}\text { Shortcomings } \\
\text { Related to } \\
\text { Date of Hire } \\
\text { (4) }\end{array}$ & $\begin{array}{l}\text { Fosters antagonism between younger and } \\
\text { older workers given differential impacts of } \\
\text { benefit cuts }(0.60) \\
\text { Creates different levels of morale and } \\
\text { commitment between new hires and } \\
\text { existing employees }(0.60) \\
\text { Makes hiring of the most talented prospects } \\
\text { more difficult due to longer vesting }(0.70) \\
\text { Makes hiring of the most talented prospects } \\
\text { more difficult due to Increased retirement } \\
\text { age }(0.67)\end{array}$ & & & 0.82 \\
\hline \multicolumn{2}{|c|}{$\begin{array}{c}\text { Social Drivers of Reform } \\
\text { (4) }\end{array}$} & $\begin{array}{l}\text { Decreasing defined benefit pension } \\
\text { coverage of the private sector workforce } \\
(0.81) \\
\text { Decreasing overall pension coverage of } \\
\text { private sector workforce }(0.84) \\
\text { Low returns of fixed income securities } \\
(0.56) \\
\text { Lower than historical returns on stocks } \\
(0.67)\end{array}$ & $\begin{array}{c}2.75 \\
(39.76 \%)\end{array}$ & \multicolumn{2}{|c|}{0.79} \\
\hline \multicolumn{2}{|c|}{$\begin{array}{l}\text { Diffusion of Private Sector } \\
\text { Model } \\
\text { (4) }\end{array}$} & $\begin{array}{l}\text { Adoption of defined contribution plans } \\
\text { would foster greater employee mobility } \\
\text { between the public and private sectors } \\
(0.56) \\
\text { Adoption of defined contribution plans } \\
\text { would foster greater employee mobility } \\
\text { within the public sector }(0.56) \\
\text { Political and social forces will eventually } \\
\text { lead to the elimination of pensions for }\end{array}$ & $\begin{array}{c}2.20 \\
(50.7 \%)\end{array}$ & \multicolumn{2}{|c|}{0.71} \\
\hline
\end{tabular}




\begin{tabular}{|c|c|c|c|}
\hline & $\begin{array}{l}\text { public sector employees, mirroring long- } \\
\text { term trends in the private sector }(0.77) \\
\text { Taxpayer sentiment will eventually lead to } \\
\text { the adoption of defined contribution plans } \\
\text { as the default model in the public sector } \\
(0.86)\end{array}$ & & \\
\hline $\begin{array}{c}\text { Financial Literacy } \\
\text { (2) }\end{array}$ & $\begin{array}{l}\text { Obligate jurisdictions to educate employees } \\
\text { on the basics of asset allocation throughout } \\
\text { their lifetimes }(0.81) \\
\text { Encourage jurisdictions to provide access to } \\
\text { low-or no-cost independent financial } \\
\text { planning }(0.86)\end{array}$ & $\begin{array}{c}1.98 \\
(60.6 \%)\end{array}$ & 0.82 \\
\hline
\end{tabular}

Note: Extraction Method: Principal Component Analysis.

Rotation Method: Varimax with Kaiser Normalization.

\subsubsection{Indexes Creation and Regression Results}

The next step of the analysis is to construct composite measures for the attitude structure of public pension reforms. Based on the results of EFA, five indexes were developed. Along with the PCA process, the factor scores for each survey items are generated simultaneously. The composite measures are created by calculating the average of the factor scores of the survey items comprising each of the five factors, giving equal weights to each survey item within each index (Neuman, 2004). The value of the indexes ranged from 1 to 5 , where 1 means respondents strongly disagree with the theme of the factor and 5 means they strongly agree. Descriptive statistics for the five indexes are showcased in Table 5.8. The glance at the statistics reveals that respondents are more aware of the impacts of social drivers and the necessity of financial literacy training than the other three measures.

In addition to the individual characteristics, this study also utilized the city-level data of respondents as independent variables. The tax levied per capita is included to indicate the financial status of the municipality, which may affect the perceptions of 
the local officials to public pension reform. The pension plan type for general employees in each municipality is introduced to reflect the impact of the default pension model to respondents' attitude. Among the participants, the DB model retains the predominant pension type for general public employees, followed by FRS, Hybrid, and DC plans. The information of location is selected in order to examine the regional disparity. Over 40 percent of respondents cluster in the Southeast Florida. The East Central and Tampa Bay areas are the second and third major venues of respondents. Due to the low ratio of the other regions, this study only selects these three areas as indicators of location.

Table 5.8 Descriptive Statistics of Indexes and City Level Characteristics

\begin{tabular}{|c|c|c|c|c|c|}
\hline Variables & Obs. & Mean & Std. Dev. & Min & Max \\
\hline \multicolumn{6}{|l|}{ Indexes } \\
\hline General Shortcomings & 112 & 3.19 & .82 & 1 & 5 \\
\hline Shortcomings__Date of Hire & 112 & 3.21 & .83 & 1.25 & 5 \\
\hline Social Drivers of Reform & 112 & 3.71 & .75 & 1.5 & 5 \\
\hline Diffusion of Private Sector Model & 111 & 3.39 & .78 & 1 & 5 \\
\hline Financial Literacy & 103 & 3.51 & .87 & 1.5 & 5 \\
\hline \multirow[t]{2}{*}{ Tax Per Capita } & 113 & 440.27 & 485.42 & 12.26 & 4534.4 \\
\hline & & & Frequency & Percent & $\mathbf{N}$ \\
\hline Plan Type for General Employees & & & & & 112 \\
\hline DB & & & 52 & 46.4 & \\
\hline $\mathrm{DC}$ & & & 11 & 9.8 & \\
\hline Hybrid & & & 20 & 17.9 & \\
\hline FRS & & & 29 & 25.9 & \\
\hline Region & & & & & 113 \\
\hline East Central & & & 26 & 23.0 & \\
\hline North Central & & & 1 & 0.9 & \\
\hline North East & & & 8 & 7.1 & \\
\hline North West & & & 8 & 7.1 & \\
\hline South Central & & & 1 & 0.9 & \\
\hline South East & & & 46 & 40.7 & \\
\hline
\end{tabular}


At this exploratory stage of research, the regression model does not intend to test any specific hypotheses, but to uncover the potential factors that may influence Florida local government officials' attitude towards the public pension reform issues. Table 5.9 provides the regression results and highlights the significant individual and local features that affect their recognition of the five factors extracted from survey responses. The first finding of interest is that being male and becoming older, respondents will be less aware of the diffusion of private sector model. This could be explained that in the public sector male employees usually earn higher salary than female, and earn higher benefit under the status quo (GAO, $2011 \& 2012)$. As reaching to retirement, the generous retirement income is nearly at hand, so these respondents are more resistant to or less cognizant of the mobility of DC plans, and they may be less aware of the changes in the pension coverage in the private sector. The male and senior respondents may be more reluctant to forgo the earned retirement benefits for the sake of greater mobility.

The results for the variable of department suggest that HR directors see a greater need than Finance people to enhance the financial literacy of employees in terms of asset allocation over a lifetime, as well as to provide low- or no-cost financial planning for employees. This result is as expected since HR staff might be more sensitive to this perspective. However, the HR variables is not significant in any of other indexes, in particular not evident in the attitude to the shortcomings related to date of hire, which 
is also an issue should have triggered their professional sensitivity. This may reflect the two-tier issue is relatively new so its impact has not showed yet.

Table 5.9 Regression Results

\begin{tabular}{|c|c|c|c|c|c|}
\hline Explanatory Variables & $\begin{array}{c}\text { General } \\
\text { Shortcomings }\end{array}$ & $\begin{array}{l}\text { Shortcomings } \\
\text { Date of Hire }\end{array}$ & $\begin{array}{l}\text { Social } \\
\text { Drivers }\end{array}$ & $\begin{array}{c}\text { Diffusion } \\
\text { of Private } \\
\text { Sector } \\
\text { Model }\end{array}$ & $\begin{array}{l}\text { Financial } \\
\text { Literacy }\end{array}$ \\
\hline \multicolumn{6}{|l|}{ Individual Characteristics } \\
\hline Male & $\begin{array}{l}-0.228 \\
(0.201)\end{array}$ & $\begin{array}{c}0.086 \\
(0.200)\end{array}$ & $\begin{array}{l}-0.154 \\
(0.170)\end{array}$ & $\begin{array}{c}-0.343^{* *} \\
(0.176)\end{array}$ & $\begin{array}{l}-0.126 \\
(0.186)\end{array}$ \\
\hline Age & $\begin{array}{l}-0.548 \\
(0.077)\end{array}$ & $\begin{array}{l}-0.135 \\
(0.092)\end{array}$ & $\begin{array}{l}-0.008 \\
(0.086)\end{array}$ & $\begin{array}{l}-0.154^{*} \\
(0.082)\end{array}$ & $\begin{array}{l}-0.052 \\
(0.088)\end{array}$ \\
\hline HR & $\begin{array}{c}0.090 \\
(0.202)\end{array}$ & $\begin{array}{c}0.036 \\
(0.215)\end{array}$ & $\begin{array}{l}-0.264 \\
(0.196)\end{array}$ & $\begin{array}{l}-0.154 \\
(0.183)\end{array}$ & $\begin{array}{l}0.487 * * \\
(0.212)\end{array}$ \\
\hline $\begin{array}{l}\text { Currently Contribute to } \\
\text { DC }\end{array}$ & $\begin{array}{l}0.416 * \\
(0.237)\end{array}$ & $\begin{array}{c}0.090 \\
(0.286)\end{array}$ & $\begin{array}{c}0.042 \\
(0.226)\end{array}$ & $\begin{array}{l}0.368 * \\
(0.190)\end{array}$ & $\begin{array}{l}0.667 * * \\
(0.298)\end{array}$ \\
\hline $\begin{array}{l}\text { Currently Contribute to } \\
\text { Hybrid }\end{array}$ & $\begin{array}{c}0.024 \\
(0.193)\end{array}$ & $\begin{array}{l}-0.161 \\
(0.198)\end{array}$ & $\begin{array}{l}-0.037 \\
(0.178)\end{array}$ & $\begin{array}{l}-0.224 \\
(0.169)\end{array}$ & $\begin{array}{l}-0.130 \\
(0.220)\end{array}$ \\
\hline DC_Retirement Income & $\begin{array}{l}-0.050 \\
(0.213)\end{array}$ & $\begin{array}{l}-0.256 \\
(0.277)\end{array}$ & $\begin{array}{c}0.124 \\
(0.234)\end{array}$ & $\begin{array}{l}-0.100 \\
(0.227)\end{array}$ & $\begin{array}{l}0.094 \\
(0.287)\end{array}$ \\
\hline $\begin{array}{l}\text { Hybrid_Retirement } \\
\text { Income }\end{array}$ & $\begin{array}{c}-0.868^{* *} \\
(0.394)\end{array}$ & $\begin{array}{l}-0.168 \\
(0.595)\end{array}$ & $\begin{array}{c}0.220 \\
(0.521)\end{array}$ & $\begin{array}{l}0.640 * * \\
(0.236)\end{array}$ & $\begin{array}{c}0.366 \\
(0.490)\end{array}$ \\
\hline Professional Designation & $\begin{array}{l}0.464 * * \\
(0.227)\end{array}$ & $\begin{array}{l}-0.011 \\
(0.232)\end{array}$ & $\begin{array}{l}0.132 \\
(0.175)\end{array}$ & $\begin{array}{c}0.084 \\
(0.177)\end{array}$ & $\begin{array}{c}0.124 \\
(0.219)\end{array}$ \\
\hline \multicolumn{6}{|l|}{ City Level Characteristics } \\
\hline Tax Per Capita & $\begin{array}{c}0.000 \\
(0.000)\end{array}$ & $\begin{array}{c}0.000 \\
(0.000)\end{array}$ & $\begin{array}{c}0.000 \\
(0.000)\end{array}$ & $\begin{array}{c}0.000 \\
(0.000)\end{array}$ & $\begin{array}{l}0.000 * \\
(0.000)\end{array}$ \\
\hline DC for General & $\begin{array}{c}-0.635^{* *} \\
(0.318)\end{array}$ & $\begin{array}{l}-0.244 \\
(0.395)\end{array}$ & $\begin{array}{c}- \\
0.709 * * \\
(0.258)\end{array}$ & $\begin{array}{l}-0.089 \\
(0.278)\end{array}$ & $\begin{array}{l}-0.496 \\
(0.382)\end{array}$ \\
\hline $\begin{array}{l}\text { FRS for General } \\
\text { Employees }\end{array}$ & $\begin{array}{l}-0.187 \\
(0.229)\end{array}$ & $\begin{array}{l}-0.179 \\
(0.216)\end{array}$ & $\begin{array}{l}-0.229 \\
(0.187)\end{array}$ & $\begin{array}{l}-0.273 \\
(0.187)\end{array}$ & $\begin{array}{l}-0.048 \\
(0.198)\end{array}$ \\
\hline Hybrid for General & 0.144 & -0.251 & 0.104 & -0.149 & -0.079 \\
\hline Employees & $(0.266)$ & $(0.259)$ & $(0.232)$ & $(0.221)$ & $(0.230)$ \\
\hline East Central & -0.354 & 0.001 & -0.154 & -0.242 & 0.195 \\
\hline
\end{tabular}




\begin{tabular}{lccccc} 
& $(0.263)$ & $(0.263)$ & $(0.236)$ & $(0.199)$ & $(0.291)$ \\
South East & -0.156 & -0.379 & -0.252 & $\mathbf{- 0 . 4 4 6 * *}$ & 0.147 \\
Tampa Bay & $(0.255)$ & $(0.256)$ & $(0.217)$ & $\mathbf{( 0 . 2 0 9 )}$ & $(0.268)$ \\
& $\mathbf{- 0 . 2 3 7 *}$ & 0.010 & 0.001 & -0.219 & 0.161 \\
\hline Constant & $\mathbf{( 0 . 2 7 5 )}$ & $(0.290)$ & $(0.227)$ & $(0.238)$ & $(0.278)$ \\
\hline No. of Obs. & 3.547 & 4.157 & 4.142 & 4.686 & 3.207 \\
R-squared & $(0.475)$ & $(0.534)$ & $(0.486)$ & $(0.477)$ & $(0.549)$ \\
& 105 & 105 & 105 & 105 & 103 \\
\hline
\end{tabular}

Note: Bold characters indicate that variables are significant at $05(* *)$, or $.10\left(^{*}\right)$.

The results of variables about the individual pension model indicate that the respondents who are currently contributing to DC plan only will have greater recognition of the general shortcomings of reform, the diffusion of the private sector model and the need of financial literacy training, perhaps based on their own experiences dealing with the DC model. However, participants who rely on hybrid plans to provide their retirement income, although still more aware of the pension changes in the private sector, are less attentive to the general shortcomings of pension reform. This may reflect they have learned lessons from pension reform practices in the private sector and have well-prepared for all kinds of risks that may jeopardize their retirement security by allocating their pension savings into hybrid plans. The variable of professional designation is only significant for the general shortcomings of reform and the sign is as expected. With more professional knowledge, respondents will better comprehend the potential negative impacts related to public pension reform.

The analysis of the city-level data does not reveal many significant factors that may affect the attitude structure. Although the tax levied per capita shows significance for the financial literacy, the substantial influence is too small to detect. For respondents 
from the cities that offer DC plans to their general employees, the results suggest lower recognition of the general shortcomings and social drivers of the reform. This could be explained that these cities do not face the challenges of the recent pension reform since they have already designated the DC model.

Results of the location variables suggest the Southeast region, where this study draws most survey responses, has a substantial negative impact to the recognition of diffusion of private sector model, indicating perhaps the unwillingness of these city officials to face the reality and pressure from the pension changes in the private sector. Respondents from Tampa Bay may be less aware of the general shortcomings of reform, perhaps because respondents in this region are not as conversant.

It is worth noting that none of the factors generate significance in the model of shortcomings related to date of hire. This may imply the novelty nature of this theme for Florida municipalities and reveal the necessity to further investigate this issue through other research techniques such as interviews, which will be introduced in the next chapter.

\subsection{Summary}

The analysis of survey responses furthers our understanding of the readiness of Florida municipalities to conduct the DB-to-DC transition and broader issues regarding retirement policy. The descriptive analysis of the survey items provides several important findings. First, there is no expected significant difference between 
perceptions of Finance and HR directors towards the pension reform issues: the two groups only differ on five of thirty-six common questions. Their different professional domains do not bring distinctive outlooks over the issues, thus this study can treat them as a collective of senior managers, which facilitates the descriptive summary of survey results and the principal components analysis. The general overview of the pension issues suggests that respondents admit the DC model that fosters employee mobility may enhance the overall productivity. They are also aware that pension policies and the trend in the private sector and the taxpayer sentiment may lead up to substantive pension reforms in the public sector.

Second, regarding the organizational impacts of the pension reform changes, respondents acknowledge the potential adverse impact on recruitment and retention for junior rather than senior employees. They also agree on the remedies to the pension reform, such as enhancing financial literacy training to employees and retirement savings through alternative voluntary plans. Respondents recognize that a two-tier benefit structure will negatively affect the workplace morale and recruitment, but this issue is perceived to be remediated along with the retirement of senior cohorts.

Third, the revenue cuts due to the stock market downturn are perceived as the most important drivers of pension changes during the public pension crisis. However, responses suggest that peer input on the organizational impacts of DB reforms may be limited. Pension policy changes of the state or neighboring jurisdictions are not perceived as a significant driver for public pension reform. 
The results of the principal component analysis reveal that respondents perceived the public pension reform issues based on five common scales: the general shortcomings of reform, the shortcomings related to date of hire, the social drivers of reform, the diffusion of the private sector model, and financial literacy. The five extracted factors are utilized to create indexes of the attitude structure, which implies a fairly organized worldview. Findings confirm previous descriptive statistics that respondents are aware of the negative organizational impacts of the incremental reform changes. They also recognize that the two-tier benefit structure may decrease workplace morale and hurt recruitment of prospective employees. The fluctuation of the market performance of pension assets is perceived as an important social driver of pension changes. The reality of the decrease in DB ubiquity and the overall pension coverage in the private sector is also recognized as a driver for the spillover of DC plans to the public sector. With the advent of DC model adoptions, respondents perceive it's critical to enhance financial literacy of the workforce to better prepare for the forthcoming pension model transition in the public sector.

The regression models examine the influences of individual and municipal characteristics on the extracted attitude structure. The results uncover several significant factors. As for the individual characteristics, male and senior directors show less attention to the diffusion of private sector practices in pension plans. HR directors are more aware of the necessity of financial literacy training in the workplace. Holding a professional designation will promote the understanding of the general shortcomings 
of the incremental pension reform. Contribution to DC plans will prompt respondents to better comprehend the general shortcomings of incremental reform changes, the lessons from the private sector, and the necessity of financial literacy training. Similarly, relying on hybrid plans to provide retirement income appears to make directors more aware of the pension changes in the private sector in order to overcome the undesirable impacts of public pension reforms.

The city-level features do not suggest significant findings. The municipalities, which have already adopted the DC model for their general employees, show less attention to the general shortcomings of the recent pension reform and social drivers of pension changes since they have already done a paradigm shift. The regional disparity suggests that respondents from Southeast Florida are less aware of the diffusion of the private sector model, while the general shortcomings of pension reform are new to directors from Tampa Bay.

In sum, the analysis of survey responses provides rich intellectual food for thought at this exploratory stage of research. Respondents perceive the imperative of pension reform, at the same time they are hesitant to know about the shortcomings along with the recent pension reform. The attitude structures suggest their vacillation between preserving the status quo and conducting a paradigm switch. Meanwhile, this study also leaves further space for exploration. For example, respondents are not aware of younger employees' preference for DC plans, and they are not acquainted with the recruitment and retention issues related to the two-tier benefit structure. These puzzles 
call for in-depth examinations through interviews. The following chapter will target these specific perspectives by analyzing the interview results.

\section{CHAPTER 6}

\section{PUBLIC PENSION REFORM: MORE THAN FISCAL SUSTAINABILITY}

\subsection{Introduction}

Survey results provide empirical evidence of the attitudes to public pension reform in Florida municipalities. However, the survey responses may not reveal the rationale behind these perceptions. This requires for supplementary interviews as one part of the larger triangulated effort to verify and illuminate the key findings from survey results. This chapter employs ten structured phone interviews with selected respondents. The interviewees split almost equally by department, gender, and plan coverage (DB, DC, and FRS), for the purpose of reducing the sample selection bias.

The interview questions were developed based on the analysis of survey results to provide further elaborations and in-depth insight into the issues, including the sustainability of the DB model, the major drivers and impediments of conducting the pension paradigm switch, the impacts of the transition to public recruitment and retention, the imperative of the financial literacy training, the issue of the two-tier benefit structure, and the ultimate solution to the public pension crisis. The congruence of the worldview of Finance and HR directors is also included as one question to gain justifications for the shared mindset. 
Therefore, this chapter focuses on the description and recapitulation of the interviews. The following sections are organized according to the themes of interview questions to interpret the interview transcripts with important quotations. In doing so, this study aims to capture the missing pieces in the cognitive construct of public pension reform.

\subsection{Quote Analyses of Interview Questions}

In order to summarize the interview findings, the interview questions are classified into four themes in the following analyses: the financial perspective of public pension reform, the human resources impacts of public pension reform, the pros and cons of the DB-to-DC transition, and the congruence of Finance and HR perceptions.

\subsubsection{The Financial Viability of Public Pension System}

This study argues that the public pension issues straddle the professional boundary of finance and human resources. Therefore, it is myopic to consider this subject solely through the fiscal prism. However, most frequently, the public pension crisis is viewed as a fiscal sustainability or affordability concern. The financial viability of the public pension system becomes the top priority when state and local governments initiate pension reform strategies. The first question introduced explores whether the Finance and HR directors deem that current predominant DB model as sustainable and how they define the sustainability. Their inclinations will be closely associated with 
their answers to the second question: what is the long-term solution to the public pension "crisis".

\section{The Sustainability of Public DB Model}

Table 6.1 presents the responses to the questions asking how the officials define a sustainable public pension system and whether they think the current DB model is sustainable. The definitions of a sustainable public pension system given by the interviewees confirm the expectation that the financial viability is the major concern regarding public pension reforms. The majority of the interviewees emphasize fiscal solvency in terms of sustainability. Only two finance directors (interviewee \#1 \& \#2) mention the HR perspective. Except for asserting that the current DB model is sustainable, they also praise the superiority of $\mathrm{DB}$ pensions to recruit and retain qualified public employees: “...[I]n a selfish world, defined contribution is more advantageous to the employer, except for the fact that in attracting employees and retaining employees, defined benefit plans have a real advantage. They are much more attractive, especially in the public safety realm" (interviewee \#1). Other interviewees, no matter they regard the DB plans are sustainable or not, the common focus of sustainability is the affordability of the pension costs, clearly put by one HR specialist: "To me sustainable is affordable to the people we have to pay for. ...[W]e made some modifications [benefits reductions] in the last year, our DB plans are sustainable at their current benefit level" (interviewee \#7). 
As for the responses to whether the current DB model is sustainable, half of the interviewees contend the current DB model is, or will be sustainable in an idealistic world (interviewee $\# 1, \# 2, \# 4, \# 5, \& \# 7$ ), if governments could improve the management of pension funds by adopting realistic assumptions of investment return and setting reasonable benefit level. This point is particularly shared by the finance directors: "The DB model is sustainable based on the efficiency of having the pension fund professionally managed to provide the optimal return on investment" (interviewee $\# 1)$.

By contrast, another half of the interviewees believe the DB model is not sustainable, due to its vulnerability to the market performance and increasing unfunded pension liabilities associated with the plan features. This view is particularly held by the HR staff from cities offering DC plans: "I think the most sustainable kind is the defined contribution. Defined benefit plan of course is subject to unfunded liabilities, and the ability for the employer to pay the normal cost of the plan every year, whereas on the defined contribution plan, the employer will set the contribution rate based on its financial recourses every year, or could change it every year"(interviewee \#10). Along with the acknowledgement that DB plans are not sustainable, they also point out the difficulties of changing the status quo and negotiating benefit reductions with unions. One of the HR directors expresses it clearly: “...[W]ith regards to the general employees, the DB plan is currently not a sustainable model. In order to be sustainable, there has to be tiers built into it, which would have to be negotiated with the Union. 
But those tiers would outline a model of lessening benefits and two-tier system" (interviewee \#9). The same concerns are echoed by one of the financial directors in the sample: "With the DB plan, you are kind of stuck unless you can change benefits. Changing benefits is not an easy thing to get through unions.... and a DB portion needs to be fairly stable with the benefit level" (interviewee \#3).

Nevertheless, the interviewees widely admit that the DB pension system is abused even though they have contrary opinions of its sustainability: "I would describe [a sustainable system] as a system that has realistic expectations of returns, with a proper board that chooses the right investment managers, and does not increase the benefits to retirees, which in turn makes the expected rate of returns unfeasible. The [DB] plan beneficiaries actually push for such modifications for their own interests, so that when they retire they will get this great retirement [benefit]. But what they are doing is crushing [the system] for the individuals later in the future to continue to maintain the pension" (interviewee \#5).

The unfeasible benefit enhancement during the good times, especially for the police and fire pension plans, is mentioned frequently as the major cause for the unsustainability of the DB model nowadays. One of the finance directors is pretty straightforward about this practice: "There were a lot of benefit enhancements over the last 10 years and it wasn't an issue at the time because the economy developments were so strong. It was not an issue and it didn't flash out until the great recession" (interviewee \#4). 
Table 6.1 The Sustainability of Current Public Pension Model

\begin{tabular}{|c|c|c|}
\hline ID & Dept. & $\begin{array}{l}\text { Q: In your own words, how would you define a sustainable public pension } \\
\text { system? In general, do you think the current public pension model (DB) is } \\
\text { sustainable? }\end{array}$ \\
\hline 1 & Finance & $\begin{array}{l}\text { "DB model is sustainable based on the efficiency of having the pension fund } \\
\text { professionally managed to provide the optimal return on investment. There is a lot of } \\
\text { political pressure to award additional pension benefits, particularly in public safety } \\
\text { employees. That has led to many plans currently being unsustainable. Simply their } \\
\text { plans are too rich in benefits. ...[I]n a selfish world, defined contribution is more } \\
\text { advantageous to the employer, except for the fact that in attracting employees and } \\
\text { retaining employees, defined benefit plans have a real advantage. They are much more } \\
\text { attractive, especially in the public safety realm." }\end{array}$ \\
\hline 2 & Finance & $\begin{array}{l}\text { "For general employees, I think DB model is sustainable. ...I [F] inancially it's not as } \\
\text { bad as everybody believes to be. You get what you pay for. So if they don't want to pay } \\
\text { their employees then they are not gonna get very good employees." }\end{array}$ \\
\hline 3 & Finance & $\begin{array}{l}\text { "I do think the combination of a small DB and a DC that can be changed during } \\
\text { economic good times and bad make that sustainable. With the DB plan, you are kind } \\
\text { of stuck unless you can change benefits. Changing benefits is not an easy thing to get } \\
\text { through unions... and get a DB portion needs to be fairly stable with the benefit level." }\end{array}$ \\
\hline 4 & Finance & $\begin{array}{l}\text { "I think the traditional defined benefit program is sustainable. To have a sustainable } \\
\text { DB plan, you need have reasonable assumptions and reasonable benefit levels...there } \\
\text { were a lot of benefit enhancements over the last } 10 \text { years and it wasn't an issue at the } \\
\text { time because the economy developments were so strong. It was not an issue and it } \\
\text { didn't flash out until the great recession." }\end{array}$ \\
\hline 5 & Finance & $\begin{array}{l}\text { "I would describe it as a system which has realistic expectations with returns, with a } \\
\text { proper board that choose the right investment managers, to properly give the returns } \\
\text { that are not beyond the reasonable, and not increasing the benefits to retirees which } \\
\text { puts the expected rate of returns unfeasible. The [DB] plan benefactors actually push } \\
\text { for these modifications for their interests so that when they retire they will get this } \\
\text { great retirement [benefit]. But what they are doing is crushing for the individuals later } \\
\text { in the future to continue to maintain the pension." }\end{array}$ \\
\hline 6 & HR & $\begin{array}{l}\text { "Sustainable means affordable....[W]e actually closed our general employees pension } \\
\text { plan, which is a defined benefit plan, and transition to the Florida retirement system. } \\
\text { The contribution rates of the old plan were about } 28 \text { percent of the payroll. The new } \\
\text { contribution for the Florida Retirement System is about } 8 \text { percent of the payroll, so } \\
\text { that it is easily sustainable." }\end{array}$ \\
\hline 7 & HR & $\begin{array}{l}\text { "To me sustainable is affordable to the people we have to pay for....[W]e made some } \\
\text { modifications [benefits reductions] in the last year, our DB plans are sustainable at } \\
\text { their current benefit level. And I believe it's a good model for a pension benefit." }\end{array}$ \\
\hline 8 & HR & $\begin{array}{l}\text { "Yes the } 401 a \text { will always be sustainable because we just give a percentage and then } \\
\text { that's it." }\end{array}$ \\
\hline 9 & HR & $\begin{array}{l}\text { "...[W]ith regards to the general employees the DB plan is currently not a sustainable } \\
\text { model. In order to be a sustainable model, there has to be tiers built into it, which } \\
\text { would have to be negotiated with the Union. But those tiers would outline a model of } \\
\text { lessening benefits and new tier system." }\end{array}$ \\
\hline 10 & HR & $\begin{array}{l}\text { "I think the most sustainable kind is the defined contribution. Defined benefit plan of } \\
\text { course is subject to unfunded liabilities, and the ability for the employer to pay the } \\
\text { normal cost of the plan every year, whereas on the defined contribution plan, the } \\
\text { employer will set the contribution rate based on its financial recourses every year, or } \\
\text { could change it every year." }\end{array}$ \\
\hline
\end{tabular}

The Ultimate Solution for Public Pension "Crisis” 
The unfunded pension liabilities emerging in the American public sector are staggering and pose a so-called public pension "crisis" in some state and local governments. These concerns have forced public agencies to take actions to ensure their financial solvency by either incremental modifications to current DB plans or transitions to the DC model. This study attempts to elicit the preference of the two reform strategies from Florida local officials by inquiring what is the long-term solution for the current public pension tensions. The quote summary is provided in Table 6.2.

Similarly to the question about whether the DB model is sustainable or not, the interviewees equally bifurcate in their preference for the two streams of reform strategies. Half of the interviewees, especially those from cities offering DB plan only, advocate that the public DB model still can be sustainable if only state and local governments could prudently invest the pension funds and set appropriate benefit level: "I think if we are prudent in managing the benefits, managing adequate reserves to be able to deal with the volatility, DB plans are very sustainable and they are best interests for both those employees and employer in the long-term"(interviewee \#1). The officials frequently mention the necessity to maintain a reasonable benefit level as the prior tactic for the DB model to survive: "For communities got involved in the spiraling benefits, the structure of benefits have to be changed because the citizenry isn't going to stand for benefits that are way over what they're receiving"(interviewee \#3).

Some interviewees even think that referring to the widespread pension problems as a crisis is hyperbole because they believe the issues exist only in 
governments misbehaving in their pension funding: "I don't think there is a crisis. I think the crisis is contrived. I think some local governments have been irresponsible in increasing the benefits without looking into the long-term impact. ... Once you get irresponsible you have to pay that bill" (interviewee \#6). One HR director argues that the DB model itself is not the origin of the pension tension, but the irresponsible funding practice: "I believe there are places in crises, but it's not a broad-brush every pension plan is in a crisis. For those who chose not to fund theirs using the actuarially required contributions, they have a different issue than the model" (interviewee \#7). This view is echoed by one of the Finance specialists regarding the lack of enough tax revenues to fund the benefits, especially for police and fire, is the real cause of pension issues: "I don't really know that there is a pension crisis. If there is a pension crisis anywhere it's with the police and fire pension plans. DB pension becomes a critical issue, which is not because it's a bad design or they don't work, but because taxpayers don't want to pay employees that provide the services to the city" (interviewee \#2). Another finance director also expresses the difficulty to curb the benefit level for rich police and fire plans: "I know it's a tough battle dealing with the police and fire and union lobbies and that definitely is putting pressure on politicians to not make drastic changes. I don't know where the balance is but there has be given up on both sides" (interviewee \#3).

On the other hand, half of interviewees are inclined to the DB-to-DC transition as the ultimate solution, with the belief that public DB plans will not be sustainable. 
This view is widely implied by officials from cities that have conducted the transition for the feasible pension costs with DC plans: "It gives the employer flexibility to fund the way they are able to fund it and in the way that they think is reasonable. The future of it, I think, really, it's very clear, it's to the DC plan (interviewee \#10). One HR director from the city offering both DB and DC plans suggests that the DC model is the ultimate solution with the reluctance to admit that DB is not sustainable: "I think ultimately that $[\mathrm{DC}]$ is where public sector will go, I don't think it's the ultimately best idea, but that's neither here or there. ... Now we have private industry pay scales or close to them and public pension benefit, that is not a sustainable model"(interviewee \#7).

Nevertheless, although this group of interviewees advocate the pension model transition, they are not promoting the drastic fix overnight but a interim hybrid plan as a start: "I think a hybrid plan of both DB and DC would solve all those problems. Both employees and employers have equal responsibility to the risk (interviewee \#5). Due to the concern of the insecurity that the DC model may bring, one of the HR specialists indicates it's more palatable for retirees to get benefits from both DB and DC plans: "So you know no matter how bad the market goes, you're gonna get something as retirement security. ... You cannot have management cutting everything. You have to meet in the middle"(interviewee \#8). Another HR staff raises the same concern about the transition and contends the governments have to take that into consideration when conducing the transition: "when they do get to the point where they have no choice but 
to transition to a DC model, there has to be some commitment from senior management

to make that transition in order to resolve any crisis that may loom ahead for public sector agency" (interviewee \#9).

Table 6.2 The Ultimate Solution to the Public Pension "Crisis"

ID Dept. Q: What would you recommend is the long-term solution to the current public
pension "crisis"?

"I don't really know that there is a pension crisis. If there is a pension crisis anywhere

it's with the police and fire pension plans. DB pension becomes a critical issue, which

2 Finance is not because it's a bad design or they don't work, but because taxpayers don't want to pay employees that provide the services to the city. That would solve the crisis if people would pay for their taxes like they should."

"For communities got involved in the spiraling benefits, the structure of benefits have to be changed because the citizenry isn't going to stand for benefits that are way over

3 Finance what they're receiving. I know it's a tough battle dealing with the police and fire and union lobbies and that definitely is putting pressure on politicians to not make drastic changes. I don't know where the balance is but there has be given up on both sides."

Well I think "long-term" hits the nail on the head. You can't go and fix a pension plan overnight. It should be a long-term approach of making changes, maybe not whole field

4 Finance changes over night but maybe incrementally over time, to assumptions that are being used, levels of benefits, etc. ... So number one people shouldn't rush to try to fix something that isn't really broke, and number two don't try to fix something overnight, and last just take a realistic long-term approach, not try to do anything drastic.

"I think a hybrid plan of both DB and DC would solve all those problems. Both employees and employers have equal responsibility to the risk. ... Other than that, if

5 Finance United States was doing what we did, which is to go straight for us to the DC plan, that is feasible. Obviously it's easy to budget, you are not at the mercy of the market, you're determined on a certain percentage, of which you and employees must agree and live by. So be it."

"I don't think there is a crisis. I think the crisis is contrived. I think some local governments have been irresponsible in increasing the benefits without looking into the

$6 \quad \mathrm{HR}$ long-term impact. ... Once you get irresponsible you have to pay that bill. So, unfortunately, but I don't consider that is crisis for all local governments. ... It is management of prioritization of where people want to spend their money on."

"I believe there are places in crises, but it's not a broad-brush every pension plan is in a crisis. For those who chose not to fund theirs using the actuarially required contributions, they have a different issue than the model. ... I do think to the extent more and more of local governments annual operating budget goes to pay for annual legacy

7 HR cost, less and less likely they will maintain the DB plan. So some folks are gone, they are just too far down the road. I think ultimately that [DC] is where public sector will go, I don't think it's the ultimately best idea, but that's neither here or there. ... Now we have private industry pay scales or close to them and public pension benefit, that is not a sustainable model." 
" I suggest a hybrid plan. Either the State or organizations that have DB helps sustain people retirement or they end up going to the welfare program. But let's say 50,000 is the most that's gonna be a defined benefit. So you know no matter how bad the market goes, you're gonna get something as retirement security. ... You cannot have management cutting everything. You have to meet in the middle. You know someone is sick, you don't go there and kill them but you're trying to make them better."

"I believe that the long-term solution is that pension models will exist only if they are willing to add additional tiers of lesser benefit and lesser cost for employers and the public sector role. And along with that, when they do get to the point where they have

$9 \quad \mathrm{HR}$ no choice but to transition to a DC model, there has to be some commitment from senior management to make that transition in order to resolve any crisis that may loom ahead for public sector agency. ... So first is to establish a two-tier system and in the end will conduct the switch if necessary."

I think there are ways for those employers in those states that have DB plans to shore them up financially if they're willing to do it, and to keep them from being financially insolvent. ... [I]f you don't cheat on the funding, have reasonable benefits, and include employee funding, I think those [DB] plans are viable. On the other hand, I think the same for DC plans. It gives the employer flexibility to fund the way they are able to fund it and in the way that they think is reasonable. The future of it, I think, really, it's very clear, it's to the DC plan."

\subsubsection{The Human Resources Perspective of Public Pension Reform}

Unlike their financial counterparts who view pension issues as a matter of actuarial soundness, the HR professionals may perceive from different angles: How does the pension paradigm switch impact the ability to recruit and retain the qualified public employees with potential intergenerational consequences? This section of analysis explores the human resources perspectives of public pension changes.

The Impact of Pension Paradigm Switch to Public Recruitment

The relative paucity of DC plans in the public sector may allow decision-makers to ignore cues from pension type, despite what we know from prior work. The underlying assumption is that the public sector will remain attractive to younger employees, regardless of pension type. Thus the public officials may not fully understand the link between pension type and recruitment. However, the impending 
DB-to-DC transition may alter this HR perspective and raise the concern that the sufficiency of DC plans to recruit qualified public sector employees. Table 6.3 summarizes the quotes dealing with the impact of pension type preferences.

As expected, a few of interviewees still see the traditional DB plan as an attractive tool for recruitment in the public sector compared to the DC model: "I think that the defined benefit pension is more attractive to the applicant as far as the benefit package than defined contribution. I know that there are other people that feel like they need to have more control over their retirement and they are more comfortable with a defined contribution plan, so that they can manage their own retirement money within the stock market. But I think overall most people are looking for a DB plan, and find these employers more attractive" (interviewee \#10). Another HR director from the sample links the importance of pension type to economic performance and the rate of unemployment: "In a period like now, with high unemployment, I don't think it [a switch to a DC plan] is a problem. In the future, when you get low unemployment and you have to compete for people, then governments will to have to do one of the two things, either to continue with the defined benefit programs, or to raise their salaries to be more competitive with the private sector" (interviewee \#6).

Nevertheless, the majority of the interviewees do not think the transition to DC will have significant impact to the public recruitment, at least for general employees. There is a consensus among officials from cities offering DB plans only that the transition may bring adverse impact to the recruitment of public safety due to the 
difficulty to change their benefit level and political pressure: "I think it definitely would have an adverse impact, particularly in the area of public safety, because in those highrisk areas they become accustomed to the protection of DB plans" (interviewee \# 4). Offering DC in the environment of most neighboring communities providing DB benefits may result in challenges to hire qualified police and fire: "Overtime, as other cities change their plans, it may equal out, but for the time being, if we offer lower benefits than others, it may be tougher for us to hire police and fire" (interviewee \#3).

For the recruitment of general employees, these officials from the sample do not think that the transition will be an issue because professionals from the private sector can fill these positions. Since most private organizations do not offer DB plans, they believe the salary with DC plans of public employment could be sufficient to recruit qualified employees: I don't think it would be a significant issue for general employees because to a large part we are competing with private businesses for clerical help and management.... We could make the defined contribution plan along with the pay plan, attractive enough to easily compensate for the losses of defined benefit plan" (interviewee \#1).

Several interviewees may not be aware of how pension makes up for salary, thus the pension plan change is not believed to affect the recruitment process: "DC versus DB wouldn't make the break of anybody's decision whether to work for the city or not" (interviewee \#2). This view is particularly shared by officials from cities offering DC plans: "A lot of places [like us] have done that [the switch to DC plans] 
against the private sector. We've never had anyone says that I'm not coming because of your pension" (interviewee \#8).

Interestingly, one of our interviewees clearly suggests that pension type affects the sector choice, with older workers selecting government as a preferred employment option. In the words of one HR director: "The majority of people who take government jobs with the goal of collecting a pension are those near retiring. Because of that I truly believe that there will be a significant impact [of a switch to a 401(k) type of plan] on people deciding whether or not to go into the public sector" (interviewee \#9). By contrast, another HR staff claims that a DC plan will essentially make government employment more attractive to younger professionals: "It will help recruitment on a lot of professional type positions. Younger potential employees like the mobility that a defined contribution plan offers. And this generation is not looking for a place to work for 30 years. ... I think they are less committed to spending a career in any one employer whether it's public or private" (interviewee \#7).

\section{Table 6.3 The Impact of Pension Paradigm Shift to Public Recruitment}

ID Dept. $\quad \begin{aligned} & \text { Q: How might the implementation of } \mathbf{4 0 1 ( k )} \text { style pensions change recruitment? } \\ & \text { Will the pension type preference impact people's selection of employer? }\end{aligned}$
"I think the most significant impact for us would be on public safety employees, that
is police and fire employees, because that is the norm in that industry. Because the
other governments in the area are continuing to offer defined benefit plans, if we
were to go to the defined contribution, we would not be able to hire the good cops
and the good firefighters.... I don't think it would be a significant issue for general
employees because to a large part we are competing with private businesses for
clerical help and management.... We could make the defined contribution plan along
with the pay plan, attractive enough to easily compensate for the losses of defined
benefit plan."


" I don't think it would change the quality of people that we could hire, as long as

2 Finance it's clear from the beginning what they are starting with. The conversion is the problem. ... DC versus DB wouldn't make the break of anybody's decision whether to work for the city or not."

"It probably will have an impact, especially on police and fire, because their plans are more rich... Overtime, as other cities change their plans, it may equal out, but

3 Finance for the time being, if we offer lower benefits than others, it may be tougher for us to hire police and fire.... General employees are totally different because you can hire a clerical staff from businesses that don't have pension plans. ... And the salaries I believe in government are as attractive, if not more, for general employees."

"I think it definitely would have an adverse impact, particularly in the area of public safety, because in those high-risk areas they become accustomed to the protection of

4 Finance DB plans. ...[G]eneral employees don't seem to have as much cloud with legislatures...if everybody eventually converted over to the DC plan it wouldn't have much impact."

much impact."
"The answer is that it depends [on the plan the city offers]. ... My gut's
saying...people don't come here for a job because of the retirement system.... That
may be more of the case in an organization where they have FRS [not DC]."
"In a period right now with high unemployment, I don't think it's a problem. In the
future, when you get low unemployment and you have to compete, then governments
are gonna have to do one of the two things, either continue with the defined benefit
programs, or they gonna have to raise their salaries to be more competitive with the
private sector."

The Impact of Pension Paradigm Switch to Public Retention

Lacking the vesting requirements, DC plans offer employees greater mobility

between public agencies within public sector or between the public and private sector.

This may result in another HR perspective concern of the DB-to-DC transition: whether

the DC plans are capable to retain the talented public employees. This question is

particularly important with the millennials, whose attachment to a particular workplace 
is best thought in terms of days and months, rather than years and decades (Pew, 2010b). According the survey conducted by the Pew Research Center, millennials are twice as likely to work part-time as the representatives of the Generation X. In fact, these new realities have been recognized in the Public Administration research (Klingner \& Lynn, 2005; Thompson \& Mastracci, 2005). From a moral-ethical standpoint, obligating members of this generation to join a traditional DB plan with five or more years of vesting would put them at risk of losing contributions. From the broader design perspective, the question becomes whether DB is suitable for the Generation Y? Table 6.4 lists the perceptions of Florida local officials towards the impact of pension model transition to public retention.

Except for one Finance director who holds the neutral position and believes the pension model change would not affect the retention (interviewee \#2), all the other officials agree that the switch to DC plans will increase mobility either within the public sector or across sectors since there is no differences in terms of the pension type between sectors: "I don't think that is a hinder to somebody moving from one sector to another sector. Because you are going from one DC plan to another DC plan, where differences are not big really" (interviewee \#10).

Nevertheless, they hold opposite opinions about the impact of the mobility brought by DC plans to public retention. Some DB advocates express concern that DC will not be enough to retain valuable employees since it does not have the limitation of a vesting period. A finance director from the sample points out the mobility with DC 
plans could bring both good and bad consequences for governments: "Obviously you don't want people sticking around that are dead wood, that aren't happy in their jobs, simply because they feel tied down by a pension plan. But at the same time, it does help retain good long-term productive employees because they have a vested interest in pension that is growing with the term of their employment. So overall I'll say a DB plan is definitely preferred over a DC plan for retention of productive valuable longterm employees" (interviewee \#1).

At the same time, our interviewees acknowledge the necessity of a certain degree of turnover, which could give organizations the opportunity to hire new talents and avoid stagnancy. This point is especially emphasized by one HR director in the sample: "I think people should have the ability to leave and not be forced to stay in the organization because they are married to the particular pension situation. ... So the defined contribution is going to give more flexibility but I don't see that as a negative thing. I have a better opportunity to attract talents instead of people staying here and not leaving. Obviously you don't want a lot of turnover but you need some turnover, so you can bring in new people and new ideas. Right now we have very low turnover and I'm stuck with all the people we have" (interviewee \#6).

However, all the officials from cities that have conducted the transition suggest that the introduction of DC model hasn't affected the retention of their employees, although they admit that DC plans can foster mobility. One reason pointed by one Finance director is the more affordable contribution for employees under the DC 
regime: “As we switched from DB to DC, we haven't lost any employees. And the employees are not complaining. They love it because they are not required to contribute 7 [percent], they are allowed to go up to 7 . Some employees are contributing 3 [percent] because that's what they can afford at this time" (interviewee \#5). Another reason could be that pension is not as crucial as salary when changing jobs; furthermore, the public DC model is still superior to the private one: "We've done that [the switch to DC] and our turnover has been extremely low. And usually when they are moving, pension is only one of their concerns. They are looking at salaries.... We are actually more generous than the private sector, we do 6 percent you [employees] don't have to match that"(interviewee \#8).

Several interviewees acknowledge the intergenerational differences among the workforce, especially the officials from cities offering DB plans only. They clearly realize that younger generations are less committed to public sector jobs and prefer the portability of DC plans, although they prefer the DB model themselves as a senior manager with vested pension benefit: "So the DC plan might be attractive when you're younger, or mobile, but [when] you get to the end of your career, the DB plan is really the best plan out there for employees" (interviewee \#4). One HR professional in the sample also describes this contrast between generations: "There is definitely going to be people that are going to weigh whether or not the public agency that they are with only offers a DC plan as opposed to another public sector agency that may still offer a [DB] pension plan. They may definitely be moved to the other public agency to be 
eligible for a pension. ... A millennial have said to me, I really think that I don't want

to get involved with any organization that offers a defined benefit plan. It's so much as

the commitment that I would have to make to it. And they have even refrained from

joining a DB plan because of it, which I found quite interesting"(interviewee \#9).

Another Finance director also realizes the different mindset of the younger generation:

"Some people 20 years ago may have preferred to stay with one place like their fathers

did but maybe it's not the case anymore" (interviewee \#3).

Table 6.4 The Impact of Pension Paradigm Shift to Public Retention

\begin{tabular}{|c|c|c|}
\hline ID & Dept. & $\begin{array}{l}\text { Q: How might the adoption of } 401 \mathrm{k} \text { style pensions affect retention? Will switch } \\
\text { to } 401 \text { (k) foster greater mobility between public agencies within public sector; } \\
\text { and between the public and private sector? }\end{array}$ \\
\hline 1 & Finance & $\begin{array}{l}\text { "Defined contribution plan makes employees more mobile. It's good and bad. } \\
\text { Obviously you don't want people sticking around that are dead wood, that aren't } \\
\text { happy in their jobs, simply because they feel tied down by a pension plan. But at the } \\
\text { same time, it does help retain good long-term productive employees because they have } \\
\text { a vested interest in pension that is growing with the term of their employment.... So } \\
\text { overall I'll say a DB plan is definitely preferred over a DC plan for retention of } \\
\text { productive valuable long-term employees." }\end{array}$ \\
\hline 2 & Finance & $\begin{array}{l}\text { "No, I don't really think it's going to have a huge effect on mobility. I don't see that } \\
\text { as positive or negative. I think it's just a neutral thing. I don't really think it's gonna } \\
\text { increase or decrease mobility. " }\end{array}$ \\
\hline 3 & Finance & $\begin{array}{l}\text { "Yeah, it definitely can [foster greater mobility], especially if employees can take the } \\
\text { money with them instead of being restricted to staying with one municipality for a } \\
\text { long period of time....The DC type model allows employees to move around faster at } \\
\text { their own desire. And it's possible the younger generation would prefer that... Some } \\
\text { people } 20 \text { years ago may have preferred to stay with one place like their fathers did } \\
\text { but maybe it's not the case anymore." }\end{array}$ \\
\hline 4 & Finance & $\begin{array}{l}\text { "...[Y]ounger employees may like that idea of portability and being able to switch } \\
\text { [from] job to job, private to government or vice versa. So the DC plan might be } \\
\text { attractive when you're younger, or mobile, but [when] you get to the end of your } \\
\text { career, the DB plan is really the best plan out there for employees." }\end{array}$ \\
\hline 5 & Finance & $\begin{array}{l}\text { "Yes, because they are able to take it with them and we don't have any minimum } \\
\text { requirements. As we switched from DB to DC, we haven't lost any employees. And the } \\
\text { employees are not complaining. They love it because they are not required to } \\
\text { contribute } 7 \text { [percent], they are allowed to go up to } 7 \text {. Some employees are } \\
\text { contributing 3[percent] because that's what they can afford at this time." }\end{array}$ \\
\hline 6 & HR & $\begin{array}{l}\text { "I think people should have the ability to leave and not be forced to stay in the } \\
\text { organization because they are married to the particular pension situation. ...So the } \\
\text { defined contribution is gonna give more flexibility but I don't see that as a negative } \\
\text { thing. I have a better opportunity to attract talents instead of people staying here and } \\
\text { not leaving. ... [O]bviously you don't want a lot of turnover but you need some } \\
\text { turnover so you can bring in new people and new ideas. Right now we have very low } \\
\text { turnover and I'm stuck with all the people we have." }\end{array}$ \\
\hline
\end{tabular}




"It would absolutely increase mobility between the public and private sector where
equivalent jobs exist. I think in some cases there are some areas where it would impact
retention and those are typically the areas where the skillsets are limited out there to
begin with, and it is highly competitive bringing people in ... Yes, I think retention will
be tougher... [but] sometimes the organization needs turnover to ensure that it's not
stagnating."
"We've done that [the switch to DC] and our turnover has been extremely low. And
usually when they are moving, pension is only one of their concerns. They are looking
at salaries.... We are actually more generous than the private sector, we do 6 percent
you [employees] don't have to match that."
"I really believe that would affect retention. There is definitely going to be people that
are going to weigh whether or not the public agency that they are with only offers a
DC plan as opposed to another public sector agency that may still offer a [DB]
pension plan. They may definitely be moved to the other public agency to be eligible
for a pension. ... A millennial have said to me, I really think that I don't want to get
involved with any organization that offers a defined benefit plan. It's so much as the
commitment that I would have to make to it. And they have even refrained from joining
a DB plan because of it, which I found quite interesting."
" Yeah I think it's true. I'm on a DC plan. Because all the private sector employees
have is defined contribution. I don't think that is a hinder to somebody moving from
one sector to another sector. Because you are going from one DC plan to another DC
plan, where differences are not big really. You go there you don't lose anything. "

The Impact of the Two-tier Benefit Structure

While public sector pension reforms are not likely to be dramatic in their scope or visibility, there is no doubt that pension reforms undertaken in many state and local governments have created a two-tier structure of pension benefits. Having two tiers of employee benefits for the workforce under one roof may reduce the morale of newhired employees who enjoy lower benefits. However, evidences from Florida local governments, which have experienced significant pension system reforms, reveal that senior finance and human resource professionals may not view this as a serious issue. Furthermore, they believe the problem with a two-tier structure can be solved with full disclosure at the time of recruitment. As long as the applicants are aware of what plan they will get (DC not DB), they are responsible for their own decisions to work in the organization or not, so there should be no animosity issue brought up. 
The view of one finance director is representative: "It was definitely a concern when we went to the two tiers, but our thought was that when new employees apply for work here, they learn at that point what their benefit plan is. It's their choice whether to come to work here. So they come into with their eyes wide open. There is a potential morale issue... but I think it's just more of a jealousy issue that's relatively minor" (interviewee \#1). Similarly, another finance official describes it as a jealously issue: "I don't think that there is a great deal of animosity with the two-tier system, as long as you know what you're getting when you start out. People are always going to be jealous about what other people have; you're not going to eliminate that..."(interviewee \#2). HR officers generally share the same position, though their views are a bit more nuanced than those of finance directors: "I do think the difference in the model, the defined contribution versus the defined benefit, probably would have some ill effects on the workforce, but that being said, you know the rules, you know what your plan is when you are hired" (interviewee \#7).

Interviewees also ponder the effects of the two-tier situation in the short versus long term. The cities that just installed the two-tier system may not be able to observe the effect: "[O]ur police department has gone ahead and adopted the switch [to DC]. There does not seem to be animosity between those that are collecting a higher level of pension benefit and those collecting a lesser benefit. Now keep in mind that the addition of the new tier is recent, so we have not been able to determine any long-term effect" (interviewee \#9). One finance director assumes "over time that [two-tier system] may 
cause problems"(interviewee \#3). However, several officials argue that although at the beginning the two-tier structure may cause frictions between different generations of employees, eventually it would fade away when there is only one-tier left in the workplace: "In the short term, there might be some resentment, but in the long term, once the first tier leaves the organization and we are back to one tier, then that won't be a problem"(interviewee \#6). The common ideology is the acknowledgement that the good old days have gone and this is the harsh fact and tough luck. One HR specialist describes the situation: "Even though people will talk about the good old days when they used to get much better pension benefits, I believe that will die out over time with the retirement of the senior employees"(interviewee \#9).

The officials from cities that have established the two-tier benefit structure for a long time have not observed any animosity among different groups of employees. One reason could the full disclosure of the benefit change: "It has already been a year or a year and half that we implemented this [the switch to a DC plan], but I don't hear any rumblings and discussions out on the street or between employees. I think they all learned the fact that some are already in [DB], some are not and it won't be offered again. And we've got a good number of new employees" (interviewee \#8). Another point raised by HR professionals is that as long as the second tier of benefit is applied only to new-hired and it will keep stable, there should be no problem: "We don't have any issues with the two-tier system. There's no animosity. People just want the defined benefit because it's more stable for them not because somebody else has it. People who 
are already in FRS, we have to keep them in there. As they go away, they will not be replaced. It will make a lot of difference if some people could go into it [FRS] and some cannot. But that's not the case" (interviewee \#8).

\section{Table 6.5 The Impact of the Two-tier Benefit Structure}

\begin{tabular}{|c|c|c|}
\hline ID & Dept. & $\begin{array}{l}\text { Q: How will public organizations deal with "two-tier" workforce issues? Do two } \\
\text { tiers of benefits "under the same roof" cause animosity among different generation } \\
\text { of employees and reduce morale? Or this issue will "die out" over time along with } \\
\text { the retirement of senior employees? }\end{array}$ \\
\hline 1 & Finance & $\begin{array}{l}\text { "It was definitely a concern when we went to the two tiers, but our thought was that } \\
\text { when new employees apply for work here, they learn at that point what their benefit plan } \\
\text { is. It's their choice whether to come to work here. So they come into with their eyes wide } \\
\text { open. There is a potential morale issue... but I think it's just more of a jealousy issue } \\
\text { that's relatively minor. }\end{array}$ \\
\hline 2 & Finance & $\begin{array}{l}\text { "I don't think that there is a great deal of animosity with the two-tier system, as long as } \\
\text { you know what you're getting when you start out. People are always gonna be jealous } \\
\text { about what other people have, you're not gonna eliminate that..." }\end{array}$ \\
\hline 3 & Finance & $\begin{array}{l}\text { "...[O]ver time that [two-tier system] may cause problems. But still I don't believe just } \\
\text { applying something to new hires is really much of cost-savings, especially if you are not } \\
\text { hiring a lot of people currently." }\end{array}$ \\
\hline 4 & Finance & $\begin{array}{l}\text { "Not sure. My first thought is yeah it could cause some type of morale issues... but I } \\
\text { think eventually overtime it would fade away. I think it could cause a little bit friction } \\
\text { between different classes and groups of employees." }\end{array}$ \\
\hline 5 & Finance & $\begin{array}{l}\text { "It has already been a year or a year and half that we implemented this [the switch to a } \\
\text { DC plan], but I don't hear any rumblings and discussions out on the street or between } \\
\text { employees. I think they all learned the fact that some are already in [DB], some are not } \\
\text { and it won't be offered again. And we've got a good number of new employees." }\end{array}$ \\
\hline 6 & HR & $\begin{array}{l}\text { "In the short term there maybe some resentment [because of the two-tier situation], but } \\
\text { in the long term, once the first tier leaves the organization, and we are back to one tier, } \\
\text { then that won't be a problem." }\end{array}$ \\
\hline 7 & HR & $\begin{array}{l}\text { "I do think the difference in the model, the defined contribution versus the defined } \\
\text { benefit, probably would have some ill effects on the workforce, but that being said, you } \\
\text { know the rules, you know what's your plan when you are hired." }\end{array}$ \\
\hline 8 & HR & $\begin{array}{l}\text { "We don't have any issues with the two-tier system. There's no animosity. People just } \\
\text { want the defined benefit because it's more stable for them not because somebody else } \\
\text { has it. People who are already in FRS, we have to keep them in there. As they go away, } \\
\text { they will not be replaced. It will make a lot of difference if some people could go into it } \\
\text { [FRS] and some cannot. But that's not the case." }\end{array}$ \\
\hline 9 & HR & $\begin{array}{l}\text { "...[O]ur police department has gone ahead and adopted the switch. There does not } \\
\text { seem to be animosity between those that are collecting a higher level of pension benefit } \\
\text { and those collecting a lesser benefit. Now keep in mind that the addition of the new tier } \\
\text { is recent, so we have not been able to determine any long-term effect. Even though } \\
\text { people will talk about the good old days when they used to get much better pension } \\
\text { benefits, I believe that will die out over time with the retirement of the senior employees." }\end{array}$ \\
\hline 10 & HR & $\begin{array}{l}\text { "...[W] switched over in 1996, so actually the majority of our employees are on the DC } \\
\text { plan anyway. It's just us, the old-timers, who are still on the DB plan. There's not any } \\
\text { kind of animosity. Nobody even thinks about it." }\end{array}$ \\
\hline
\end{tabular}




\subsubsection{The Pros and Cons of the Public Pension Model Shift}

The striking contrast between the frequency of the initiative to conduct the DBto-DC transition and the few cases of implementation in state and local governments demonstrates that the public pension paradigm switch entails both advantages that attract governments to consider the action and negatives that prevent them from making the actual move. This section will analyze the answers to the two interview questions regarding the drivers and impediments of the public pension model shift and one question dealing with the concern of financial literacy training with the advent of the transition.

The Drivers to Conduct the Public Pension Model Shift

The investment losses in public pension funds due to the stock market plunge in 2008 imposed heavy contribution burden to state and local governments, which directly triggered the initiative to reduce the pension costs by switching to the more cost-efficient DC model. Other than the financial incentive, survey results also indicate there are political motivation and social pressure to promote the public pension model shift. The investigation of the major drivers to conduct the DB-to-DC transition through survey is limited to the five scales. Therefore, the interview question is adopted to gather more profound illustrations of the imperatives to do so.

As expected, the primary motive for switching the public pension model perceived by almost all interviewees focuses on the financial perspective. Both Finance 
and HR directors acknowledge that the snowballing benefit obligations with DB model is the prevailing reason to call for the transition to DC model, which has the feature of foreseeable and manageable costs and transfers the investment risk from employers to employees: "I think it's more of the fact that the city can budget properly and confident, because they know the annual contribution rating is gonna be set by the organization. There's no outside element such as rate of investment return. ... So the burden of investment is no longer held by the organization, it's now the responsibility of the actual pension person, beneficiary" (interviewee \#5). One HR specialist puts this point in a more forthright manner: "Most definitely, it's cost. That's the bottom line between a defined benefit plan and a defined contribution plan” (interviewee \#9). A group of interviewees point out that the skyrocketing benefit costs are rooted in the rich benefits granted previously, especially for the police and fire (interviewee \# $3 \& 8$ ), the stock market recession just exposed the severity of the issue: "The 2008 disaster was just the final straw, but it is an accumulation of a number of events that have been occurred" (interviewee \#1). The unpopularity of raising taxes to fund the benefits during economic depressions facilitates the inclination to DC model because "when times were worse, taxpayers weren't receptive to increasing property tax to pay for these extra benefits granted in good times" (interviewee \#3).

However, some interviewees call attention to the political impetus for the pension model shift. This point is particularly held by interviewees who contend the public DB model is still sustainable: "I think the legislature desires to control what they 
think are unsustainable DB plans, which is not the case because the state plan is one of the best funded in the country" (interviewee \# 4). One HR director point out the exceptional pension abuse, primarily in the police and fire pension plans "will just create obviously a perception that pension plans are very rich plans for everybody and it's gonna create a huge future liabilities, which in some cases is true. However, if you would look at the general employees, that's not the case. However everybody looks at the exceptions only. So you get this big backlash that needs reaction to reducing benefits of public employees"(interviewee \#6). Another argument emerged in the sample is that some interviewees believe that elected officials try to impress the constituencies by this move and they are doubtful about whether the transition could ensure the financial solvency: "I think it's very political motivated. They think they can gain some recognition if they changed the pension plan under the guide of saving money, which is debatable whether they are really gonna save money or not"(interviewee \#2). The similar point is stated by one HR staff: "And that's something that is easy to attack for not just the legislators, also for the people that elect them: You have something that I don't have. So I think it's more politics than whether one model is more efficient than the other"(Interviewee \#7).

It's noteworthy that quite a few interviewees mention the impact of the pension coverage change in the private sector, which may generate spillover effects to the public agencies (interviewee \#2, \#4, \#7, \&\#10). Besides the cost-saving feature of DC plans, interviewees claim that it's advocated because the DC model is more common 
in the private sector, and the transition is "reflective of what's available in private industry" (interviewee \# 7). The taxpayer sentiment of the generous benefit in the public sector fuels this argument, as stated by an HR director: "The other part of it, with the State of Florida, looking to close the defined benefit plan, is because it's not in line with the private sector employees. Private sector employers are getting rid of the DB plans and most of them are DC plan. ... And taxpayers don't like that government employees get more that private sector employees get"(interviewee \#10). In addition, the similar experience of accounting rule changes undergone in both private and public sector may also trigger the transition to DC plans, as suggested by a Finance director: "When the private sector has started recording liability they overwhelmingly moved to DC. I think that's the trend now because the governmental accounting standard board is requiring government to put the liabilities on the book"(interviewee\#2).

\section{Table 6.6 The Drivers of Public Pension Paradigm Switch}

Q: As you know, The original intention of the 2011 pension reform was to replace
ID current DB plan with DC plan for new hired employees, but it did not go that
far in the end. What do you think are the drivers behind this initiative of pension
model switch?
"I think the primary part of the issue is that the defined benefit plans grew too rich in
benefits, end up expensive and unsustainable. Also the volatility of the required
contribution has always been a concern ... because all of the market risks are on the
shoulders of the employer. ... The 2008 disaster was just the final straw, but it is an
accumulation of a number of events that have been occurred."
"I think it's very political motivated. They think they can gain some recognition if they
changed the pension plan under the guide of saving money, which is debatable whether
they are really gonna save money or not. ... When the private sector has started
recording liability they overwhelmingly moved to DC. I think that's the trend now
because the governmental accounting standard board is requiring government to put
the liabilities on the book."


"The cost to sustain those benefits. FRS is not as generous as some local plans, but for police and fire it is. ... [T] ax values declined so dramatically there is no residual to fund 3 Finance these benefits. And the actuarially determined pension cost was skyrocketing ... that's definitely why cities and State had to do something different than what they currently have. ... [W] hen times were worse, taxpayers weren't receptive to increasing property tax to pay for these extra benefits granted in good times."

"I think that we have a very conservative control-of-budget legislature in Tallahassee. They truly believe that the defined contribution is the way to go, because first, it is more

4 Finance common in the private sector and second, because of the much lower costs [of DC plans]...basically it's shifting the risk from the employer to the employee. ... I think the legislature desires to control what they think are unsustainable DB plans, which is not the case because the state plan is one of the best funded in the country."

"I think it's more of the fact that the city can budget properly and confident, because they know the annual contribution rating is gonna be set by the organization. There's

5 Finance no outside element such as rate of investment return. That's the key to my understanding. ... So the burden of investment is no longer held by the organization, it's now the responsibility of the actual pension person, beneficiary."

"I think it's political motivated. Unfortunately, in the State of Florida, elsewhere in the country as well, there are some examples of abuse by pensioners and huge payouts, primarily in the police and fire pension plans. Over time the approval of elected officials

$6 \quad \mathrm{HR} \quad$ to increase benefits will just create obviously a perception that pension plans are very rich plans for everybody and it's gonna create a huge future liabilities, which in some cases is true. However, if you would look at the general employees, that's not the case. However everybody looks at the exceptions only. So you get this big backlash that needs reaction to reducing benefits of public employees."

"The absolute certainty of cost of DC is one of its benefits [of pension model switch].... I think it's reflective of what's available in private industry. And that's something that is easy to attack for not just the legislators, also for the people that elect them: You have something that I don't have. So I think it's more politics than whether one model is more efficient than the other."

"I think it's just the financial sustainability when they look out to the future. Based on market, you are not gonna be able to keep going and that's why there needs to be some

8 HR changes, especially for police and fire. ... Isn't that really what is everything aboutcost?

$9 \quad \mathrm{HR} \quad$ "Most definitely, it's cost. That's the bottom line between a defined benefit plan and a defined contribution plan."

"I think there's a couple of different reasons. One reason, of course is the cost. The state employer is subjected to the cost for the pension and the up and down of stock market. And they're always having difficulties meeting their budget and the cost of pension figures into it. ... The other part of it, with the State of Florida, looking to close the defined benefit plan, is because it's not in line with the private sector employees. Private sector employers are getting rid of the DB plans and most of them are DC plan. ... And taxpayers don't like that government employees get more that private sector employees get."

The Impediments to Conduct the Pension Model Shift

One major purpose of this study is to find the readiness of Florida municipalities

to conduct the public pension model transition. In the survey section of general

questions related to pension model, this study tries to investigate whether respondents 
perceive that the unfunded pension liabilities under the current DB model is a big obstacle to implement the pension paradigm switch. Although the new employees with DC plans will not add future cost burdens, the government still need continue the funding the accrued benefit obligations of those staying in the DB system due to legal restrictions, with fewer dollars available since new employees will not make contributions to the old plan anymore. However, the survey results suggest underestimation of the deterrence of the transition costs. The possible explanation is that respondents may be more concerned with other obstacles such as political pressure, or probably they believe the painful therapy is worth taking for the ultimate sustainability. Therefore in the interview, the question about transition costs is included to probe into the rationale behind this recognition.

The interview results support both of the hypotheses. Although all of the interviewees acknowledge that the transition cost could be an issue, they regard its deterrence to pension model transition in various degrees. Interestingly, the three interviewees who straightforwardly regard the transition costs as the biggest obstacle to the DB-to-DC transition are all HR specialists (interviewee \#7, \#9, \& \#10), which suggests HR people are fully aware of the financial perspective like their finance counterparts: "I think that if you focused on the contribution rate, it could be a barrier to the transition, because you get the smaller payroll which to contribute the percentage of payroll adds-up. ... Yes, the perception that it's gonna be more expensive could be the biggest obstacle to switch to DC" (interviewee \#7). 
On the other hand, the finance directors, although they are fully aware of the detrimental transition costs, show greater anxieties concerning the political perspectives of the pension model shift (interviewee \#1,\#3, \& \#4), especially for the union negotiation of the special risks: "[T] here's always the political consideration too because the public safety unions still have a great deal of power, and they would've been putting a lot of pressure on our elected officials to not go down that road [of switching to DC]" (interviewee \#1). One finance director even considers the union issues as the biggest impediments to the transition: "The biggest obstacle that comes to mind would be union issues, collective bargaining, just resistant from those groups, especially PBA and IAFF” (interviewee \#4). Even for the general employees, the retirement insecurity caused by the deprivation of guaranteed benefits is a big issue, according to one interviewee: "[T]he biggest detriment to the transition is the uncertainty employees are facing because they know what they came in with and now they don't know what they're gonna leave with" (Interviewee \#2).

It's worth noting that political concerns are raised from the municipalities that keep the dominant DB model for their general employees. For the municipalities that have closed their DB plans, the interviewees hold more objective opinions about the impact of transition costs (interviewee $\# 5, \# 6, \& \# 8$ ). They are well informed of the short-term cost increase after the transition, but they emphasize more on the long-term cost reductions of the DC model: "Even though it will increase costs in the short term, but in the long run it still reduce costs, because with the DC plans you decide how much 
you are gonna to give the employees instead that the plan telling you how much you are gonna pay to sustain it"(interviewee \#6). Municipalities have to deliberate on the tradeoff in the transition as mentioned by HR: “There's going to be a financial burden but you have to look and see the end result: do you suffer for ten years and you are good for a hundred, or do you suffer for fifty and only good for fifty (interviewee \#8)?" Since the transition is conducted just recently, the uncertainty about the ultimate result of the transition in future is also reflected frankly by one Finance director: "We think it's only gonna get worse so we were trying to cut the bleeding now, kicking the pain off the roof for another several years. And then at that moment, making the determinations that would be self-sustainable or we're gonna choke out and self-end the employees and make higher contribution to the plan" (interviewee \#5).

Unfortunately, when the municipalities are already mired in tough fiscal challenges, the skyrocketing costs with the pension model shift make it difficult for the elected officials to make the move: "Once management and elected officials see that really moving to a DC plan provide long-term costs reduction, but in the short-term it's gonna increase your cost significantly, many have been chased away and said no, we can't go down that road"(interviewee \#1). Due to the short horizon of their operation, elected officials might be indifferent to the long-term effect of transition: "And it's tough to get elected officials to focus on what happens over 10, 20 or 30 years once you get out. ... And that's a tough thing to communicate" (interviewee \#7). Hence municipalities may flinch from the exorbitant transition costs and instead take 
alternative strategies to reduce their fiscal pressure such as benefit reductions, indicated

by one Finance director: "So that's why we went with the hybrid system and kept the

DB plan opened but just reduced the benefits, because that resulted in significant

savings to us. So to close a plan entirely and just start a DC was cost-prohibitive"

(interviewee \#3).

Table 6.7 The Impediments to Public Pension Paradigm Switch

\begin{tabular}{|c|c|c|}
\hline ID & Dept. & $\begin{array}{l}\text { Q: Do you think the need to continue the funding of those "in the system" is the } \\
\text { biggest deterrent to a DC transition? }\end{array}$ \\
\hline 1 & Finance & $\begin{array}{l}\text { "Yes, that has been very significant in discouraging governments from making that } \\
\text { transition currently, because the pressure has been that we got to find something to } \\
\text { relieve the burden on balancing the budget. Once management and elected officials } \\
\text { see that really moving to a DC plan provide long-term costs reduction, but in the } \\
\text { short-term it's gonna increase your cost significantly, many have been chased away } \\
\text { and said no, we can't go down that road, what can we do to decrease benefits instead } \\
\text {.. [T] here's always the political consideration too because the public safety unions } \\
\text { still have a great deal of power, and they would've been putting a lot of pressure on } \\
\text { our elected officials to not go down that road." }\end{array}$ \\
\hline 2 & Finance & $\begin{array}{l}\text { "That is a huge obstacle but I don't think that is the primary obstacle.... [T] he biggest } \\
\text { detriment to the transition is the uncertainty the employees are facing because they } \\
\text { know what they came in with and now they don't know what they're gonna leave with. } \\
\ldots \text { The cost should be the secondary factor because eventually the DB plan will be } \\
\text { funded and you cost will go down with the defined contribution." }\end{array}$ \\
\hline 3 & Finance & $\begin{array}{l}\text { "Yeah. When we run numbers on that to just close our old plan and pop up to a brand } \\
\text { new plan, we found those numbers were huge. Because you have to reduce the } \\
\text { amortization, you have to fund a lot more all at once. So that's why we went with the } \\
\text { hybrid system and kept the DB plan opened but just reduced the benefits, because that } \\
\text { resulted in significant savings to us. So to close a plan entirely and just start a DC } \\
\text { was cost-prohibitive.... [U]nion negotiation is also a big issue. You have to changing } \\
\text { benefits." }\end{array}$ \\
\hline 4 & Finance & $\begin{array}{l}\text { "Oh yes it definitely can be an obstacle, even though for healthy fund like FRS. But if } \\
\text { they close the plans off, you not only lose the dollars that employees would be } \\
\text { contributing but also the ending unfunded liability then has to be amortized over a } \\
\text { shorter period of time, which in the near term future increases the annual contribution } \\
\text { by the employer pretty significantly.... The biggest obstacle that comes to mind would } \\
\text { be union issues, collective bargaining, just resistant from those groups, especially } \\
P B A^{1} \text { and IAFF". }\end{array}$ \\
\hline
\end{tabular}




\begin{tabular}{|c|c|c|}
\hline 5 & Finance & $\begin{array}{l}\text { "Absolutely. And we know there's gonna be, I think the next } 10 \text { years, our contribution } \\
\text { is going up. ...But at the end of the day, it's a move for the future. We think it's only } \\
\text { gonna get worse so we were trying to cut the bleeding now, kicking the pain off the } \\
\text { roof for another several years. And then at that moment, making the determinations } \\
\text { that would be self-sustainable or we're gonna choke out and self-end the employees } \\
\text { and make higher contribution to the plan. I mean it was a way it's gonna suck, no } \\
\text { matter which way you went. So you choose your poison." }\end{array}$ \\
\hline 6 & HR & $\begin{array}{l}\text { "Yes and no. ...Even though it will increase costs in the short term, but in the long run } \\
\text { it still reduce costs, because with the DC plans you decide how much you are gonna } \\
\text { to give the employees instead that the plan telling you how much you are gonna pay } \\
\text { to sustain it." }\end{array}$ \\
\hline 7 & HR & $\begin{array}{l}\text { "I think that if you focused on the contribution rate, it could be a barrier to the } \\
\text { transition. Because you get the smaller payroll which to contribute the percentage of } \\
\text { payroll adds-up. And it's tough to get elected officials to focus on what happens over } \\
10,20 \text { or } 30 \text { years once you get out.... And that's a tough thing to communicate...Yes, } \\
\text { the perception that it's gonna be more expensive could be the biggest obstacle to } \\
\text { switch to DC." }\end{array}$ \\
\hline 8 & HR & $\begin{array}{l}\text { "That is one issue we look out even with our police and fire. I have heard that it can } \\
\text { cause a problem because you don't have anyone coming in now to sustain that. } \\
\text { There's going to be a financial burden but you have to look and see the end result: do } \\
\text { you suffer for ten years and you are good for a hundred, or do you suffer for fifty and } \\
\text { only good for fifty?" }\end{array}$ \\
\hline 9 & HR & $\begin{array}{l}\text { "I would say a resounding yes, definitely, most definitely. Funding is going to be the } \\
\text { biggest challenge for public agencies with regard to the DB system or the dying out } \\
\text { of DB system if you will. The challenge of the future cost burden is going to have to } \\
\text { be met with innovative ways to fund it." }\end{array}$ \\
\hline 10 & HR & $\begin{array}{l}\text { Yeah I think that is a problem. ... [Y]ou don't have new employees coming into the } \\
\text { plan. You have to pay benefits to those retiring people. Especially if it's in public } \\
\text { safety, DB plans in police and fire, they have a higher number of disability } \\
\text { retirements. That's gonna cost more. That's gonna be the biggest issue with transition. } \\
\text { You don't have new money coming into the plan and you have no control over what } \\
\text { the costs are gonna be in the future. }\end{array}$ \\
\hline
\end{tabular}

1. PBA: Police Benevolent Association.

2. IAFF: International Association of Fire Fighters.

The Necessity of Financial Literacy Training in the Transition

Financial illiteracy is a widespread American epidemic. Most Americans

cannot balance their checkbooks, calculate their net worth, obtain competitive bids for

insurance or loans, or allocate assets across investment classes. In the context of

retirement planning, traditional government DB plans imply a paternalistic outlook.

Adequacy aside, an employee under the traditional DB model is relieved of investment

decision-making and guaranteed a given return. As some scholars note, for an

investment-illiterate clientele, this "paternalism" may be something of a godsend in 
light of the damage done to $401(\mathrm{k})$ accounts during the recent fiscal crisis. While such paternalism may be viewed as necessary, the fact remains that in the event of a pension paradigm shift, the sovereign can no longer remain indifferent to addressing the widespread financial illiteracy.

All the interviewees recognize this sad reality of financial illiteracy and believe this will pose a risk to the employees under the DC regime. A finance director in the sample describes this situation: "We have a lot of folks who don't have any idea of how to invest money prudently, and diversify their portfolios. So it would be very dangerous for them... And it would be difficult getting people committed enough to learn what they need to learn to manage their own investments. It's not an ideal situation for much of our labor force" (interviewee \#1). They all strongly agree on the necessity for employer to offer financial training to employees after the pension model transition to avoid potential negative impacts to employees' retirement security, although some directors doubt the willingness of politicians to give the financial education: "I don't think that's something [financial training] that the politicians are considering. ... [Y]ou have been holding these employees' hands for their entire life, and now you switch them over to defined contribution, you're gonna have to provide some kind of assistance with education training. You have the fiduciary duty to oversee. Otherwise we'll have another Great Depression with a hundred millions eighty-year-old homeless people" (interviewee \#2). Similar concern is raised by one HR specialist: "There are people that are not financially literate enough to invest their own money. Employers 
should do more financial training, but whether they will, I kind of doubt it. If the downside now is having an aging workforce, wait till nobody can afford their retire"(interviewee \#7).

Therefore, interviewees suggest that the implementation of the transition should not be the end of the efforts for public agencies to solve their financial problems. Employers should be alert to the financial illiteracy of employees in the DC model and be prepared to take necessary actions for a long period after the pension model switch: "If employees are gonna be responsible for their own financial security in future, they need to be well-educated, and on the on-going basis... It's not fair to employees just to implement a plan and say now you are responsible, and let them up to their own device... I think the employer does have the responsibility for training and on-going education for the employees"(interviewee \#4). One finance director expects the employer to take the responsibility of investment even under the DC model: "[T]here are some hybrid plans out there where they're technically defined contribution plans but the employer manages the investments rather than each employee being responsible for managing the investments. That actually appeals to me"(interviewee \#1).

Several interviewees from cities that have adopted the DC model point out that in the pubic DC plans, there are some protective investment products that offer default investment choices similar to the qualified default investment alternatives (QDIA) in the private sector through working with ICMA (International City/County Management Association), which assists the financially illiterate employees to better 
manager their retirement funds: "We partnered with ICMA and they are on call at any

time for any employee. It's one of the benefits provided to our employees. We made

that a priority because we knew that moving to a DC plan requires a little bit more on

the employee's part and they are managing their own future. ICMA has different plans

that do not require much thinking, you choose what products you want, and they invest

in the way you want" (interviewee \#5).

Table 6.8 The Necessity of Financial Literacy Training

\begin{tabular}{|c|c|c|}
\hline ID & Dept. & Q: Will the adoption of DC plans require increasing financial literacy training? \\
\hline 1 & Finance & $\begin{array}{l}\text { "There is no question about it [the need for financial literacy training]. ... [T] here are } \\
\text { some hybrid plans out there where they're technically defined contribution plans but } \\
\text { the employer manages the investments rather than each employee being responsible for } \\
\text { managing the investments. That actually appeals to me. ... [W]e have a lot of folks who } \\
\text { don't have any idea of how to invest money prudently, and diversify the portfolios. So } \\
\text { It would be very dangerous for them... And it would be difficult getting people } \\
\text { committed enough to learn what they need to learn to manage their own investments. } \\
\text { It's not an ideal situation for much of our labor force." }\end{array}$ \\
\hline 2 & Finance & $\begin{array}{l}\text { "I don't think that's something [financial training] that the politicians are considering. } \\
\text {... [Y] ou have been holding these employees' hands for their entire life, and now you } \\
\text { switch them over to defined contribution, you're gonna have to provide some kind of } \\
\text { assistance with education training. You have the fiduciary duty to oversee. Otherwise } \\
\text { we'll have another Great Depression with a hundred millions eighty-year-old homeless } \\
\text { people." }\end{array}$ \\
\hline 3 & Finance & $\begin{array}{l}\text { "Definitely. We are concerned that the employees, even the sophisticated employees, } \\
\text { may have trouble picking the right investments, so we're trying to work with ICMA } \\
\text { [International City/County Management Association] to improve their program } \\
\text { outreaches to the employees. }\end{array}$ \\
\hline 4 & Finance & $\begin{array}{l}\text { "If employees are gonna be responsible for their own financial security in future, they } \\
\text { need to be well-educated, and on the on-going basis... It's not fair to employees just to } \\
\text { implement a plan and say now you are responsible, and let them up to their own } \\
\text { device... I think the employer does have the responsibility for training and on-going } \\
\text { education for the employees." }\end{array}$ \\
\hline 5 & Finance & $\begin{array}{l}\text { "We partnered with ICMA and they are on call at any time for any employee. It's one } \\
\text { of the benefits provided to our employees. We made that a priority because we knew } \\
\text { that moving to a DC plan requires a little bit more on the employee's part and they are } \\
\text { managing their own future. ICMA has different plans that do not require much thinking, } \\
\text { you choose what products you want, and they invest in the way you want." }\end{array}$ \\
\hline 6 & HR & $\begin{array}{l}\text { "Yes, because when employees are faced with choices of mutual funds investments, } \\
\text { some people are not going to always make the best choice. There is a risk for the } \\
\text { employee." }\end{array}$ \\
\hline 7 & HR & $\begin{array}{l}\text { "There are people that are not financially literate enough to invest their own money. } \\
\text { Employers should do more financial training, but whether they will, I kind of doubt it. } \\
\text { If the downside now is having an aging workforce, wait till nobody can afford their } \\
\text { retire." }\end{array}$ \\
\hline
\end{tabular}




\begin{tabular}{c}
\hline HR $\begin{array}{l}\text { "The city has ICMA-RC for our 401a [plan], and they're coming once a month to do } \\
\text { individual education. Once a year we have them talked to everybody during open } \\
\text { enrollment..." }\end{array}$ \\
\hline $\begin{array}{l}\text { "Just going ahead and making a transition may not be the end of financial problems for } \\
\text { public sector employer." }\end{array}$ \\
$\begin{array}{l}\text { "... [W]e definitely have done that [financial training] to get employees to think about } \\
\text { it. It's called the three-legs stool: One is your pension or your defined contribution } \\
\text { money, the other leg is social security, and the third leg is your own savings." }\end{array}$ \\
\hline
\end{tabular}

\subsubsection{The Shared Mindset of Finance and HR Directors}

Public pension issues straddle traditional boundaries between finance and human resources, thus this study involves both groups of professionals. Prior survey findings did not find significant differences between the perceptions of Finance and HR directors about the pension reform issues. This contradicts the expectation that Finance and HR people would view the pension reform through different prisms based on their profession domains: Finance directors would be more sensitive to the budgetary soundness of the pension plans whereas HR staff are more concerned with the competence of the alternative model to recruit and retain qualified employees. The uncovered congruent worldview of the two sets of professionals claims for explanations. One interpretation would be that both groups are essentially long-term employees working in a DB environment and that they are comfortable with the status quo. Another assumption might be that they are unsure of what a DC transition might bring and their unified worldview reflect this uncertainty. In order to find the valid justification, the interview includes the question requesting explanations about the virtually identical views between Finance and HR directors, the important quotes are provided in Table 6.9. 
The first explanation gets supported from only two HR directors. One suggests that most of respondents probably participated the DB model, there might be "a bias toward the status quo if it's good for you. That's just a human nature" (Interviewee \#7). Similarly, another HR staff indicates that since the respondents are long-term employees, they might prefer the fact of DB: "Most of them are eligible for a pension and they would like that to continue" (Interviewee \#9).

Since half of the interviewees are from municipalities where the DC model has been adopted, the second interpretation does not hold substantial weight. On the contrary, most interviewees suggest they are on the same page of their counterparts because they shared the same knowledge about the issues and have the same goal to guide their thoughts and actions. One of the reasons is that in the public agencies, when dealing with pension issues, Finance and HR staff work closely and have good communication with each other, bluntly expressed by three interviewees (interviewee $\# 1, \# 4$, and \#6). Therefore, the two groups share the same knowledge and concerns of the current pubic pension system. Both of them have to admit that the DB model would not be sustainable unless some joint efforts are taken to save the financially stressed public agencies. The grossly inflated benefit level, especially for police and fire pensions, will obviously raise a red flag for Finance directors, such that in union negotiations HR people "probably became frustrated and realized that that wouldn't be sustainable" (interviewee \#3). 
It's interesting to see that the shared concern of both groups is from the financial perspective - the pension costs. This point is particularly emphasized by some HR specialists: "Personally I think it's because HR has been so much brought into the financial level. ... [Y] ou would be irresponsible as an HR person to not to take benefit costs into consideration" (Interviewee \#8). Especially under the fiscal stress, HR people perceive the similar budgetary pressure as Finance staff. Thus, other than the personnel issues of pension in the HR administration, "the bottom line is the cost" (interviewee $\# 10)$.

Consequently, the interview results imply that although the two sets of specialists have different responsibilities, they "agree on the results for two different reasons" (interviewee \#2). No matter which stance is taken, Finance and HR professionals will not deviate much from the same goal of maintaining the operational efficiency of the public agencies. Moreover, the two groups have to share the same view because they work for the same "boss" - the city manager, as stated by one Finance director: "The truth of the matter is, me and HR is getting on the same boat. Now we are going to go on the same direction to accomplish what the manager wants us to accomplish" (Interviewee \#5).

Table 6.9 The Congruence of Finance and HR Perceptions

\begin{tabular}{ll}
\hline Q: Our survey results showed that HR and Finance Directors have virtually \\
ID Dept. & $\begin{array}{l}\text { identical views of transition issues. We expected otherwise. How would you } \\
\text { explain our findings? }\end{array}$
\end{tabular}


"Probably as much as any thing it's good communication. Within governments HR and finance work very closely. So we're sharing ideas, concerns and concepts. ... I think

1 Finance it's just a natural outcome of being educated on the issues and once we're fully educated, we end up pretty much the same place because it's pretty obvious what the issues are, where we're in and where we need to go."

"... [M] ost of the finance directors are probably looking at the transitioning costs. But if you look in long-term then the costs will go down. ... [F]or HR I think they're looking

2 Finance at from the personnel viewpoint. This uncertainty, you know what you come in to when you start but now they're gonna switch everything and you don't know what you're gonna have when you leave. But we agree on the results for two different reasons. That would be my opinion."

"I think we both feel the benefits were not sustainable. Obviously for budget perspectives the finance directors are keenly aware of it. So like forward, HR also deal

3 Finance with the collective bargaining side more and they saw the police and fire model was becoming just grossly inflated. ... [W]ith union negotiations they probably became frustrated and realized that that wouldn't be sustainable."

"I guess from my point of view, I work closely with our HR director and anything deals

4 Finance with the pension we are both involved in, so we would kind of have the same knowledge about it and the same concerns would be brought up in meetings that we are in."

Because we have the same goal, her [HR director's] responsibility is also for the employees but at the same time has to protect the city from liabilities. ... [I]f the HR

5 Finance doesn't share the same view as the Finance director, the ball won't be moving. And that's not really an option, especially with the city manager, which is our boss. The truth of the matter is, me and HR is getting on the same boat. Now we are going to go on the same direction to accomplish what the manager wants us to accomplish."

HR $\quad \begin{aligned} & \text { "We have good communication and we are all on the same page when it came to that } \\ & \text { transition. There wasn't any difference of opinion between the two." }\end{aligned}$
"I think part of it with both of HR and Finance folks, at least in public employer, they
probably participate the same [DB] model right now. I do think there is a bias toward
the status quo if it's good for you. That's just a human nature. ... Then when you take
a look at the efficiency of the models, depends on which model your organization goes
on, I don't think the finance and HR have different goals from a recruitment/retention
perspective."
"I really believe that as public agencies go, both finance and HR people love the fact [of DB] because they are long-term employees. Most of them are eligible for a pension and they would like that to continue. They don't like the pension model switch. Even 9 HR though there are cost savings available, but I think more and more they are starting to understand the fact that DB model is not sustainable. And so in order to keep their public agencies from sinking financially they have to work together to make the transition."

"I think the shared concern is financial. ... [E]specially in this state of age, we try to

10 HR think about other things like the perceptions and tier of employee, but the bottom line is the cost. That's shared with finance and human resources. That's the main concern." 


\subsection{Summary}

As one part of the triangulated efforts, interviews with Florida local officials provide additional evidence about their perceptions to public pension reform and indepth illustrations of the rationale behind their inclinations. This chapter sorts through the important interview quotes by theme and reports summaries. It discusses the financial perspective of the public pension reform, the human resources impact of the public pension reform, the pros and cons of the public pension model switch, and the congruence of the Finance and HR perceptions. With the quote analyses, the viewpoints deduced from the survey results gain further validations and interpretations.

First, the interviewees are queried about whether the current public DB plans are sustainable and what they think is the long-term solution to the current public pension "crisis". As expected, almost all the interviewees define the sustainability of public pension systems solely from the financial perspective-the affordability of pension costs becomes the top priority when they determine whether a pension plan is feasible. The perceptions from the sample split into two opposite streams. The DB advocators believe the current DB plans are sustainable, or will be sustainable, if only they are managed in a more prudent way, so the incremental changes by enhancing the administration of the DB model is the ideal solution for them. On the contrary, the officials from cities offering DC plans assert the DB model is not sustainable because of its design features and contend that the DB-to-DC transition is the right way to go for the public pension system to survive. 
Second, this study solicits answers from interviewees for three questions from the human resources perspectives: How pension reforms would affect the public recruitment and retention, and how a two-tier benefit structure would impact the workforce morale. The analyses suggest most interviewees do not recognize that pension type could serve as an employment cue for different generations. The traditional DB promoters still believe the DB model is more attractive to applicants than DC. But almost all of them agree that the pension model transition will not bring significant impacts to the public recruitment especially for general employees, since they can be hired from the private sector and the officials believe the government salary with DC pension is competent enough.

As for the retention, all interviewees believe that the $\mathrm{DC}$ model without vesting requirements would increase employee mobility within the public sector and between the public and private sector. The DB supporters argue that the DC plan is not as sufficient as DB plans to retain qualified employees, although they acknowledge a certain degree of turnover is necessary for public agencies to avoid stagnancy, the socalled "Golden Handcuffs". The officials from city that have conducted the switch do not perceive the negative impacts to retention, because salary is more crucial than pension type to retain public employees nowadays. At the same time, quite a few directors observe the intergenerational differences in the pension model preference: Younger employees are less committed than older generations to work in one organization for long time; hence they favor the portability of DC model. 
The interviewees do not regard the potential negative impact of the two-tier benefit structure to the workforce morale as a serious issue. Even though there might be some resentment, they believe it could be solved by clear disclosure at the time of hiring, so the employees are responsible for their own decision to work in the agency with lower pension benefits. In addition, the interviewees think this issue will be selfsolvent along the retirement of senior employees, when there is only one tier left in the workplace.

Another set of questions regards the readiness of local governments to conduct the public pension paradigm switch from DB to DC plans by exploring the drivers and impediments of the model shift and the necessity of the financial literacy training after the switch. The most direct impetus for the transition is the immediate need for governments to relieve the fiscal burden of the snowballing pension obligations. Some DB supporters mention the political motivation to imitate the private sector practices in order to impress the constituency. As regards to the cons of the transition, the cities offering DB plans imply that the significant transition costs of pension model switch is the biggest deterrent for elected officials to take the move, so they will adopt the alternative incremental reform strategies of reducing pension obligations. By contrast, the cities that have conducted the switch think it is better to cut short the suffering with the tradeoff between the short-term higher costs and the long-term cost saving. Another concern with the transition is that the financial illiteracy of public employees will incur risks to their retirement security under the DC regime. All the interviewees agree that 
it is necessary for employers to offer financial literacy trainings to protect employees from investment losses.

Finally, the study solicits explanations from interviewees about the congruence of perceptions to public pension reforms between Finance and HR directors in the survey results. A partial reason is that both groups are senior employees who are eligible for DB pensions so there is a bias towards the status quo. However, the major reason that Finance and HR have an almost identical worldview is because they share the same knowledge of the pension issues and have the same goal of maintaining the effectiveness of organizational operations. Although they may consider the pension issues from their different professional stance, it requires a joint effort from both departments to work for the city manger in dealing with public pension reform. 


\section{CHAPTER 7}

\section{CONCLUSIONS}

\subsection{Introduction}

The 2008 economic downturn exposed the issue of financial viability of the prevailing DB pension model in public sector. The widespread concern about skyrocketing pension obligations gave many state and local governments the impetus to reform DB plans in order to relieve these fiscal burdens. Their reform strategies can be classified into two categories: the incremental changes to the current DB system by reducing benefit level or increase employee contribution, and the pension model transition from DB to DC plans. The adoptions of reform strategies are subject to all kinds of economic, political and social factors confronted.

Although the state retirement system in Florida has been evaluated as one of the best-funded public pension systems, the reform initiative led by State Governor in 2011 suggests the severe fiscal pressure to maintain the sustainability of FRS. The new

pension law enacted after July 1, 2011 consists of incremental changes to the state- 
sponsored DB plan instead of the original proposal of a pension paradigm switch. In Florida, local governments have undertaken both streams of reform strategies have been undertaken to improve the funding status of the pension plans.

The study examines the applications of both kinds of strategies and aims to uncover the potential issues related to the adoption of each reform tactic at the local level. The primary motive for public agencies to conduct the pension reform is to achieve financial solvency. Therefore, the first step of the study is to investigate whether the incremental reform strategies are sufficient to improve the fiscal status of the current DB model. Second, the study explores the alternative reform choice of pension paradigm switch from DB to DC plans by unveiling the major drivers and impediments to implement the transition. Third, the more common incremental changes existing in the public agencies have created a two-tier benefit structure for different generations of workforce, which posed an interperiod equity issue. The study examines the organizational impact of this newly established two-tier system to public agencies.

The study contributes to the previous literature about pension reforms. It fills an important knowledge gap in the scholarly literature by presenting a comprehensive analysis of the two categories of public pension reform strategies. It assesses the potential impacts of the pension paradigm switch from DB to DC plans and the readiness of Florida municipalities to conduct the transition through analyzing the 
perceptions of Florida local government officials. The study also addresses the lack of primary data about public pension reforms in previous academic literature.

The study developed a triangulated research method, drawing on secondary data from Florida's local retirement system, and primary data from a survey of the Finance and HR directors of Florida municipalities as well as interviews with the representative officials in these cities. The findings of the study suggest that the incremental changes about DB plans are not adequate to improve the financial solvency of the DB model at the local level. The alternative reform approach is promoted by financial concerns, political motives, and social pressures. However, given the latent obstacles from the fiscal and political perspectives, public agencies may prefer the intermediate way to start the reform action.

The rest of the chapter includes the following contents: first, it provides the summary and discussions about the major findings for each research questions; second, it discusses the implications of the findings to the public pension reform policy; third, it introduces the limitations of the study and future research directions about this topic and finally concludes with a brief summary.

\subsection{Summary of Research Findings}

This section provides the highlights of key findings for major research questions, which consists of three major themes: the financial solvency of public 
pension systems, the pension paradigm switch in the public sector, and the interperiod issue during the public pension reforms.

The Financial Solvency: Incremental Tweaks are Just Palliatives

In order to alleviate the fiscal stress of ever-increasing pension costs, many state and local governments have implemented the reforms to sustain their public pension plans. At the present time the mainstream reform strategy is to preserve the default DB model in the public sector through the incremental changes, which are exemplified by the 2011 pension reform law of Florida state retirement system. By altering the plan design characteristics such as reducing the benefit levels and increasing contributions, public agencies tweak their DB plans with the hope relieving their financial burden and achieving sustainability. However, this study argues that these incremental tweaks may not be efficient enough so that state and local governments could not rely on them to improve the financial solvency of the public DB plans.

The study presents the evidence to support this contention through identifying the determinants of financial solvency of local DB plans in order to diagnose whether the plan design features are the crucial indicators compared with other financial, political, and demographical factors. Utilizing the panel data of 151 local DB plans in 
Florida municipalities from 2005 to 2012, a regression model is established to test the research hypotheses about the explanatory variables of the financial solvency of DB plans. The generated results provide substantial evidences that bolster the author's argument.

The hypotheses of the plan design characteristics turn out to be supported, especially for the ones of contributions. The only statistically evident benefit variable is the normal retirement age. The associated coefficient suggests that the reform strategy of reducing the generosity of pension benefits by increasing the normal retirement age may not be helpful in decreasing the unfunded pension liabilities. The longer time horizon to amortize the benefit obligation might expose governments to more investment risks, which would further widen the gap between pension assets and obligations.

By contrast, the contribution hypotheses achieve significance. The results suggest that increases in the contribution rate, no matter from plan sponsors or participants, will not improve the financial solvency of the DB plans. Conversely, higher contribution rates indicates greater fiscal pressure to local governments associated with relatively low funded ratio and more pension obligations, which requires even more financial responsibilities from employers and employees to foot the pension bill. 
The major finding of the examination about the financial solvency of local DB plans is that changing plan design features is not the cure for the fiscal stress of the DB model, but more like a painkiller to cope with the public pension crisis. Therefore, the incremental reform strategies through modifying plan design features may be palliatives at the very most to relieve the immediate budgetary burden temporarily (Frank et. al, 2012). In the long run, tinkering with the DB model may not be sufficient to insure its viability.

The results of other factors demonstrate the significance of prudent investment management and realistic actuarial assumptions to the financial health of public pension plans. This contention gets supported by survey and interview findings, which reveal the vulnerability of DB pension to the market fluctuation. Although the DB advocators are reluctant to admit the defects of the DB model, some government officials have become suspicious of the adequacy of the incremental tweaks to DB plans and realize the necessity of more feasible reform approaches to achieve a sustainable public pension system.

\section{Pension Paradigm Shift: Attractive and Intimidating}

On the basis of the conclusion about the inadequacy of incremental reform strategies, this study explores the alternative reform approach — the pension paradigm switch from the DB to DC model in the public sector. The virtues of the DB-to-DC transition have attracted interests from many state and local governments. However, 
the relative infrequency of implementations suggests the existence of significant deterrents. With the primary data gathered through survey questionnaires and interviews, this study collects the perceptions of the local officials in Florida cities to investigate the readiness of Florida local governments to conduct the public pension model change.

The recent stock market downturn resulted in the severe blow to public pension funds. At the same time, governments collected less revenue due to the economic recession, making it even more difficult for politicians to set aside enough pension contributions to cover the investment loss, especially when confronting other urgent needs of government expenditure. Therefore, reducing the pension costs through the paradigm shift from DB to DC model is the foremost motive for governments to conduct the transition. In doing so, governments could minimize the investment risks associated with DB pension fund and transfer them to employees themselves. Under the DC model, public agencies would not suffer the involuntary contribution rate tied to the market performance, but be able to budget properly and confidently at the acceptable level.

Findings from surveys and interviews also suggest political incentives and social impetus to implement the pension model switch. The diminishing pension coverage in the private sector calls for public agencies join the ranks and apply the private practices to the public pension system. The taxpayer sentiment also forces the governments to curb pension expenditures rather than "spoil" public employees with 
generous retirement benefits. Thus, political officials tend to gain recognitions from their constituencies through the initiative of public pension paradigm switch in the name of saving taxpayers' money.

Although the pension model switch appears attractive from many perspectives mentioned above, this study uncovers several impediments for local governments to make the switch. One major concern is the affordability of the transition costs for public agencies with great amount of unfunded pension liabilities. Switching from DB to DC model would reduce the expense of the benefit amortization in the long run, but it would increase the short-term payments to the beneficiaries that are still in the DB system, which are cost-prohibitive for political officials that focus on the immediate budgetary need due to their short time-horizon of operation. Accordingly, instead of implementing the paradigm shift, some governments opted for incremental strategies to reduce pension benefits. By contrast, some public agencies weighed the long-term fiscal health against the short pain of increasing costs and resolved on the transition.

The potential negative impacts of the pension model transition to the public recruitment and retention are supposed to discourage the adoption of paradigm switch. However, the findings imply that although the transition can foster the employee mobility within public sector or between the public and private sector, it would not much alter the capacity of governments to recruit and retain qualified general employees. Moreover, the turnover brought by the transition is perceived to be beneficial to the public agencies to avoid stagnancy. The preference for the DC model 
among millennials is recognized to some extent, while the link between pension type and recruitment/retention are not fully grasped by Florida local governments.

Another source of anxiety concerning the paradigm switch is that the widespread financial illiteracy of Americans may threaten the retirement security of public employees after the transition. Under the DB model, public employees enjoy the paternalism that the plan sponsors are responsible for the investment decisions of pension funds. By switching the pension model, employers transfer the responsibility to employees themselves, which may put them in danger due to their financial illiteracy. The findings indicate the necessity of proactive education of financial planning and asset allocation to public employees, especially in light of the unsatisfying performance of 401(k) accounts during the recent fiscal crisis. The pension model switch does not end the employers' job but requires their further efforts to ensure the retirement security of public employees even under the DC regime.

\section{The Interperiod Equity: An Ignored Matter}

Intergeneration equity is another important subject of this study. This emerging issue in the public pension system is analyzed in two facets. First the research explores the broad aspect referring to the unfair wealth transfer from the future taxpayers to the current generation by delaying the fulfillment of contribution requirements and/or increasing benefit to an unrealistic level. This malpractice results in future taxpayers bearing higher costs from the accrued pension promises to prior public servants, and 
also because of current public services. Interview results suggest public officials believe that the direct cause of the current pension crisis is the irresponsible increase in pension benefits and not to funding pension plans at the actuarially required contribution rate. The misconduct of pension fund management implies the existence of the moral hazard issue. Due to the short horizon of operation, elected officials tend to increase the benefit to an unfeasible level or reduce the contribution to gain recognition and impress the constituency, ignoring the long-term impact.

The study also narrows the interperiod equity issue down to the impacts of the two-tier benefit structure established during the recent public pension reform. Many state and local governments created a second tier of retirement benefit for new hires with elongated retirement age and vesting periods, reduced benefit multipliers and COLAs, etc. In doing so, governments could reduce their pension costs to relieve the fiscal burden. According to the experience in the private sector, the two-tier benefit structure may cause diminished morale, which may reduce employees' commitment to the organization and spur high turnover rate.

The empirical findings of this study suggest that most local governments neglect the issue of the two-tier benefit structure. Even though some officials admit the two tiers of benefits under the same roof may cause some animosity among different generations of employees, they just regard this as a minor jealousy issue. The shared view is this issue is simply a matter of full disclosure at the time of recruitment. As long as the applicants are aware of the benefits they receive are less generous than 
previous employees, they are responsible for their decisions to work in the public agency. In light of the high unemployment rate since the depression, this issue would barely affect their decisions. Besides, many officials indicate the salary, rather than the pension type, is the major employment cue. Since the two-tier structure is newly introduced, the long-term impact cannot be observed now. However, the issue is believed to be self-correcting and will die out over time along with the retirement of senior employees. When there is only one tier left in the workforce, animosity will no longer be present.

\subsection{Implications to Pension Reform Practice}

The severe damage done to the public DB plans after the 2008 market downturn indicates that the public sector pension systems are not immune to economic fluctuations and may not be able to keep their promises of guaranteed retirement benefits. Although the DB advocates, biased by their own status quo, are unwilling to admit the unsustainability of the default DB plans, more and more governments realize the DB model is not viable, at least with the existing design features and current pension fund management. Thus, in order to reduce the pension costs, public agencies could alter the plan design characteristics and prudently administer their pension asset investment.

Nevertheless, the research findings suggest that incremental strategies to preserve the DB plans are not effective to improve the financial solvency of the DB 
model or ensure its sustainability. Like it or not, the DC model seems to be the final destination to ultimately relieve public agencies from investment risks. Following the historical course of pension coverage cuts in the private sector, public employees may not be able to enjoy the privilege of the generous DB pension plans in the wake of the negative taxpayer sentiment.

However, the overnight DB-to-DC transition may not be a feasible strategy for governments due to several impediments identified in this study: transition costs, political pressure, potential organizational impacts, and the retirement insecurity due to the financial illiteracy. Thus, the intermediate approach of the model switch may serve as the starting point for the journey of public pension paradigm switch. State and local governments may manage to reach a middle place between the DC and DB model, which could both boost the financial health of governments and ensure the retirement benefits of employees. As some officials suggest, for the new hired employees, a hybrid plan would provide a certain portion of defined benefit providing employees with the security of guaranteed retirement income, as well as a supplementary savings with the DC model offering the portability and possible higher investment returns. Even after fully switching to the DC regime eventually, public employers should endeavor to educate the employees with financial planning to avoid the risks of investment losses due to the financial illiteracy of public employees. As Munnell (2012) suggested with the case of Rhode Island's 2011 reform, the reform efforts should fairly distribute the 
responsibilities among employer, incumbent and prospective employees, retirees and beneficiaries, and taxpayers.

\title{
7.4 Limitations and Future Research
}

\author{
Limitations of the Study
}

This study adopts a triangulated research approach to utilize data from multiple sources in order to facilitate the reliability and validity of the findings. However, there are several limitations that the author has to acknowledge. First, because only $10 \%$ of the Florida cities have DC plans as their primary pension model to provide pension benefits, and most cities have just started acting to reform their local pension system, the data gathered for chapter five and chapter six is based on the perceptions of government officials rather than the actual impacts of the pension reform to public agencies. Therefore the findings are drawn from the estimations of the potential issues about the pension reform in the public sector.

The second limitation resides in the fact that this study concentrates on the local level in Florida. This focus ensures the consistency of the legal and administrative framework of research participants. However, this restriction along with the relatively low validity of the results makes it difficult to directly generalize the findings to other states, although Florida has been a renowned political and demographic trendsetter for the nation. 
Other limitations the author needs to admit refer to the representativeness of the results considering the relatively low response rate of the survey, and the reliability of the findings due to the fact that survey respondents and interviewees might not be honest or candid about the pension issue. The controversial nature of the research subject may lead to their self-censorship. It is conceivable that some participants answered questions with an eye to perceived neutrality when in fact they held stronger beliefs. The results may unveil only part of the whole story.

\section{Future Research Directions}

This study fuels the heated discussion about public pension reform since the economic recession in 2008. While the findings of the study provide answers to the present research questions, at the same time, they raise other topics. Through the comprehensive examination about the public pension reform strategies at the local level in Florida, this study paves the way for future researches to further investigate this subject. It can serve as the starting point since the long-term impacts of public pension reform cannot be fully grasped now. Therefore, the future research directions originated from this study might include the following subjects: Collect the time-series data about the pension model of the municipalities in Florida and identify the major trend of the pension model changes; develop the scale of the public pension reform strategies ranging from the incremental tweaks of existing DB plans to the ultimate pension paradigm switch to the DC model; utilize the generated reform indexes to establish regression models with the city-level political, financial, and demographical 
information, in order to find the impacts of different reform approaches to municipal fiscal status, or the factors that may affect the decision on the selection of pension reform strategies; observe and assess the future impacts of the two-tier benefit structure to the workforce morale and the actual solutions to the interperiod equity issue; collect data of the recruitment and retention in the public agencies that have conducted the DB-to-DC transition to examine the impacts of the model switch to the employee mobility; and apply the research methodology to the public pension system in other states and compare the Florida cases with similar municipalities in other states.

\subsection{Summary}

This study provides a thorough examination of the Florida local public pension system, aiming to uncover the more appropriate reform strategies to tackle the public pension crisis after the 2008 economic downturn. The incremental changes exemplified by the 2011 pension law are supposed to improve the financial solvency of the DB model. However, analysis of the panel data of Florida local DB plans from 2005 to 2012 reveals that the reform strategies by changing plan design features may not be adequate to preserve the financial health of pubic DB plans. Hence, the alternative reform approach - the DB-to-DC transition-is investigated with the primary data gathered through survey and interviews with the Finance and HR directors in Florida municipalities. The findings suggest that mangers may be attracted to the pension paradigm switch for the purpose to reduce their pension costs and political officials are willing to initiate this transition to impress the constituency by mimicking the practices 
in the private sector. At the same time, local governments are hesitant to implement the model shift with the concern of transition costs and political pressure. Thus, the feasible way of conducting the pension paradigm shift in the public sector is to offer a hybrid plan first for the new hires, then eventually switch completely to the DC model. In addition, there is a unified view that the financial illiteracy is part of a large problem of retirement security. Under the DC regime, public employers need devote more efforts to educate the financially illiterate employees about the financial planning and asset allocation to avoid investment risks. 


\section{REFERENCES}

Adams, J. (1902). Democracy and Social Ethics. New York: Macmillan.

Albrecht, W. G., \& Hingorani, V. L. (2004). Effects of governance practices and investment strategies on state and local government pension fund financial performance. International Journal of Public Administration, 8\&9(27), 673700 .

Albrecht, W. G., Shamsub, H., \& Giannatasio, N. A. (2007). Public pension fund governance practices and financial performance. Journal of Public Budgeting, Accounting \& Financial Management, 19(2), 245-267

American Academy of Actuaries (AAA). (2006). The value of defined benefit plans (Issue Brief). Washington, DC. Retrieved from http://www.actuary.org/category/site-section/public-policy/issue-briefs

Axinn, W. G., \& Pearce, L. D. (2006). Mixed method data collection strategies. Cambridge, NY: Cambridge University Press.

Babbie, E. R. (1990). Survey research methods. Belmont, CA: Wadsworth Pub. Co.

Barstow, D. (2010, Feb 15). Tea Party lights fuse for rebellion on right. New York Times. Retrieved from http://www.nytimes.com/2010/02/16/us/politics/16teaparty.html?pagewanted $=$ all\&_r $=0$

Bender, K. A. (2003). Examining equality between public- and private-sector wage distributions. Economic Inquiry, 41, 62-79.

Berne, R., \& Schramm, R. (1986). The financial analysis of governments. Englewood Cliffs, NJ: Prentice-Hall.

Bewley, T. F. (2007). Why Wages Don't Fall During a Recession. Cambridge, MA: Harvard University Press.

Bodie, Z. (1995). On the risks of stocks in the long run. Financial Analysts Journal, 51(3), 18-22.

Bodie, Z., Marcus, A. J., \& Merton, R. C. (1988). Defined benefit versus defined contribution plans: What are the real trade-offs? In Z. Bodie, J. B. Shoven, \& 
D. A. Wise (Eds.), Pensions in the U.S. economy (pp. 139-162). Chicago: University of Chicago Press.

Boivie, I., \& Weller, C. E. (2012). The great recession: Pressures on public pensions, employment relations and reforms. National Institute on Retirement Security. Retrieved from http://teamster.org/sites/teamster.org/files/111612finalissuebriefthegreatrecess ion112012.pdf

Borjas, G. J. (2003). Wage structures and the sorting of workers into the public sector. In J. D. Donahue \& J. S. Nye (Eds.), For the People: Can we fix public service? (pp. 29-54). Washington, DC: Brookings Institution Press.

Bowman, J. S., \& West, J. P. (2006). Ending civil service protections in Florida government: Experiences in state agencies. Review of Public Personnel Administration, 26, 139-157.

Brainard, K. (2005). Myths and misperceptions of defined benefit and defined contribution plans (NASRA White Paper). National Association of State Retirement Administrators.

Buchanan, J. M., \& Tullock, G. (1962). The Calculus of Consent: Logical Foundations of Constitutional Democracy. Indianapolis, IN: Liberty Fund, Inc.

Carmichael, B. (2003). John Hancock financial services survey: For most Americans, early retirement dreams evaporating. PR Newswire. Retrieved from http://www.prnewswire.com/news-releases/john-hancock-financial-servicessurvey-for-most-americans-early-retirement-dreams-evaporating74188612.html

Chaney, B. A., Copley, P. A., \& Stone, M. S. (2002). The effect of fiscal stress and balanced budget requirements on the funding and measurement of state pension obligations. Journal of Accounting and Public Policy, 21(4), 287-313.

Clark, R. L., Craig, L. A., \& Wilson, J. W. (2003) A history of public sector pensions in the United States. Philadelphia, PA: University of Pennsylvania Press.

Clark, R. L., \& Pitts, M. M. (1999). Faculty Choice of a Pension Plan: Defined Benefit versus Defined Contribution. Industrial Relations: A Journal of Economy and Society, 38, 18-45.

Clark, R. L., \& Sabelhaus, J. (2009). How will the stock market crash affect the choice of pension plans? National Tax Journal, 62 (3), 477-496. 
Coggburn, J. D., \& Kearney, R. C. (2010). Trouble keeping promises? An analysis of underfunding in state retiree benefits. Public Administration Review, 70 (1), 97 108

ConagaRetna, S. M. (2004). America's public retirement plans: Stress in the system. Atlanta, GA: Southern Office, the Council of State Governments.

Creedy, J., Li, S. M., \& Moslehi, S. (2010). Inequality aversion and the optimal composition of government expenditure. Macroeconomic Dynamics,14 (S2), 290-306.

Creswell, J. W. (2003). Research design: Qualitative, quantitative, and mixed methods approaches. Thousand Oaks, CA: Sage Publications.

Dolan, T. G. (2007, November 19). Losers win and winners lose: A study of teacher pension plans finds perverse incentives for retirements. Barron's, 137, 59.

Dillon, W. R., \& Goldstein, M. (1984). Multivariate analysis: Methods and applications. New York: John Wiley.

Dulebohn, J. H., Murray, B., \& Sun M., (2000). Selecting among employer-sponsored pension plans: The role of individual differences. Personnel Psychology, 53, 405-432.

Eaton, T. V., \& Nofsinger, J. R. (2004). The effect of financial constraints and political pressure on the management of public pension plans. Journal of Accounting and Public Policy, 23 (3), 161-189.

El-Erian, M. (2008). When markets collide: Investment strategies for the age of global economic change. New York, NY: McGraw-Hill.

Ferlauto, R. (2002, February 26). Testimony before the Subcommittee on EmployerEmployee Relations, Committee on Education and the Workforce, U.S. House of Representatives. Washington, DC: American Federation of State, County and Municipal Employees. Retried from http://archives.republicans.edlabor.house.gov/archive/hearings/107th/eer/enro nfour22702/ferlauto.htm

Ficker, R. D., Kulzy, W. W., \& Appleget, J.A. (2012). From data to information: Using factor analysis with survey data. Monterey, CA: Naval Postgraduate School 
Fletcher, J. (2010, February 19). State panel approves pension reforms. The Press of Atlantic City, pp. A1, A4.

Florida Department of Management Service (DMS). (2012, January 13). 2011 Florida local government retirement systems annual report. Retrieved from: https://www.rol.frs.state.fl.us/forms/2011_Local_Report.pdf

Florida League of Cities. (2012). Florida pensions. Retrieved from http://www.floridaleagueofcities.com/Publications.aspx?CNID $=9068$

Florida League of Cities. (2013). Florida pensions. Retrieved from http://www.floridaleagueofcities.com/Publications.aspx?CNID=9068

Florida Public Pension Trustees Association (FPPTA). (2011). Understanding Public Pension Plan's Unfunded Liability. Retrieved from http://www.fppta.org/FPPTA/MR_PressReleases.aspx

Florida Public Pension Trustees Association (FPPTA). (2010). 401(k) Accounts Are not Retirement Plans. Retrieved from http://www.fppta.org/FPPTA/MR_Articles.aspx

Florida TaxWatch \& Leroy Collins Institute. (2013). Looking at Florida's municipal pensions: How some Florida cities are dealing with pension funding issues. Retrieved from http://floridataxwatch.org/resources/pdf/MuniPensionsFINAL.pdf

Frank, H. (2009). The financial crisis of 2008: A clarion call to include economic policy and financial illiteracy on public administration's intellectual radar screen. Journal of Public Administration Theory \& Praxis, 31 (3), 409-416.

Frank, H. A., Gianakis, G., \& Neshkova, M. I. (2012). Critical questions for the transition to defined contribution pension systems in the public sector. The American Review of Public Administration, 42 (4), 375-399.

Frankfort-Nachmias, C., \& Leon-Guerrero, A. (2011). Social statistics for a diverse society. Newbury Park, CA:Pine Forge Press.

Frederickson, H. G. (1994). Can public officials correctly be said to have obligations to future generations? Public Administration Review, 54, 457-464. 
Funkhouser, M. (2013, Sep 30). Accountability, Transparency and the Uncertain Future of GASB. Governing. Retrieved from http://www.governing.com/govinstitute/funkhouser/col-accountability-transparency-uncertain-future-gasbgovernmental-accounting-standards-board.html

Giertz, J. F. (2003, August 18). The impact of pension funding on state government finances. State Tax Notes, 507-513. Retrieved from http://www.urban.org/uploadedpdf/1000608.pdf

Giertz, J. F., \& Papke, L. E. (2007). Public pension plans: Myths and realities for state budgets. National Tax Journal, 60(2), 305-323.

Gorsuch, R. L. (1983). Factor analysis. Hillsdale, NJ: Lawrence Erlbaum.

Harrison, B., \& Bluestone, B. (1990) The Great U-Turn: Corporate Restructuring and the Polarizing of America. New York: Basic Books.

Hays, S. W. (1996). The "state of the discipline" in public personnel administration. Public Administration Quarterly, 20, 255-284.

Hoddinott, S. N., \& Bass, M. J. (1986). The dillman total design survey method: A sure-fire way to get high survey return rates. Canadian Family Physician, 32, 2366-2368.

Holcombe, R.G. (2011). Protecting Florida's cities through pension reform (No. 66). Tallahassee, FL: The James Madison Institute. Retrieved from http://www.jamesmadison.org/pdf/materials/Backgrounder_PensionLiabilities _HolcombeJan11.pdf

Holland, J. H., Goodman, D., \& Stich, B. (2008). Defined contribution plans emerging in the public sector: The manifestation of defined contributions and the effects of workplace financial literacy education. Review of Public Personnel Administration, 28(4), 367-384.

Huntley, H. (2000, May 9). Workers may get pension choice. St. Petersburg Times. Retrieved from http://www.sptimes.com/News/050900/Business/Workers_may_get_pensi.sht $\mathrm{ml}$

Inman, R. (1982). Public employee pensions and the local labor budget. Journal of Public Economics, 19, 49-71. 
Ippolito, R. A. (1997). Pension plans and employee performance: Evidence, analysis, and policy. Chicago: University of Chicago Press.

Klas, M. E (2011a). Pension reform opponents point to inequities in Florida's system. Tampa Bay Times. Retrieved from http://www.tampabay.com/news/localgovernment/pension-reform-opponentspoint-to-inequities-in-floridas-system/1158495

Klas, M. E (2011b). Breaking down Florida's pension reform changes. Tampa Bay Times. $\quad$ Retrieved from http://www.tampabay.com/news/politics/stateroundup/breaking-downfloridas-pension-reform-changes/1172229

Klingner, D. E., \& Lynn, D. (2005). Beyond civil service: The politics of the emergent paradigms. In S. E. Condrey (Ed.), Handbook of Human Resource Management in Government (pp. 37-57). San Francisco, CA: Jossey-Bass.

Kohler, U., \& Kreuter, F. (2012). Data analysis using stata. College Station, TX: Stata Press

Krueger, A. B. (1988). Are public sector workers paid more than their alternative wage? In R. B. Freeman \& C. B. Ichniowski (Eds.), When public sector workers unionize (pp. 217-244). Chicago: University of Chicago.

Kuzel, A. J. (1999). Sampling in qualitative inquiry. In B. F. Crabtree \& W. L. Miller (Eds.), Doing qualitative research (pp. 33-45). Thousand Oaks, CA: Sage.

Lambert, L., \& Byrnes, N. (2012, June 25). New rules may make public pensions appear weaker. Reuters. Retrieved from http://www.reuters.com/article/2012/06/25/us-usa-pensions-standardsidUSBRE85O01Z20120625

Lechance, M., \& Mitchell, O. S. (2002). Understanding individual account guarantees (NBER working paper 9195). Cambridge, MA: National Bureau of Economic Research. Retrieved from http://www.nber.org/papers/w9195.pdf

Leroy Collins Institute (LCI). (2012). Years in the Making: Florida's Underfunded Municipal Pension Plans. Retrieved from http://collinsinstitute.fsu.edu/sites/collinsinstitute.fsu.edu/files/SEP $\% 202012 \%$ 20Years\%20In\%20The\%20Making\%20report.pdf

Lewis, G. B., \& Frank, S. A. (2002). Who wants to work for government? Public Administration Review, 62 (4), 395-404. 
Lindlof. T. R., \& Taylor, R. C. (2002). Qualitative Communication Research Methods. Thousand Oaks: Sage.

Long, J. S. (1983). Covariance structure models. An introduction to LISREL. Beverly Hills, CA: Sage.

Lusardi, A., \& Mitchell, O. S. (2005). Financial literacy and planning: Implications for retirement wellbeing. Ann Arbor: University of Michigan Retirement Research Center.

Mahoney, D. P. (2002). Toward a more ethical system of state and local government retirement funding. Journal of Public Budgeting, Accounting \& Financial Management, 14, 197-224.

Manahan, A. (2010). Public pension plan reform: The legal framework. Education, Finance \& Policy, 5, Minnesota Legal Studies Research No. 10-13. Retrieve from http://papers.ssrn.com/sol3/papers.cfm?abstract_id=1573864

Matson, P., \& Dobel, S. (2006, September 22). Arizona state retirement system: A comparative analysis of defined benefit and defined contribution retirement plans. $\quad$ Retrieved from http://www.nasra.org/resources/ASRS\%20DBDC\%20White\%20Paper.pdf

McCue, C. P. (1994). Determinants of local government pension funding: Empirical evidence from Florida. Retrieved from ProQuest Dissertations \& Theses. (AAT: 9503991).

McFarland, D. M., Marconi, D. D., \& Utkus, S. P. (2003). Money attitudes and retirement plan design: One size does not fit all (Working paper No.11). Homewood, IL: Pension Research Council.

Merton, R., \& Samuelson, P. (1974). Fallacy of the log-normal approximation to portfolio decision-making over many periods. Journal of Financial Economics, $1(1), 67-94$.

Mitchell, O. S., McCarthy, D., Wisniewski, S. C., \& Zorn, P. (2001). Developments in state and local pension plans. In Olivia S. Mitchell and Edwin C. Hustead (Eds.), Pensions in the public sector. Philadelphia: University of Pennsylvania Press, 1- 10.

Mitchell, O. S., \& Smith, R. S. (1992). Public sector pensions: Benefits, funding and unionization. In Industrial Relations Research Association Papers and 
Proceedings of the $44^{\text {th }}$ Annual Meeting, 126 -133. Madison, WI: Industrial Relations Research Association.

Mitchell, O., \& Smith, R. (1994). Pension funding in the public sector. Review of Economics and Statistics 76, 278-290.

Mittelstaedt, H. F. (2004). Research and ethical issues related to retirement plans. Journal of Business Ethics 52, 153-159.

Munnell, A. H. (2012). State and Local Pensions: What Now? Washington, DC: Brookings Institution Press.

Munnell, A. H., Aubry, J., \& Haverstick, K. (2008). The funding status of locally administered pension plans (Brief No. 40). Boston: Center for Retirement Research, Boston College.

Munnell, A.H., Aubry, J., Hurwitz, J., Medenica, M., \& Quinby, L. (2012). The funding of state and local pensions: 2011-2015. Boston: Center for Retirement Research, Boston College.

Munnell, A. H., Aubry, J., \& Quinby, L. (2010). The funding of state and local pensions: 2009-2013. (Brief No. 10). Boston: Center for Retirement Research, Boston College.

Munnell, A. H., Golub-Sass, A., Haverstick, K., Soto, M., \& Wiles, G. (2008). Why have some states introduced defined contribution plans? (Brief No. 3). Boston: Center for Retirement Research, Boston College.

Munnell, A. H., Golub-Sass, A., Soto, M., \& Vitagliano, F. (2006). Why are healthy employers freezing their pensions? (Brief No. 44). Boston: Center for Retirement Research, Boston College.

Munnell, A. H., Haverstick, K., \& Aubry, J. (2008). Why does funding status vary among state and local plans (Brief No. 6)? Boston: Center for Retirement Research, Boston College.

Munnell, A. H., Haverstick, K., \& Sanzenbacher, G. (2006). Job tenure and pension coverage (Brief No. 18). Boston: Center for Retirement Research, Boston College.

Munnell, A. H., Haverstick, K., \& Soto, M. (2007). Why have defined benefit plans survived in the public sector? (Brief No. 2). Boston: Center for Retirement Research, Boston College. 
Naisbitt, J. (1982). Megatrends: Ten new directions transforming our lives. New York, NY: Warner Books.

National Center for Policy Analysis (NCPA). (2010). Unfunded Liabilities of State and Local Government Employee Retirement Benefit Plans (Policy Report No. 329). Retrieved from http://www.ncpa.org/pdfs/st329.pdf

National Conference on Public Employee Retirement Systems (NCPERS). (2007). Traditional defined benefit pension plans-A tried and true system that benefits taxpayers. $\quad$ Retrieved from http://www.ncpers.org/Files/Media/Fsheets/1_DefinedBenefitPensionPlan_Fa ctSheets.pdf

National Conference on Public Employee Retirement Systems (NCPERS). (2008). The evolution of public pension plans: Past, present and future. Retrieved from http://www.ncpers.org/Files/evolution_of_public_pensions_2d.pdf

Neuman, W. L. (2004). Basics of social research: Qualitative and quantitative approaches. Boston: Pearson.

Nofsinger, J. R. (1998). Why targeted investing does not make sense! Financial Management, 27(3), 87-96.

Novy-Marx, R., \& Rauh, J. D. (2008). The intergenerational transfer of public pension promises (NBER Working Paper No. 14343). Retrieved from http://www.nber.org/papers/w14343.pdf?new_window=1

Novy-Marx, R., \& Rauh, J. D. (2009). The liabilities and risks of state-sponsored pension plans. Journal of Economic Perspectives, 23(4), 191-210.

Norwalk, C. T. (2012, June 25). GASB Improves Pension Accounting and Financial Reporting Standards. Governmental Accounting Standards Board. Retrieved from

http://www.gasb.org/cs/ContentServer?pagename=GASB/GASBContent_C/G $\underline{\text { ASBNewsPage\&cid }=1176160126951}$

Nyce, S. A. (2007). Behavioral effects of employer-sponsored retirement plans. Journal of Pension Economics and Finance, 6, 251-285.

Nyce, S. (2012). Attraction and retention: What employees value most. Tower Wastson. Retrieved

from 
http://www.towerswatson.com/en/Insights/Newsletters/Americas/Insider/2012 /Attraction-and-Retention-What-Employees-Value-Most-March-2012

Olleman, M. (2009). Public plan DB/DC choices. PERiScope Public Employee Retirement Systems. Omaha, NE: Milliman, Inc.

O'Donoghue, T., \& Punch K. (2003). Qualitative Educational Research in Action: Doing and Reflecting. Routledge.

Pagano, M.A. (1993). Balancing cities' books in 1992. Public Budgeting \& Finance, Summer, 19-39.

Papke, L. E. (2004). Pension plan choice in the public sector: The case of Michigan state employees. National Tax Journal, 57 (2), Part 1, 329-339.

Peng, J. (2004). "Pension fund management and government operating budget: A tale of three states". Public Budgeting and Finance, 24(2): 59-73.

Peng, J. (2008). State public pension management over the business cycle. Journal of Public Budgeting, Accounting \& Financial Management, 20, 1-21.

Rauh, J. D. (2010, May 15). Are state public pension sustainable? Why the federal government should worry about state pension liabiliteis. Standford Graduate Schoold of Business; National Bureau of Economic Research. Retrieved from http://papers.ssrn.com/sol3/papers.cfm?abstract_id=1596679

Rawls, J. (1971). A Theory of Justice. Cambridge, MA: Harvard University Press.

Rea, L. M., \& Parker, R. A. (2005). Designing \& Conducting Survey Research: A Comprehensive Guide. San Francisco, CA: Josey-Bass.

Reck, J., Wilson, E., Gotlob, D., \&Lawrence, C. (2001). Governmental capital markets research in accounting: A review, extension, and directions for future research. Research in Governmental and Nonprofit Accounting.

Rehfeld, B. (1998, October 1) Michigan Redefines Public Pensions. Euromoney Institutional Investor. Retrieved from http://business.highbeam.com/435607/article-1G1-53191446/michiganredefines-public-pensions

Reilly, T., Schoener, S., \& Bolin, A. (2007). Public sector compensation in local governments. Review of Public Personnel Administration, 27, 39-58. 
Resmovits, J. (2011, June 21). Florida's teachers union sues state over pension reform, plans further action. Huffington Post. Retrieved from http://www.huffingtonpost.com/2011/06/21/floridas-teachers-unions_n_881577.html

Romano, R. (1993). Public pension fund activism in corporate governance reconsidered. Columbia Law Review, 93, 795-853.

Rose, R. P. (2013). Preferences for careers in public work: Examining the governmentnonprofit divide among undergraduates through public service motivation. The American Review of Public Administration, 43 (4), 416-437.

Ross, S. (1999). Samuelson's fallacy of larger number revisited. The Journal of Financial and Quantitative Analysis, 34(3), 323-329.

Shaughnessy, J., Zechmeister, E., \& Jeanne, Z. (2011). Research methods in psychology. New York, NY: McGraw Hill.

Shrestha, L. B., \& Heiser, E. J. (2011). The changing demographic profile of the United States. Washington, DC: The Congressional Research Service.

Sickler, M. V. (2013). State pension reform issue dies in the Senate. Miami Herald. Retrieved from http://www.miamiherald.com/2013/04/30/3373509/statepension-reform-issue-dies.html

Smith, S. P. (1977). Government wage differentials. Journal of Urban Economics, 4, 248-271.

Stalebrink, O. J., Kriz, K. A., \& Guo, W. (2010). Prudent public sector investing and modern portfolio theory: An examination of public sector defined benefit pension plans. Public Budgeting \& Finance, 30 (4), 28-46.

Steffen, K. (2001). State employee pension plans. In Olivia S. Mitchell and Edwin C. Hustead (Eds.), Pensions in the public sector. Philadelphia: University of Pennsylvania Press, 11- 40.

Stevens, J. (1996). Applied Multivariate Statistics for the Social Sciences. Mahwah, NJ: Lawrence Erlbaum Associates

The Pew Center on the States (Pew). (2010a). The trillion dollar gap: Underfunded state retirement systems and the roads to reform. Retrieved from http://www.pewstates.org/uploadedFiles/PCS_Assets/2010/Trillion_Dollar_G ap_Underfunded_State_Retirement_Systems_and_the_Roads_to_Reform.pdf 
The Pew Center on the States (Pew). (2010b). Millennials: A portrait of generation next. $\quad$ Retrieved from http://www.pewsocialtrends.org/files/2010/10/millennials-confidentconnected-open-to-change.pdf

The Pew Center on the States (Pew). (2012). The Widening Gap Update. Retrieved from http://www.pewstates.org/uploadedFiles/PCS_Assets/2012/Pew_Pensions_Up date.pdf

Thom, M. (2010, April 24). From Defined Benefit to Defined Contribution Retirement Plans for Public Employees: An Assessment. Paper presented at 68th Annual Conference of the Midwest Political Science Association Chicago, Illinois.

Thompson, J. R., \& Mastracci, S.H. (2005). Toward a more flexible public workforce: Issues and implications. In S. E. Condrey (Ed.), Handbook of Human Resource Management in Government (pp. 125-142). San Francisco, CA: Jossey-Bass.

Tilove, R. (1976). Public employee pension funds. New York: Columbia University Press.

Trowbridge, C. L. (1952) Fundamentals of pension funding. Transaction of Society of Actuaries, 4(8), 17-43.

Trowbridge, C. L., \& Farr, C. E. (1976). The theory and practice of pension funding. Homewood, IL. Richard D. Irwin, Inc.

U.S. Census Bureau. (2011). The older population: 2010 (Brief No. 9). Retrieved from http:/www.census.gov/prod/cen2010/briefs/c2010br-09.pdf

U. S. Congress. House. Committee on Financial Services. (2008).Financial literacy and education: the effectiveness of governmental and private sector initiatives: hearing before the Committee on Financial Services, US House of Representatives, One Hundred Tenth Congress, second session, April 15, 2008 (Vol. 4). USGPO.

U.S. Department of Labor \& U.S. Bureau of Labor Statistics. (2013, January 23). Economic news release: Union members summary. Retrieved from http://www.bls.gov/news.release/union2.nr0.htm

U.S. Government Accountability Office (GAO). (2007, September 24). State and local government retiree benefits: Current status of benefit structures, protections, 
and fiscal outlook for funding future costs. Retrieved from http://www.gao.gov/assets/270/267150.pdf

U.S. Government Accountability Office (GAO). (2011, October 12). Gender pay differences: Progress made, but women remain overrepresented among lowwage workers. Retrieved from http://www.gao.gov/assets/590/585721.pdf

U.S. Government Accountability Office (GAO). (2012, July 19). Retirement security: Women still face challenges. Retrieved from http://www.gao.gov/assets/600/592726.pdf

U.S. Government Accountability Office (GAO). (2012). State and local government pension plans: Economic downturn spurs efforts to address costs and sustainability. Retrieved from http://www.gao.gov/assets/590/589043.pdf

Ward, K. (2011, June 22). Union challenge to Florida pension reform stirs backlash. Sunshine State News. Retrieved from $\mathrm{http} / /$ www.sunshinestatenews.com/story/teachers-union-challenge-floridapension-reform-stirs-backlash

Watson, C. (2005, March 29). Florida: The new trendsetter. CNN Politics. Retrieved from http:/www.cnn.com/2005/ALLPOLITICS/03/22/trendsetter/

Weller, C. E., \& Wenger, J. B. (2009). Prudent investors: The asset allocation of public pension funds. Journal of Pension Economics and Finance 8, 501-525.

Wilson, E. (1983). Fiscal performance and municipal bond borrowing costs. Public Budgeting and Finance 3(4), 28-41.

Wilson, E., \& Howard, T. (1984). The association between municipal market measures and selected financial reporting practices: Additional evidence. Journal of Accounting Research 22(1), 207-224.

Winklevoss, H. E. (1977). Pension mathematics: With numerical illustrations. Homewood, IL: Pension Research Council.

Wooldridge, J. M. (2013). Introductory econometrics: A modern approach. Stamford, CT: Cengage Learning.

Yakoboski, P. J., (2011). Rethinking defined contribution retirement plan design: a survey of experts (Trends and Issues). TIAA-CREF Institute. 
Yang, T., \& Mitchell, O. S. (2005). Public Pension Governance, Funding, and Performance: A Longitudinal Appraisal (Working paper No. 2). Homewood, IL: Pension Research Council.

York, A., \& McGreevy, P. ( 2012, August 28). Brown takes softer line in latest plan to rein in pension costs. Los Angeles Times. Retrieved from http://articles.latimes.com/2012/aug/28/local/la-me-brown-pensions-20120829 


\section{APPENDICES}

\section{Appendix 1 - Cover Letter and Survey Instrument}

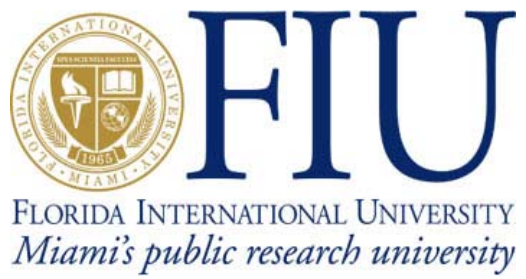

Department of Public Administration 


\section{Dear Finance/Human Resources Director,}

Public pensions and their future have become a central management issue for local governments. In recent years we have witnessed a number of pension reforms as a result of strained budgets and long-term socioeconomic realities. These reforms may foster fiscal sustainability, but their potential impact on daily operations and long-term management remains unexplored.

Dr. Frank and I are interested in assessing these impacts in your community. We undertake this effort from two prisms - financial management and human resources. From our vantage, there is a tendency to view the pension reform issue as if these were "siloed." We are sending this survey to finance and human resource professionals throughout the state on the assumption that an accurate read of pension reforms requires both perspectives for a comprehensive assessment.

The survey should take no more than 15 minutes to complete. Your responses are confidential. You can either follow the link below to take the survey online, or download the attached word file to answer it in pencil-and-paper and email or fax your response back to us.

Dr. Frank and I would be happy to provide a summary of findings. Kindly provide us with an address in the space provided. If you wish to discuss this survey or the topic, please call at (305) 779-7870 or e-mail at ycong001@fiu.edu. Each response counts; we will contribute $\$ 2.00$ to the American Cancer Society for each completed survey.

Cordially,

Ms. Yongqing Cong

Doctoral Candidate
Dr. Howard A. Frank

Professor of Public Administration

\section{Survey Questionnaire for Finance Directors}

For the purposes of this survey, we define "pension reform" broadly to include a variety of changes (e.g., longer vesting periods, higher employee contributions) to traditional defined benefit plans that characterize the default retirement program in most public agencies. Similarly, we see a "defined contribution" plan as having retirement earnings coming solely from a $401 \mathrm{k}$ or $403 \mathrm{~b}$ plan in which the employee makes all investment choices and incurs all investment risks. We define a "hybrid" retirement plan as one in 
which retirement income is derived from defined benefit and defined contribution streams, with contributions (either employee or employer) going to both components. These "hybrids" may be permanent or a transitional approach en route to defined contribution plans becoming the default model.

In considering your answers, please note that we are only interested in changes for your civilian, non-uniformed workers. We also ask that you do not consider supplemental, voluntary retirement plans such as $457 \mathrm{~s}$. Please check the number that best describes your level of agreement or disagreement along the following scale:

$\begin{array}{lll}1 & = & \text { Strongly Disagree } \\ 2 & = & \text { Disagree } \\ 3 & = & \text { Neither Disagree Nor Agree } \\ 4 & = & \text { Agree } \\ 5 & = & \text { Strongly Agree }\end{array}$

\section{A. Pension Model Questions}

Some have argued that the only long-term solution to the current public sector pension crisis is the adoption of 401(k) style defined contribution plans for new employees.

Questions in this section deal with your perception about the future of the defined benefit model as the default option for civilian, non-exempt employees.

Shifting to defined contribution for new employees is difficult because of unfunded pension liabilities under the current defined benefit model

A younger workforce prefers defined contribution plans to defined benefit plans

Adoption of defined contribution plans would foster greater employee mobility between the public and private sectors

Adoption of defined contribution plans would foster greater employee mobility within the public sector

The steady erosion of defined benefit pension coverage in the private sector puts pressure on elected officials to reduce defined benefit coverage in the public sector

Political and social forces will eventually lead to the elimination of pensions for public sector employees, mirroring long-term trends in the private sector

Taxpayer sentiment will eventually lead to the adoption of defined contribution plans as the default model in the public sector 


\section{B. Organizational Impacts of Defined Benefit Pension Reforms}

While the traditional defined benefit plan remains the default plan for most local governments in Florida and elsewhere, recent reforms such as longer vesting periods, higher employee pension contributions, and reduced Deferred Retirement Option Program (DROP) benefits could impact employee recruitment and retention, as well as other aspects of benefit administration. This section addresses your views on these possible impacts.

\section{Adoption of recent reforms will...}

Make it more difficult to retain senior personnel

Make it more difficult to attract well-qualified applicants

Increase turnover of junior personnel

Decrease competiveness of compensation with comparable private sector jobs

Make it more difficult to attract and retain a diverse workforce

Ultimately reduce efficiency and effectiveness of municipal operations

Obligate jurisdictions to educate employees on the basics of asset allocation throughout their lifetimes

Reduce pension outlays as percentage of total outlays

Encourage jurisdictions to provide access to low-or no-cost independent financial planning

Make outsourcing easier due to lower future pension costs

Encourage increased savings through deferred compensation or other voluntary plans
122345

12345

122345

122345

122345

122345

122345

122345

123345

122345

123345

\section{Organizational Impact of Pension Reforms Related to Date of Hire}

Many of the pension reforms undertaken in Florida and elsewhere impact new hires differently than current employees. Examples from the recent Florida experience include longer vesting and service requirements. These changes effectively create a two-tier benefit structure. Questions in this section address your perception of this aspect of recently enacted pension changes.

\section{Establishment of a two-tier retirement plan...}


Fosters antagonism between younger and older workers given differential impacts of benefit cuts

Creates different levels of commitment between new hires and existing employees

Makes hiring of the most talented prospects more difficult due to longer vesting

Makes hiring of the most talented prospects more difficult due to increased retirement age

Will increase participation in supplemental retirement plans such as 457 plans among younger workers

Represents an issue that straddles traditional boundaries between human resources and finance

Receives little attention given the high unemployment rate

Becomes less problematic over time given the "graying" workforce and retirement of older workers

\section{Questions Regarding Sustainability}

For the purposes of this survey, sustainability is defined as your city's ability to make your Annual Required Contribution (ARC) within the next five fiscal years, holding current economic conditions and headcount constant. Actions such as those noted in Section I (i.e., increase in retirement age, increase in years required for full retirement, etc., will maintain fiscal sustainability

1. Approximately what percentage of your annual ARC did you fund in following years (0-100 Percent)?

2009-10

2010-11

2011-12

2. What do you see as the biggest obstacles to fully funding your ARC? 
3. Assuming a time horizon of three fiscal years, please estimate the approximate percentage of the ARC you expect to make assuming no change in current economic conditions (0-100 Percent).

2012-13

2013-14

2014-15

\section{E. Drivers of Change in Public Pension "Crisis"}

In this section we would appreciate your perception of the drivers behind the current pension crisis in the public sector by indicating the degree to which you agree or disagree with the following drivers:

Changes in governmental accounting rules

12345

Decreasing defined benefit pension coverage of private sector workforce

12345

Decreasing overall pension coverage of the private sector workforce

12345

Statutory Property Tax Limitations

12345

Changes in State Pension Systems

12345

Low returns of fixed income securities

12345

Lower than historical returns on stocks

123345

Cuts in intergovernmental revenue

12345

Pension benefit changes in neighboring communities

12345

Collective Bargaining Agreements

12345

Below are a few items about yourself to be used for statistical purposes. Please respond by clicking on your response.

I am:

Male

O 
My age range is:

$\begin{array}{ll}25 \text { and under } & \mathrm{O} \\ 26-35 & \mathrm{O} \\ 36-45 & \mathrm{O} \\ 46-55 & \mathrm{O} \\ 56-65 & \mathrm{O} \\ \text { Over } 65 & \mathrm{O}\end{array}$

What type of plan are you currently contributing to?

$\begin{array}{ll}\text { DB plans } & \text { O } \\ \text { DC plans } & \text { O } \\ \text { Hybrid plans } & \text { O } \\ \text { Other: } & \end{array}$

Other:

What type of plan will provide the majority of your retirement income from the government?

$\begin{array}{ll}\text { DB plans } & \text { O } \\ \text { DC plans } & \text { O } \\ \text { Hybrid plans } & \text { O } \\ \text { Other: } & \end{array}$

Other:

Do you have any of the following professional designations?

$\begin{array}{ll}\text { CPA } & \mathrm{O} \\ \text { CMA } & \mathrm{O}\end{array}$

Other:

Are you a member of any of the following?

State Society of CPAs

$\mathrm{O}$

American Institute of CPAs

$\mathrm{O}$ 
Institution of Management Accounting

Association for Governmental Accounting

Government Finance Officers Association

American Society of Public Administration

Other
$\mathrm{O}$

$\mathrm{O}$

$\mathrm{O}$

$\mathrm{O}$

Thank you for your time and participation. If you'd like to have a summary of findings, please contact Yongqing Cong at ycong001@,fiu.edu, or provide your email address: 
For the purposes of this survey, we define "pension reform" broadly to include a variety of changes (e.g., longer vesting periods, higher employee contributions) to traditional defined benefit plans that characterize the default retirement program in most public agencies. Similarly, we see a "defined contribution" plan as having retirement earnings coming solely from a $401 \mathrm{k}$ or $403 \mathrm{~b}$ plan in which the employee makes all investment choices and incurs all investment risks. We define a "hybrid" retirement plan as one in which retirement income is derived from defined benefit and defined contribution streams, with contributions (either employee or employer) going to both components. These "hybrids" may be permanent or a transitional approach en route to defined contribution plans becoming the default model.

In considering your answers, please note that we are only interested in changes for your civilian, non-uniformed workers. We also ask that you do not consider supplemental, voluntary retirement plans such as $457 \mathrm{~s}$. Please check the number that best describes your level of agreement or disagreement along the following scale:

$\begin{array}{lll}1 & = & \text { Strongly Disagree } \\ 2 & = & \text { Disagree } \\ 3 & = & \text { Neither Disagree Nor Agree } \\ 4 & = & \text { Agree } \\ 5 & = & \text { Strongly Agree }\end{array}$

\section{A. Pension Model Questions}

Some have argued that the only long-term solution to the current public sector pension crisis is the adoption of 401(k) style defined contribution plans for new employees.

Questions in this section deal with your perception about the future of the defined benefit model as the default option for civilian, non-exempt employees.

Shifting to defined contribution for new employees is difficult because of unfunded pension liabilities under the current defined benefit model

A younger workforce prefers defined contribution plans to defined benefit plans

Adoption of defined contribution plans would foster greater employee mobility between the public and private sectors

Adoption of defined contribution plans would foster greater employee mobility within the public sector

The steady erosion of defined benefit pension coverage in the private sector puts pressure on elected officials to reduce defined benefit coverage in the public sector

Political and social forces will eventually lead to the elimination of pensions for public sector employees, mirroring long-term trends in the private sector

Taxpayer sentiment will eventually lead to the adoption of defined contribution plans as the default model in the public sector 


\section{B. Organizational Impacts of Defined Benefit Pension Reforms}

While the traditional defined benefit plan remains the default plan for most local governments in Florida and elsewhere, recent reforms such as longer vesting periods, higher employee pension contributions, and reduced Deferred Retirement Option Program (DROP) benefits could impact employee recruitment and retention, as well as other aspects of benefit administration. This section addresses your views on these possible impacts.

\section{Adoption of recent reforms will...}

Make it more difficult to retain senior personnel

Make it more difficult to attract well-qualified applicants

Increase turnover of junior personnel

Decrease competiveness of compensation with comparable private sector jobs

Make it more difficult to attract and retain a diverse workforce

Ultimately reduce efficiency and effectiveness of municipal operations

Obligate jurisdictions to educate employees on the basics of asset allocation throughout their lifetimes

Reduce pension outlays as percentage of total outlays

Encourage jurisdictions to provide access to low-or no-cost independent financial planning

Make outsourcing easier due to lower future pension costs

Encourage increased savings through deferred compensation or other voluntary plans
123345

12345

123345

122345

123345

122345

122345

122345

122345

123345

123345

\section{Organizational Impact of Pension Reforms Related to Date of Hire}

Many of the pension reforms undertaken in Florida and elsewhere impact new hires differently than current employees. Examples from the recent Florida experience include longer vesting and service requirements. These changes effectively create a two-tier benefit structure. Questions in this section address your perception of this aspect of recently enacted pension changes.

\section{Establishment of a two-tier retirement plan...}


Fosters antagonism between younger and older workers given differential impacts of benefit cuts

Creates different levels of commitment between new hires and existing employees

Makes hiring of the most talented prospects more difficult due to longer vesting

123345

Makes hiring of the most talented prospects more difficult due to increased retirement age

Will increase participation in supplemental retirement plans such as 457 plans among younger workers

Represents an issue that straddles traditional boundaries between human resources and finance

Receives little attention given the high unemployment rate

123345

Becomes less problematic over time given the "graying" workforce and retirement of older workers

12345

\section{Organizational Capacity for Pension Reform}

Hybrid or defined contribution pension models require participant choice in asset allocation throughout a lifetime. The following questions deal with your city's ability to provide employees investment advice.

\section{My city currently offers...}

Low-or No-Cost financial advice from independent financial planners for annual financial "check-ups"

Call-in services to financial planning services for general investment advice

Investment fairs at which investment providers give financial guidance

Online investment guidance with "model portfolios" depending on age and risk preference

Guest speakers for lunch or similar "brown bags" at which various investment topics are provided

Others 
E. Recent and Potential Change in Your Community's Pension Plan

In light of the recent controversies regarding traditional defined benefit pension plans in the public sector, as well as recently enacted accounting rule changes, please check actions that have been taken or under current consideration:

Please check the following in regards to your city:

Increase in Retirement Age

\begin{tabular}{|c|c|c|}
\hline $\begin{array}{l}\text { Has Taken } \\
\text { Since } 2007\end{array}$ & $\begin{array}{l}\text { Is Currently } \\
\text { Considering }\end{array}$ & $\mathrm{N} / \mathrm{A}$ \\
\hline $\mathrm{O}$ & $\mathrm{O}$ & $\mathrm{O}$ \\
\hline $\mathrm{O}$ & $\mathrm{O}$ & $\mathrm{O}$ \\
\hline $\mathrm{O}$ & $\mathrm{O}$ & $\mathrm{O}$ \\
\hline $\mathrm{O}$ & $\mathrm{O}$ & $\mathrm{O}$ \\
\hline $\mathrm{O}$ & $\mathrm{O}$ & $\mathrm{O}$ \\
\hline $\mathrm{O}$ & $\mathrm{O}$ & $\mathrm{O}$ \\
\hline $\mathrm{O}$ & $\mathrm{O}$ & $\mathrm{O}$ \\
\hline $\mathrm{O}$ & $\mathrm{O}$ & $\mathrm{O}$ \\
\hline $\mathrm{O}$ & $\mathrm{O}$ & $\mathrm{O}$ \\
\hline $\mathrm{O}$ & $\mathrm{O}$ & $\mathrm{O}$ \\
\hline $\mathrm{O}$ & $\mathrm{O}$ & $\mathrm{O}$ \\
\hline $\mathrm{O}$ & $\mathrm{O}$ & $\mathrm{O}$ \\
\hline $\mathrm{O}$ & $\mathrm{O}$ & $\mathrm{O}$ \\
\hline $\mathrm{O}$ & $\mathrm{O}$ & $\mathrm{O}$ \\
\hline $\mathrm{O}$ & $\mathrm{O}$ & $\mathrm{O}$ \\
\hline
\end{tabular}

Add Social Security to the Retirement Package

\section{F. Drivers of Change in Public Pension "Crisis"}

In this section we would appreciate your perception of the drivers behind the current pension crisis in the public sector by indicating the degree to which you agree or disagree with the following drivers:

Changes in governmental accounting rules

12345

Decreasing defined benefit pension coverage of private sector workforce

123345

Decreasing overall pension coverage of the private sector workforce

12345

Statutory Property Tax Limitations

123345 
Changes in State Pension Systems

Low returns of fixed income securities

Lower than historical returns on stocks

Cuts in intergovernmental revenue

Pension benefit changes in neighboring communities

Collective Bargaining Agreements
122345

12345

12345

123345

122345

12345

Below are a few items about yourself to be used for statistical purposes. Please respond by clicking on your response.

I am:

Male $\quad \mathrm{O}$

Female $\quad \mathrm{O}$

My age range is:

$\begin{array}{ll}25 \text { and under } & \mathrm{O} \\ 26-35 & \mathrm{O} \\ 36-45 & \mathrm{O} \\ 46-55 & \mathrm{O} \\ 56-65 & \mathrm{O} \\ \text { Over } 65 & \mathrm{O}\end{array}$

What type of plan are you currently contributing to?

$\begin{array}{ll}\text { DB plans } & \text { O } \\ \text { DC plans } & \text { O } \\ \text { Hybrid plans } & \text { O }\end{array}$

Other: 
What type of plan will provide the majority of your retirement income from the government?

$\begin{array}{ll}\text { DB plans } & \text { O } \\ \text { DC plans } & \text { O } \\ \text { Hybrid plans } & \text { O }\end{array}$

Other:

Do you have any of the following professional designations?

$\begin{array}{ll}\text { PHR } & \text { O } \\ \text { SPHR } & \text { O }\end{array}$

Other:

Are you a member of any of the following?

Society for Human Resource Management $\quad \mathrm{O}$

American Society for Training and Development $\quad \mathrm{O}$

Florida Public Human Resources Association $\quad \mathrm{O}$

Florida Public Personnel Association $\quad \mathrm{O}$

American Society of Public Administration $\quad O$

Florida Public Employer Labor Relations Association $\quad \mathrm{O}$

Other

Thank you for your time and participation. If you'd like to have a summary of findings, please contact Yongqing Cong at ycong001@,fiu.edu or provide your email address: 
Appendix 2 - Structured Interview Guide 
1. In your own words, how would you define a sustainable public pension system? In general, do you think the current public pension model is sustainable?

2. As you know, The original intention of the 2011 pension reform was to replace the current DB plan with DC plan for new hired employees, but it did not go that far in the end. What do you think are the drivers behind this initiative of pension model switch?

3. How might the implementation of DC plans change recruitment? Will the pension type preference impact people's selection of employer?

4. How might the adoption of DC affect retention? Will switch to DC foster greater mobility between public agencies within public sector; and between the public and private sector?

5. How will public organizations deal with "two-tier" workforce issues? Do two tiers of benefits "under the same roof" cause animosity among different generation of employees and reduce morale? Or this issue will "die out" over time along with the retirement of senior employees?

6. Do you think the need to continue the funding of those "in the DB system" is the biggest obstacle to a DC transition?

7. Will the adoption of DC plans require increasing financial literacy training?

8. Our survey results showed that HR and Finance Directors have virtually identical views of transition issues. We expected otherwise. How would you explain our findings?

9. What would you recommend is the long-term solution to the current public pension crisis? 


\title{
VITA
}

\section{YONGQING CONG}

\author{
$2001-2005$ \\ B.A., Teaching Chinese as A Foreign Language \\ Shanghai University of Finance and Economics \\ Shanghai, China \\ $2002-2004$ \\ Intercollegiate Minor, International Economy and Trade \\ Fudan University \\ Shanghai, China \\ $2005-2008$ \\ M.A., Curriculum and Teaching Methodology \\ Beijing Language and Culture University \\ Beijing, China \\ $2006-2008$ \\ Chinese Teacher \\ Beijing University of Aeronautics and Astronautics \\ Beijing, China \\ 2009 - present $\quad$ Doctoral Program, Public Administration \\ Florida International University \\ Miami, Florida \\ 2012 - present Teaching Assistant \\ Florida International University \\ Miami, Florida
}

\section{PUBLICATIONS AND PRESENTATIONS}

Yongqing Cong, Milena I. Neshkova, and Howard A. Frank (2014). "The End of the Defined Pension Paradigm in Government: More than Fiscal Sustainability." In Pensions: Policies, New Reforms and Current Challenges, ed. Thom Reilly, page 199226. Happauge, NY: Nova Science Publishers.

Yongqing Cong, Howard A. Frank, Gerasimos Gianakis, \& Hai Guo (2014). Critical Issues in the Transition from the Defined Benefit to the Defined Contribution Model: Perception from Florida Municipal Finance and Human Resource Directors. Review of Public Personnel Administration. Advance online publication. DOI: 10.1177/0734371X14533572 
Yongqing Cong, "Sustainable Public Pension Systems for Florida Local Governments: Financial Solvency and Paradigm Switch", the Association for Public Policy Analysis \& Management Fall Research Conference, Baltimore, Maryland, November, 2012

Yongqing (Carrie) Cong, Howard Frank, "Pension Reform in Local Governments in Florida", Northeast Conference on Public Administration, Boston, Massachusetts, November, 2012

Yongqing Cong, "The Financial Solvency of the Pension Systems for the General Public Employees in Florida Local Governments", Southeastern Conference for Public Administration, Coral Spring, Florida, October, 2012

Yongqing Cong, Howard A. Frank, Hai Guo, "The Potential Impacts of the Public Pension Reform to Florida Local Governments", the 24th Annual Association for Budgeting \& Financial Management Conference, New York City, October, 2012

Yongqing Cong, "Improve the Human Resources Management of Pension Benefit Guaranty Corporation", on the Second International Conference on Engineering and Business Management, pp1-4, Wuhan, China, March 2011

Yongqing Cong, "How to Improve the Funded Level of Defined Benefit Plans in Public Pension System?", on the Southeastern Conference for Public Administration, Wilmington, North Carolina, October 2010

Howard Frank, Jerry Gianakis, Milena Neshkova, Yongqing Cong, "The Big Questions of Public Pension Management", on the 52nd Annual Conference for the Western Social Science Association, pp172-173, Reno, Nevada, April 2010 